\title{
Cber die Entwicklung der ersten Blutgefäße und des Herzens bei Torpedo in morphologischer und histiogenetischer Hinsicht.
}

\author{
Ton \\ Dr. Johannes Rückert, \\ o. ̈. Protessor der inatomie in Mundhen. \\ I. Teii. \\ Mit 7 rextahbildngen und 7 Tafeh. \\ (Eingegangen am 12. Amil 1901.)
}

\section{Vorwort.}

Bei dex Bearbeitung der frühen Gefabentwicklung für das Hertwigsche Handbuch sind Herr Kollege Mollier und ich dazu geführt worden, neben unserer eigentlichen, histiogenetischen Aufgabe auch der Morphologie der ersten Gefa $B$ bahnen, und zwar speziell der visceralen Venenstämme der Wirbeltiere unsere Aufmerksamkeit zuzuwenden. Auf diesem Gebiet bestehen Unklarheiten Sie betreffen erstens die Yena subintestinalis, deren von Balfour bei Selachiern eingefuhrter Begriff für das gleiche Objekt durch einige spittere Forscher ohne Angabe von Gründen abgeändert worden ist. Dazu kommt zweitens, daß die Vena omphalo-mesenterica, ein AmniotengefäB, ohne weiteres für andere Wirbeltiere übernommen wurde. Und zwar übertug man dieses GefuB eines meroblastischen Eies nicht bloß auf niedrigere meroblastische Eiformen, was allenfalls noch anginge, sondern auch auf holohlastische, und zwar wieder ohne jede Motivierung.

Fs ist klar, daß auf diesem Wege eine Homologisierung der ersten visceralen Venenbahnen für die verschiedenen Wirbeltiedlassen nicht durchführbar ist. Diese bis heute noch ungelöste Aufgabe kann nur erledigt werden, wenn man zwei im Grunde selbstverstiandliche Bedingungen erfült, die bisher vernachlässigt worden sind. Man muB als Ausgangspunkt die niederen Formen wählen und man muB die weitgehenden Umgestaltungen dieser Gefußbahnen durch den Nahrungsdotter berücksichtigen.

Von diesen Gesichtspunkten ausgehend, war ich vor nunmehr fast 20 Jahren auf Grund meiner Untersuchungen bei Torpedo zu folgender Vorstellung über das primitive Verhalten der Visceralvenen der Wirbeltiere gelangt: Ws sind im Rumpf ursprünglich zwei unter sich and mit der Aorta parallele, durch QuergefüBe unter sich und mit der Aorta verbundene, paarige Längsvenen vorhanden, von denen die eine ventral am Darm liegt, die Subintestinalis, die andere dorsal ubber ihr an der Seitenwand des Darms. Für letztere schien mir daher der Name "Parintestinalis" geeignet. An ihrem kranialen Ende steht die erstere primär mit der Blutanlage in Ferbindung, mit der sie gemeinschaftlichen Ursprung hat, die letztere mit dem venösen Ende des Herzens. Caudal konfluieren beide Venen am Urmund bzw. am After. 
Als ich diese Auffassung damals mit Herrn Kollegen Mollier besprach, ergab sich, daß er, unabhängig von mir, bei Amphibien ein der Parintestinalvene entsprechendes Gefaß, in der gleichen Anordnung wie ich es für die Holoblastier postulierte, beobachtet hatte. Wir verabredeten damals, den Gegenstand nach Fertigstellung unseres Handbuchartikels in einer gemeinsamen Arbeit. ein jeder von uns für sein Objekt, zu behandeln; denn eine Hereinnahme dieser Untersuchungen in das Hertwigsehe Handbuch bätte sich mit unserer dort gestellten Aufgabe nicht vereinigen lassen.

In der inzwischen verflossenen langen Zeit drohten der Text und namentlich der figürliche Teil der Arbeit einen solchen Umfang anzunehmen, daß ich zwei kleinere, zu selbständiger Behandlung geeignete Kapitel in besonderen Publikationen abzustoBen mich entschloB. Es sind dies die Abschnitte uber die Vornierenglomeruli (1917) and über die Umwachsung des Eies durch die Dottersackgefäße (1921).

Nach diesen und anderweitigen längeren Unterbrechungen ist nun die Hauptarbeit so weit fertiggestellt, daB ich ihren I. Teil dem Druck übergeben kann.

Es ist selbstrerständlich, daß die Untersuchung sich nicht auf die Morphologie der ersten Gefäßbahnen beschränken konnte, sondern die Entwicklung anderer Organe, wie des Darms, der Leber und der Voroiere, mit berücksichtigen mußte. Eine besondere Aufmerksamkeit war den embryonalen Verlagerungen und Ver. schiebungen der Organe, wie der Leber, des caudalen Herzendes, der Kloake und vor allem der beiden Darmpforten, zuzuwenden, weil nur durch Klarstellung dieser komplizierten Vorgänge ein zuverlässiger Finblick in die Ausgestaltung der ersten GefäBstämme zu gewinnen war. Auch sonst wurde eine entwicklungsmechanische Analyse der GefäBentwickung, soweit sie ohne das Experiment möglich erschien, angestrebt. Die Histiogenese muBte eingehend verfolgt werden, und zwar nicht nur das viel erörterte Thema der Abstammung des Zellmaterials der Gefäße und des Herzens aus den Keimblättern, sondern namentlich die Frage der lokalen Entstehung desselben und dessen Beziehungen zur Mesenchymentwicklung. Diese sowie andere Probleme der allgemeinen Angiogenese - ich erwähne nur die angebliche Herausdifferenzierung der Gefabe aus netzförmiger Anlage - sollen in einem Schlußkapitel im Zusammenhang abgehandelt werden.

Das reiche Untersuchungsmaterial für die Arbeit stammt aus der Neapler Station, von wo mir in der Vorkriegszeit alljährlich eine Anzabl frischer Keimscheiben und Embryonen von Torpedo zur Ergänzung meiner älteren Bestände in dankenswerter Weise zugesandt worden ist. Eine Anzahl Schnittserien von alteren Embryonen verdanke ich Herrn Prof. H. Marcus. Die Bearbeitung des Materials warde großenteils mit Hilfe von Rekonstruktionen durchgeführt. Soweit es anging, habe ich mich mit der graphischen Methode begnügt. Die betreffenden Abbildungen werden im II. Teil der Arbeit erscheinen. Aber überall da, wo es sich um eine dreidimensionale Darstellung des GefäBverlaufs handelt, also z. B. bei der gleichzeitigen Wiedergabe der Gefäße des Blastoderms und des Embryos, mußten Plattenmodelle hergestellt werden. Die Anfertigung solcher $1 / 3-1 / 2 \mathrm{~m}$ messenden Modelle der Keimscheiben mit ihrem dichten GefäBnetz war eine äuBerst mühsame Arbeit und zugleich eine recht schwierige für die jüngeren Stadien, in denen 
an Stelle der Hohlgefüße die oft schwer zu verfolgenden, ,soliden" Anlagen, 1. h. Züge oder Stränge von Gefißzellen, vorliegen. Aber diese We thode war nicht zu umgehen, wenn man Klarheit über die Entwicklung der extraembryonalen GetäBbahnen erhalten wollte, denn die Untersuchung ganzer Keimscheiben bei durchfallendem Licht erwies sich für diese jüngeren Entwicklungsstadien als vollig unzureichend. In diese Aufgabe hat sich Frl. stud. med. Bach hammer unter meiner Anleitung eingearbeitet und hat sie mit dankenswerter Hingabe und Ausdauer durchgeführt. Auch fast sämtliche Zeichnungen der Arbeit ent. stammen ihrer geschickten Hand. Auch den Damen Frl. H. RiezJer und Frl. Nereshei mer muB ich an dieser Stelle Dank sagen für die ebenso mühsame Herstellung von Modellen der Pfortaderkreislaufentwicklung. Von Abbildungen dieser instruktiven Modelle muBte in der vorliegenden Arbeit mit Rücksicht auf die Kosten leider Abstand genommen und ein notdürftiger Ersatz durch schematische Textiguren beschafft werden. Auch einen Teil der Figuren, so die Modellbilder der Tafel VII und Abb. 1 und 2 von Tafel I verdanke ich der zuletzt genannten Künstlerin.

Was den Text der Arbeit anlangt, so habe ich denjenigen Lesern, welche dem Gegenstand ferner stehen und auf meine Beweisführung kein Gewicht legen, ihre Wühe zu erleichtern gesucht dadureh, daB ich jedem Kapitel eine ausführliche, zum Teil mit Abbildungsverweisen versehene Zusammenfassung folgen lasse.

Herr Kollege Mollier hat die Untersuchung der GefäBentwicklung der Amphibien alsbald seiner Schülerin Frl. Dr. Adele Hartmann übertragen, deren Arbeit schon längere Zeit fertiggestellt ist und nun in mehreren Abschnitten gleichzeitig mit der meinigen im Druck erscheinen soll. Die beiden Untersuchungen, wenn sie auch dem gleichen Ziel zustreben, sind doch unabhüngig voneinander durchgeführt, so daB jeder von uns beiden die Verantwortung nur für seine *igene Arbeit trägt. Auch Frl. Dr. Hartmann hat in der Zwischenzeit die Entwioklung der VomierengefäBe (1920) als Vorläufer ihrer Hauptarbeit publiziert.

München, April 1921 .

J. Rückert.

Kapitel $\mathrm{I}$.

\section{Die Entwicklung der äußeren Ringvene (Randsinus), der hintereu Dotter- vene und der Vena subintestinalis.}

\section{Entwicklung des peripheren Mesoderms und der Blatinseln.}

Die Entstehung des Sinus terminalis und der Dottervenen in ihrer Beziehung zu der Bildung der übrigen GefäBe kann man nux im Rahmen der Gesamtentwicklung der Area vasculosa verstehen. Wir gehen daher von der ersten GefäBbildung auf dem Dotter aus und beginnen mit der Beschreibung eines Stadiums, in welchem das periphere oder Dottermesoderm in Entstehung begriffen ist und die ersten Spuren der Blatinseln sich, zwar noch nicht im Obertlachenbild, aber doch auf Schnitten bemerkbar machen.

$\mathrm{Zu}$ dieser Zeit, in welcher die Embryonalanlage ein erstes noch unscharf abgegrenztes Urwirbel paar erkennen läßt, bildet das periphere Mesoderm, 
wie die beistehende halbschematische Textabb. A einer etwas älteren Keimscheibe zeigt, einen schmalen Streifen $(p m)$, der ringförmig den gesamten Keimscheibenrand umsäumt, ein großes zentrales mesodermfreies Feld $(m f)$ umschließend. Hinten wird der Streif etwas breiter, denn das vom verdickten Hinterrand der Keimscheibe, dem Randwulst, entspringende periphere Mesoderm dringt schon jetzt etwas tiefer gegen das Innere des Blastoderms vor, und zwar um so stärker, je mehr es sich median der. Einbiegung des Randwulstes in die axiale Embryonalanlage nähert. An dieser Stelle setzt es sich, nach vorne umbiegend, in das axiale Mesoderm (am) fort. Dieser hintere, jetzt schon breitere Abschnitt des peripheren Mesoderms wurde von mir (Hertwigs Handbuch der

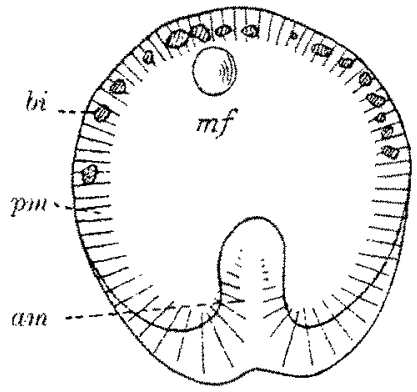

Ab). A. Halbschematische Oberliachenausicht einer Keimscheibe ron Torpedo oc. Stad. der beginnenden Abgrenzing der 2 ersten Urwirbelpaare. Die Strichelung gibt die Ausdehnung and die inutminliche Wachstumsrichtung des Mesodeums an. $a m=$ axiales Mesoderm. ma $=$ peripheres Mesoderm. $m f=$ mesoltermiteie Zone. $b i=$ Blatinseln. Entwicklungsgeschichte Bd. I, S. 1091) als, hinteres Mesoderm feld" der Keimscheibe von dem sohmäleren Streifen des Vorderseitenrandes, dem ,. vorderen Mesodermfeld"i) unterschieden. Die Breitendifferenz der 2 Felder nimmt später, wie Textabb. B (S. 11) zeigt, erheblich zu.

Auf Schnitten läbt das mittlere Keimblatt zur Zeit der Abgrenzung des ersten Crwirbelpaares folgendes Verhalten erkennen:

In der caudalen. Häfte der Keimscheibe erscheint deren im Oberflächenbild aufgewulsteter Rand. an welchen sich bekannthich das äußere in das innere Keimblatt umschlägt, vom Dotter abgehoben, so daß zwischen dem Cmschlagsrand und dem Dotter ein Raum frei bleibt, der am vorderen, zugespitzten Ende des Randwulstes nur die Form einer niedrigen Rinne hat, nach rückwärts gegen den Hinterrand der Keimscheibe aber allmählich an Tiefe zunimmt, um sich daselbst spaitförmig als Trdarmhöhle kranial auszudehnen. Dieser freie Umschlagsrand ist als palinge. netiseher Urmundrand aufzufassen. Von ihm entsteht das Mesoderm in folgender Weise. Am eigentlichen Finterrand, der in Abb. 8, Tafel II, auf einem seitlichen Längsschnitt dargestellt ist, liegt sein Ursprung völlig klar: Es wuchert ausschliellich aus dem unteren Blatt der Falte hervor, also aus dem Entoderm, ebenso wie das axiale Mesoderm, in welches es hier nach vorne umbiegt. Und wie das axiale, läBt auch das periphere Mesoderm des eigentlichen Hinterrandes sich auf eine Colombildung zurückführen. Das Entoderm des Urdarmdaches zeigt dicht ror diesem Rand eine ihm parallel rerlaufende rinnenförmige Einbuchtung oder Einknickung (cr), die Cölom rin ne des hinteren Blastodermandes (Rückert 1887), die nach vorn umbiegend sich in die einer Cölombucht entsprechende Ursprungslinie des axialen Mesoderms fortsetzt.

Von der Cölomrinne aus breitet sich nun das Mesoderm des Hinterrandes

1) H. Virchow hat in seiner Beschreibung der Oberflächenbilder von Torpedokeimseheiben (1898) das vordere Mesodermfeld als das ,schmale Feld", das hintere als das „breite Feld ${ }^{\mathfrak{c}}$ bezeichnet. 
zunächst frei, d. h. ohne jede Verbindung mit dem unter ihm gelegenen Entoderu der Urdarnwand, nach vorn aus, verhalt sich also auch in dieser Hinsicht wie das axiale Mesoderm. Aber bei seinem weiteren Vorwachsen gegen das Keimscheibeninnere dringt es, seiner von Anfang an starken Masienentwicliung entsprechend, über die kurze Urdarmwand des Hinterrandes nach vorn hinaus in das Bereich des Dotters. Hier ist es nun nicht mehr durchweg frei, sondern zeigt Verbindungen mit dew Dotterentoderm (de'), wie das Mesoderm des übrigen Keimscheibenrandes, wenn auch nicht in dem gleichen MaB. Dementsprechend treten daselbst auch später GefäBanlagen auf, wie wir sehen werden.

Auch in seiner weiteren Entwicklung schließt sich das Mesoderm des Hinterrandes an das axiale an. Nedianwärts, gegen die axiale Embryonalanlage zu, nimmt es mehr und mehr urwirbelartigen Charakter an. Das tritt besonders deutlich an zur Keimscheihenoberlache parallel geführten Flachschnitten zutage, weil auf solchen die Mesodermplatte des Hinterrandes in ganzer Ausdehnung vorliegt und ihr Einbiegen in das axiale, schon in Uxwirbelgliederung begriffent Vesoderm zu übersehen ist. Eine dbgrenzung von Urwirbeln läßt diese Schicht freilich nicht oder höchstens nur andeutungsweise erkennen ${ }^{1}$ ), aber sie enthält, da sie im weiteren Verlauf der Entwicklung in das axiale Mesoderm einaückt und $\mathrm{zu}$ dessen caudaler Verlingerung verwendet wird (s. unten S. 15), jedenfalls Ma terial für Urwirbel. Sie stellt also gegenüber dem übrigen Randmesoderm eine Art Urwirbelplatte dar und muB daher, wenn sie auch bei ihrer Entstehung, rein topographisch betrachtet, noch zum peripheren Mesoderm gehört, ihrer prospektiven Bedeutung nach zum axialen gerechnet werden.

Geht man auf den lateralen Teil des Hinterrandes und von da auf den hinteren Teil des Seitenrandes über: so indert sich das Bild insofern, als die Mesodermwacherung allmählich schwächer wird. Hier, wo keine Urdarmhöhle mehr zur Ausbildung gelangt, läßst sich das Mesoderm zunächst nicht mit der gleichen Sicherheit ausschlieBlich rom Entoderm ableiten. Fis tritt dicht am Keimscheibenrand auf, wo das äuBere in das innere Keimblatt sich umschlägt, greift aber von da auf das innere Blatt über. Zum mindesten sein Hauptanteil wuchert aber auch hier aus dem Entoderm aus.

Gegen die vordere $\mathrm{Hälfte}$ der Keimseheibe zu vollzieht sich nach und nach eine weitere Umgestaltung des Randes. Daselbst ist die Urmundrinne, die schon hinter der Mitte des Seitenrandes ausläuft, verschwunden. Doch biegt das immer noch deutlich verdickte Ektoderm des Randes auch hier noch in das gleichfalls verstärkte Entoderm um (Abb. 5), aber das letztere Blatt liegt dabei dem Dotter

2) Ich habe vor langer Zeit ( $R$ üc lert 1886 und 1887) in dieser Mesodermplatte des Hinterrandes an Flachschnitten von Torpetokeimseheiben die "Spuren" einer beginnenden Ur. wirbelbildung an der Stellung der Zellen erkemen zu können geglaubt. Doch möchte ich es jetzt lieber offen lassen, ob die Anordnung der Begmu einer nach den Einrucken in die Axialanlagen wirklich auftretenden segmentalen Gliederung der Platte bedeutet oder nicht. ${ }^{*}$ Am Wesen der Sache ändert dies nichts, denn das fragliche Mesodermmaterial wird für die Embryonalanlage und damit auch für die Urwirbel verwendet. Die Behauptung RabIs (89, S. 125), $\mathrm{da} B$ ich in meiner Mesodermarbeit (87) die Urwirbelbildung rom peristomalen Mesodern aus. gehen lasse, ist irrtümlich. Da Rabl besonderes Gewioht darauf legt, diesen meinen angeblichen Febler zu korrigieren, betone ich auscaricklich, dab nach meiner damaligen Darstellung die Colom- und Urwirbelbildung zu beiden Seiten des hinteren Chordaendes, also am hinteren Ende des axialen oder gastralen Mesoderms ihren Ausgang nimmt. 
a uf und ist mit thm verwachsen (= Dotterentoderm de). Es kommt also atch hier ein deutlicher Umschlag der beiden primären Keimblatter ineinander zustande wie hinten und infolge der Verdickung derselben auch eine leichte, nach vorn sich allmählich verlierende, Aufwulstung des Blastodermrandes, aber ohne eine Urmundrinne (cenogenetischer Urmundrand).

Wie entsteht nun hier das Mesoderm? An einzelnen Stellen des vorderen Keimscheibenumfangs ist es im vorliegenden Stadium noch nicht als selbständiges Blatt abzugrenzen. Hier findet man (Abb. 5) am Rand nur das ursprüngliche, verdickte, einheitliche Dotterentoderm $=$ primäres Dotterentoderm $(d e)$, entdeckt aber dann häufig in ihm schon eine unvollständige Spaltung (über de' in $A b b .5$ ), durch welche eine tiefe. im allgemeinen nur aus einer einzigen Reihe flacher Zellen bestehende Lage, das definitive oder sekundäre Dotterentoderm (de'), von den darüber gelegenen Zellreihen, dem Mesoderm geschieden wird. An den meisten Schnitten geht die Trennung weiter und kann so einen Zustand erreichen, der in Abb. 6 dargestellt ist. Der Mesodermstreif liegt hier frei zwischen dem Ektoderm und dem dünnen Dotterentoderm (de') und versehmälert sich dabei gegen das Keimscheibeninnere zu mehr oder weniger, so daß er auf den Schnitten Keilform annehmen kann. Unter ihm ist häufig, oft infolge $\nabla$ on Flüssigkeitsausscheidung; die mit Entoderm überzogene Dotteroberfläche grubig eingesenkt, doch sind dies vorübergehende Bildungen, die sich nicht mit der späteren Randsinusanlage in Verbindung bringen lassen.

So bildet sich am größeren vorderen Abschnitt der Keimscheibe das periphere Mesoderm durch Delamination aus einem primären Dotterentoderm. DaB dem wirklich so ist, wird unter anderem auch durch den sich ausbreitenden Innenrand des Mesodermstreifens bewiesen. Dieser endet nämlich jetzt und auch noch bei älteren Embryonen auf den meisten Schnitten nicht frei, sondern in Verbindung mit dem Dotterentoderm, in das er sich verliert (bei del in Abb. 6). Von dieser Stelle an nach einwärts wird nun das letztere Blatt plötzlich wieder höher und mehrschichtig, es ist eben hier noch in Form des ursprünglichen primären Entoderms erhalten, das erst im Begriff steht, das Mesoderm abzuspalten. Diese Stelle mag als "Delaminationsgrenze" bezcichnet werden.

Der Unterschied zwischen dieser Mesodermbildung and derjenigen des hinteren Keimscheibenrandes (= palingenetischen Umuundrandes) ist kein so einschneidender, wie es den Ansehein hat. In beiden Zonen nimmt das Mittelblatt seinen Ausgang aus dem vom Ektoderm umgebogenen primären Entodem des Keimscheibenrandes, und zwar in der Weise, daB die oberflachlichere, erheblich dickere Schicht des letzteren in das neugebildete Blatt eingeht, daher man auch an beiden Randabschnitten den Eindruck erhält, als ob das Mesoderm: und nicht das darunter zurückgebliebene Entoderm, die eigentliche Fortsetzung des umgeschlagenen Elstoderms wäre (vgl. Abb. 6 u. 8). Der Cnterschied besteht nur darin, daß am Hinterrand zur Zeit der Mesodermbildung bereits ein fertiges. d. h. epithelial geschlossenes, primäres Entoderm in Gestalt einer vom Dotter abgehobenen Urdarmwand vorliegt, aus welchem das Mesoderm als Wucherung heraussproßt, während an dem in der Entwicklung zurückgebliebenen Vorderrand (cenogenetischen Urmundrand) bei einsetzender Mesodermbildung das mit den Dotter verbundene primäre Entoderm ein noch unfertiges, d. h. lockerer 
gefügtes Zellenlager darstellt, dessen für das Mesoderm hestimmtes oberflächliches Vaterial sich einfach durch einen Spalt rom Rest abtrennt. Erst nach erfolgter Abspaltung schlieBen sich hier die beiden Sohichten zu epithelialen Biattern.

Bei dieser prinzipiellen Ubereinstimmung zwischen den beiden Formen Aer Mesodermbildung versteht man auch, daß diese am Seitenrand der Keimscheibe unmerklich ineinander übergehen in gleichem Schritt mit der Um. gestaltung des Urdarmentoderms zum Dotterentoderm. Und daß ferner da. wo das Mesoderm des Hinterrandes (Abb. B), sich kranial gegen das Keimscheibeninnere ausbreitend, auf den Dotter gelangt, es ohne weiteres auch seine üblichen Beziehungen zum Dotterentoderm aufnimmt, d. h. nicht mehr ganz frei auswächst, sondern sich durch Delamination von diesem Blatt aus ergänzt.

Im voriegenden Stadium trifft man am eigentlichen Vorderrand der Keimscheibe, also etwa am vorderen Viertel ihres Umfangs, die ersten Anlagen ron Blutinseln ${ }^{2}$ ) als Anschwellungen innerhalb des Wesodermstreifens bzw. des an seiner Stelle noch vorhandenen ungespaltenen primären Dotterentoderms. Der Schnitt in Abb. 7 ist quer lurch den Vorderand der Keimscheibe, also tangential zu ihm, geführt und zeigt 3 solehe nebeneinander gelegene Bildungen. Dieselben unterscheiden sich durch ihre rundlichen Kerne und die innige, syncytiumartige Verbindung ihrer feinkörnigen, dotterhaltigen Zellenleiber deutlieh von den meist spindelfömigen, locker verbundenen und scharf abgegrenzten Elementen des umgebenden Mesoderms bzw. primären Dotterentoderms. Nur an der Oberfläche finden sich schon einzelne, vielleicht durch Druek von seiten der Rundzellen etwas abgeplattete Elemente.

Im Bereich dieser ersten Blutinseln ist die Mesodermdelamination meist noch mehr im Rückstand als in den Interstitien zwischen ihnen. So zeigen auch 2 von den 3 Blutinseln der $A b b .7$ noch eine mehr oder minder ausgedehnte Verbindung wit dem Dotterentoderm.

An einer zweiten gleichaltrigen Keimscheibe, an weicher die Abspaltung des Mesoderms noch nicht so weit gediehen ist. befinden sich die schon nachweisbaren Blutinseln des Vorderrandes noch vollständig in einem primären Dotterentoderm. Die Bilder gleichen dem der Abb.5, nur mit dem Cinterschied, daß in den Spindelzellenhaufen des Dotterentoderms schon die charakteristischen blutbildenden Elemente kenntlich sind.

An Embryonen, die nur wenig älter sind als der beschriebene. erscheinen die Blutinseln auch im Oberflachenbild der Keimscheibe. Sie bilden hier, wie bekannt, eine Kette rundlicher; $z$. T. länglicher Knötchen nahe am Innenrand des Mesoderminges, deren Lage, Verteilung und Zahl an verschieden alten Torpedokeimscheiben von H. Virchow (1898) an Oberflichenansichten genan verfolgt worden ist. Ein solches Stadium von einem Embryo mit 2 in Abgliederung begriffenen

1) Es sind also, wie ich sehon früher ( $R$ üe kert 1887) für Torpedo angegeben, die Blut. inseln in ihrem frühesten Entwicklungsstadium nur am Vorderrand der Keimscheibe angelegt. Im Oberflüchenbild sind sie freilich zu dieser Zeit noch kaum als Anschwellnngen deutlich. Hierans erklärt sich der Widerspruch won $\mathrm{H}$. Virchow (1898), der, nur auf die Oberflächen. bilder gestützt, geneigt ist, die Blutinseln gleichzeitig am Vorder- und Seitenrand auftreten zu lassen. 
Crwirbelpaaren ist das in der Textabb. A balbschematisch abgebildete. Die Anschwellungen erstrecken sich hier schon über die ganze vordere Hälfte der Keimscheibenperipherie, also auch ein Stück weit auf den Seitenrand.

Offenbar greift das Auftreten der Blutinseln rasch nach hinten weiter, denn ich finde sie auf einem zweiten kaum alteren Torpedoei schon fast in der ganzen Ausdehnung des Mesodermaringes ror. Der Embryo dieser nun nüher zu beschreibenden Keimseheibe hat einen fast vollständig abgegrenzten ersten Urwirbel, vor dem ein zweiter und auf der einen Seite ein dritter sich zu differenzieren beginnen. Die Ausbreitung der Blutinseln bei diesem Objekt entspricht der Kette der großen Inseln, die in Textabb. B auf Seite 11 von einem älteren Stadium zu ersehen sind: Die Anschwellungen erstrecken sich über das ganze vordere Mesodermfeld. Die hintersten biegen von da medianwärts in das hintere Feld ein, hinter dessen Vorderrand sie bis nahe an das axiale Mesoderm heranrücken, ohne aber dieses zu erreichen. Damit ist die definitive Ausdehnung der Kette der groBen BIutinseln erreicht.

Uber die Strukturveränderungen in der Mesoderm- oder Gefäßzone dieses Embryo von 2-3 Trwirbeln geben $4 b b, 9$ a. 10, 2 Sagittalschnitte durch den Vorderrand seiner Keimscheibe, AufschluB. Der Schnitt der Abb. 9 trifft den Zwischenraum zwischen 2 Blutinseln und zeigt das Verhalten des peripheren Mesoderms in reiner Form. Das Blatt hat sich seit dem vorigen Stadium etwas in die Länge ausgezogen (was nur in $\mathrm{Abb} .10$ deutlich ist) und an seiner Basis verschmälert, so daß seine ursprüngliche Keilgestalt verlorengegangen ist. Es ist jetzt schärfer von seiner Unterlage abgetrennt und abgehoben. Fine Ausnahme macht nur sein vorwachsender Innenrand. Dieser endet an der Mehrzahl der Schnitte nicht frei, sondern senkt sich zum Dotterentoderm herab und verbindet sich nach wie vor mit ihm, indem er sich an der "Delaminationsgrenze: in die oberflächliche Schicht dieses Blattes fortsetzt.

In $A b b .10$ ist eine der Blutinseln getroffen. Diese Gebilde haben sich zusammen mit dem peripheren Mesoderm vom primären Dotterentoderm abgespalten. Sie liegen daher jetzt innerhalb des freien Mesoderms und erscheinen auf den Schnitten als elliptische Anschwellungen dieses Blattes. Gegenüber unserem Ausgangsstadium sind sie etwas von Keimscheibenrand abgerückt, weil der letztere, worauf anch die Streckung des Randmesoderms in Abb. 10 hinweist. sich seitdem ein wenig auf dem Dotter ausgebreitet hat.

Die Hauptmasse einer Blutinsel besteht aus den oben beschriebenen charak. teristischen blutbildenden Elementen. Dazu kommen vereinzelte sie deckende platte Zellen, welch letztere sich später zu einer zusammenhängenden, die Insel uberkleidenden Schicht zusammenschließen und zuletzt als definitives, colombildendes Mesoderm sich von ihr abtrennen und abheben werden. Vorläutig aber stellen diese Zellen mit den Blut und Gefaßwand bildenden Elementen ein nicht zerlegbares Ganzes dar, und muB daher jetzt die Blutinsel trotz ihrer entodermalen Abstammung bis auf weiteres als Bestandteil des Mesoderms angesprochen werden.

Nach innen zu ragt das Mesoderm als dünnes Blatt auf den meisten Schnitten schon etwas äber die Insel hinaus. Anch hier endet sein Rand gewöhnlich nicht frei, sondern in mehr oder minder inniger Verbindung mit dem Entoderm, also an einer Delaminationsgrenze. 
๑. Erste Inlage des Sinus terminalis. Wandungslose Gefïbbahneu auf dem Dotter.

Einen weiteren Fortschritt in der Entwicklung zeigt der Keirascheibenrand eines Torpedoembryos von 3-5 Crwirbeln. Am Quersehnitt der Abb. 11, der durch den Seitenrand der Keimscheibe, etwas vor deren Mitte, geführt ist, also der Lage nach dem Querschnitt der $4 b b .5$ unseres jüngsten Stadiums entspricht, wieht man das gegen früher stark verdünte Ektoderm des Randes in das ebenfalls platte und vorwiegend einschichtige Dotterentoderm des Randes übergehen. Damit hat sich der leicht gewulstete Umschlagsrand der Abb. 5, 6 a. 9 am vorderen und seithichen Keimscheibenumfang in einen flachen, spitz auslaufenden Umwachsungsrand umgewandelt. Auch das periphere Mesoderm hat sich dabei noch weiter dün ausgezogen, so dab es meist nur mehr eine einzige und zudem oft defekte') Lage von Spindelzellen bildet. Diese ganze Umgestaltung des Randes ist durch ein fortdauerndes geringtügiges Auswachsen desselben über den Dotter entstanden. DaB ein solches tatsichlich stattgefunden hat, wird durch folgende Beobachtung erwiesen. An einem Tell der Schnitte, so \%. B. in Abb. 11, entspringt das Mesoderm in einiger Entfernung vom Keim. scheibenrand aus dem Dotterentoderm, statt rom Rande selbst wie bisher. Dies ist nur so erklarlich, daß die beiden Grenzblätter oder eines derselben über den ehemaligen Randumschlag hinausgewachsen sind. Vielleicht ist im vorliegenden Fall der Ektodermrand rorgeschoben worden, wobei ein Stück dieses Blattes auf den Dotter umgelegt und dem Entoderm angegliedert worden ist.

Die Blutinseln zeigen noch im wesentlichen das gleiche Verhalten wie im vorigen Stadium und ebenso das über sie hinansragende innere Ende des Mesodermblattes, dessen weitere Delamination vom Entoderm man an vielen Schnitten verfolgen kann.

An dem so gestalteten Rande machen sich die exsten Spuren eines Sinus terminalis bemerkbar. Sohwache grubige Einsenkungen des Dotterentoderms unterhalb der Blutinseln. durch den Druck der letzteren bedingt, waren schon ron deren Auftreten an wahrnehmbar. Jetzt sind sie etwas deutlicher $d . h$. tiefer geworden. In der peripher von ihnen gelegenen Randstreeke ist nun an vielen Stellen des vorderen Keimscheibenumfanges schon eine zweite, zunächst noch recht seichte, aber von der Nachbargrube doch schon abgesetzte Einsenkung des ron dünnem Entoderm überzogenen Dotters aufgetreten: Der Vorläufer des späteren Pandsinus $(r r)$. Dieser besteht also zuerst in einer freien, d. h. von GefäBzellen nicht ausgekleideten Rinne, der "Randrinne", welche gegen die Tiefe zu rom Dotterentoderm begrenzt wird und sich seitlich und nach oben in den Spalt zwischen diesem Blatt und dem Mesoderm eröffnet.

Die Randrin ne bildet, obwohl sie sich schon in diesem frühesten Entwicklungszustand über die vorderen zwei Drittel des Keimscheibenumfanges erstreckt, doch für lange Zeit keineswegs eine clurchlaufende Vertiefung, sondern setzt sich aus einzelnen getrennten Gruben zusammen, die sich über eine Reihe von Schnitten verfolgen lassen, um nach einer Unterbrechung durch ein abgeflachtes Randstück

1) Die auf Schnitten von jetzt ab häufig wahmehmbare Abtrennung des dünnen Mesoclerms fom Keimscheibenrand ist vernutlich ein Artefakt. 
wieder aufzutanchen. Diese, Randgruben" (Rückert 1903) werden in einem späteren Entwicklungsstadium, wenn sie sich stärker ausgebuchtet haben, auch in der Oberflächenansicht der Keimscheibe wahmehmbar. Sie entsprechen dann den von H. Virchow (1898) beschriebenen ,blasigen Räumen" des Keimhautrandes von Torpedo, über deren Bedeutung der genannte Autor sich nicht klar geworden ist. Die Randgruben buchten dann den Keimscheibenkontur auch peripher aus, so daß dieser eine Zeitlang einen auffallend welligen Verlauf nimmt, ein Phänomen, auf welches H. Virchow ebenfalls schon aufmerksam gemacht hat.

Aus obiger Beschreibung geht die bemerkenswerte Tatsache hervor, ala die erste Anlage des Randsinus anmittelbar am AuBenrand der Blutinseln erscheint. Würde bei der Weiterentwicklung keine Lageverschiebung der Teile eintreten, so müßten später die von der Insel sich ablösenden Blutzellen direkt in den Sinus fallen, was bei den Sauropsiden bekanntlich der Fall ist. Bei diesen erweist sich noch in späteren Entwicklungsstadien dieser Sinus als ein an die Blutinseln unmittelbar angeschlossenes Sammelgefä $B$, das die Aufgabe hat, das neugebildete Blut dem Kreislauf zuzuführen. Bei Selachiern hingegen folgt der sich entwickelnde Sinus terminalis, weil er am Keimhautrande gelegen ist, diesem bei der Umwachsung des Dotters. Er ist daher in der Zeit, in welche: die Blutzellen aus den Inseln frei werden, von diesen bereits ein Stück abgerückt. so daß die hohl gewordenen. Blutinseln nun nicht mehr direkt, sondern mittels peripherer kurzer Ausläufer an ihn sich anlehnen.

Die Rinne des Sinus terminalis stellt nicht die einzige ihrer Art dar. Bald nach ibrem Auftreten erscheinen in der sich verbreiternden Vesodermzone der Keimscheibe weitere grubige oder rinnenförmige Vertiefungen des Dotterentoderms als Vorläufer von echten Gefäßen. Zum Teil liegen sie unter jungen soliden GefäBanlagen ( $\mathrm{g} g l$. Abb. 13 des nächsten Stadjums beiderseits von $k n$ ). die nach dem Auftreten der Blutinseln in der Mesodermzone sich entwickeln. wie gleich beschrieben werden soll. In solchen Fallen sind sie durch den Druck dieser Zellenhäufchen hervorgerufen und werden später, wenn die letzteren sich zu Endothelröhren höhlen, von diesen ausgekleidet. Ein anderer Teil der Vertiefungen entsteht aber nicht im Bereich von GefäBzellengruppen, sondern in Form selbständiger Einsenkungen der vom Entoderm äberzogenen Dotteroberfläche, also ebenso wie die Randrinne. Wieweit diese letzteren Gruben und Rinnen später durch in sie hinein gelangendes Gefäßzellenmaterial endothelial austapeziert werden oder inwieweit sie, ohne sich zu definitiven Gefäßen zu entwickeln, wieder verstreichen bzw. durch neue Einsenkungen der plastischen Dotteroberflache ersetzt werden, entzieht sich der Kontrolle. Häufig sentt sich das Mesoderm zum Rand dieser Vertiefungen hinab und verbindet sich wit ihm. einen seitlichen Abschluß dex Gruben bildend.

Die Tatsache, daß wandungslose, Plasma führende Rinnen als Vorlaufer echter DottergefäBe anf dem Selachlerblastoderm vorübergehend auftreten. ist beachtenswert, weil damit ein AnschluB an die langst bekannten provisorischen GefäBbahnen auf dem Dotter ron Petrom yzon. den Teleostiern und Amphibien gegeben ist. 


\section{Anlagen bIntleerer Gefäe. Die kleinen Blatinseln des hinteren Mesodermfehtes.}

Wir gehen zu einem Stadium von $6 \mathrm{U} x$ w ir be ln über, dessen Oberflächenbild in beistehender Textabb. $B$ dargestellt ist. Die Randrinne erstreckt sich hier noch wie bisher über die vorderen zwei Drittel des Keimscheibenumfanges, also über das ganze vordere Mesodermfeld, in dessen Bereich der Blastodermrand jetzt dunn ausgezogen ist und flach auf dem Dotter ausläuft. Sie hat sich. wie der durch die Nitte des seitlichen Keimscheibenrandes geführte Querschnitt der Abb. 12 zeigt, etwas vertieft. Ihr Breitendurchmesser wechselt ebensosehr wie ihre Tiefenausdehnung, hat aber auch im allgemeinen zugenommen.

Das Dotterentoderm hat jetzt die Anordnung eines regelmäBigeren und hoheren Epithels angenommen. Im Bereioh der Mesodermzone besteht es aus einer einzigen, an vielen Stellen aus 2 Reihen kubischer oder rundlicher bis niedrig zylindriseher Zellen unter denen, innerhalb des Dotters, die Merocytenkerne und leren Sprößlinge liegen. Nur in der Randrinne hat sich das einreihige Plattenepithel, welches nach der Delamination des Mesoderms in fliesem Teil der Gefäßzone vorhanden war (vgl. Abb. 11) noch teilweise arhalten, aber es ist doch auch höher geworden (Abb. 12).

Betrachten wir das hintere Mesodermfeld unseres Stadiums. Der Querschnitt der Abb. 13, an der Grenze des cau dalen Drittels der Keimscheibe geführt, streift den rorderen Rand dieser Zone. Ex triff das hintere Ende der Randrinne (rr) und die letzte aus der Kette der großen Blutinseln, ein hier besonders mächtiges, zellenreiches Gebilde. Fs ist entsprechend

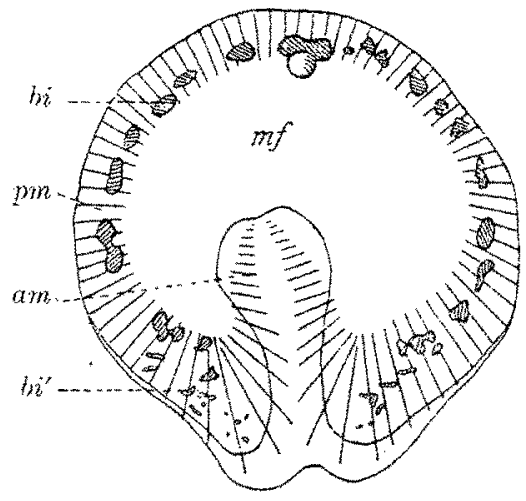

Albb. B. Keimscheibe von Torpedo oc. Stadiun ron 6 Urwirbelpaaren. Gleiche Darstellung un! Bezeichnungen wie in Abb. A.

$7 x^{\prime}=$ keine Blutimatn des hiaberen Mesodermtelles. dem oben geschilderten topographischen Verhalten der Blutinseln von der Randrinne weiter abgerückt als die Insel der $A b b .12$. Auf der Strecke zwischen ihr und dem Randgefäl begegnen wir in $A b b .13$ bei $g$ zum ersten Male einer GefäBanlage, die im Gegensatz zu den vorher entstandenen Blutinseln keine Blutzellen entwickeln wird, also eines ,blutleeren" Gefäßes, wie es in Kürze genannt werden soll. Dasselbe erscheint hier nicht als selbständige Buldung, sondern als peripherer Fortsatz der Blutinsel und ist gerade in Delamination vom Entoderm begriffen. Ein Stück von ihm, das oberhalb einer Dottergrube liegt, ist schon von der Unterlage abgetrennt, während an den Randem der Einsenkung die Verbindung noch besteht, besonders am Innenrand, wo die Anlage geradezu die Form einer: Knospe des Entoderms (kn) aufweist. dus der geringen Dicke der Zellenplatte läBt sich ersehen. dab sie ein blutleeres GefäBrohr bilden wird, las von der Insel znm Randsinus gerichtet, deren Blut in diesen abzuleiten bestimmt ist.

An der oberen Wand der Insel hat sich schon eine zusammenhängende dünne Mesodermsehicht gebildet, die aber mit ihr noch in innigem Zusammen- 
hang steht. Peripher dagegen zieht das mit der Insel verbundene Mesodermblatt frei über die sich delaminierende blutleere GefäBanlage weg. Somit erscheint die letztere, da sie bei ihrer Entstehung schon ein differenziertes Mesoclermblatt über sich vortindet, als eine rein entodermale Bildung im Gegensatz zu den früher auftretenden Blutinseln, die rorübergehend im Verband eines noch unfertigen Mesoderms gestanden waren, aus dem sie sich erst später abgespalten haben. Man sieht, đaßß diese beiden Entstehungsweisen von Gefäßen, welche bei oberflächlicher Betrachtung als "mesodermale" und ,entodermale" durch eine unüberbrïckbare Kluft getrennt zu sein scheinen, im Wesen nicht verschieden voneinander sind.

AnBer der beschriebenen findet sich noch eine Anzahl weiterer Gefäßanlagen im hinteren Mesodermfeld, deren erste Spuren schon im vorigen Stadium kenntlich waren. Zunächst können sich im vorderen Pandgebiete dieses Feldes an die oben (S. 8) beschriebene, einbiegende“" Blutinsel (bi in Abb. 13) medianwärts von vornherein noch weitere, meist kleinere, anschließen. DaB solche durch Abgliederung von einer schon vorhandenen, dem Seitenrand näher gelegenen Insel entstehen können, geht nicht nur aus Schnitten, sondern schon aus Oberflitchenbildern hervor (vgl. Textabb. B), welch letztere auch an anderen Stellen der Kette Teilungen ron Blutinseln erkennen lassen.

Namentlich treten aber jetzt weiter caudal, also im Immern des hinteren Mesodermfeldes, solide GefäBanlagen, und zwar in allen GröBenabstufungen. auf (Textabb. B). Die stärkeren unter ihnen, die voraussichtlich außer der Gefäß. wand eine kleine Zahl on Blutzellen lefern werden, kann man im Gegensatz zu der einreihigen Kette der großen Blutinseln des vorderen Mesodermfeldes als ,kleine Blutinseln" des hinteren Mesodermfeldes bezeichnen. Sie können bei Flächenansicht der Keimscheibe als unregelmäBige kleine Erhebungen oder bei durchfallendem Licht als verdichtete Stellen wahrgenommen werden. Die übrigen noch schwächeren Gefäßzellenstränge oder -häufchen dagegen sind Anlagen leerer Gefäße. Der durch die Grenze des caudalen Fünftels der Keim. scheibe geführte Querschnitt der Abb. 14 zeigt mehrere solcher Gebilde. Man findet sie, wie oben beschrieben, oft in deutlicher Verbindung mit dem Entoderm, zuweilen als Sprossen desselben $(k n)$, die sich von unten in das Mesoderm hineinschieben, wie ich dies im Hertwigschen Handbuch (S. 1111 und Abb. 791) beschrieben und abgebildet habe.

Im Stadium von $8 \mathrm{Urw}_{\mathrm{r}}$ ir bel $\mathrm{n}^{1}$ ) sind auch im vorderen Mesodermfeld unzweifelhafte Vorläufer von blutleeren Endothelröbren als ,solide Anlagen", d. h. als GefäBzellengruppen aufgetreten. Sie sind wie die des hinteren Feldes von unten an das Masoderm angeschlossen, in welches sie sich mehr oder weniger hineingeschoben haben, dessen Zellen auseinander drüngend. Sie lassen sich, wenn man ihnen in der Schnittserie bis zu ihrem Ende nachgeht, ebenfalls oft. bis an das Dotterentoderm heran und in dasselbe auch hinein verfolgen. Wiederholt konnte ich nachweisen, daß an solchen Stellen dieses Blatt unvermittelt höher wird.

1) Es werden für diese jumgen Studien nur die großen Urwirbel gezähit, Die im Kopfmesoderm vor dem vordersten groken Urwirbel gelegenen kleinen Segmente bleiben unberücksichtigt. 
Das hintere Mesodermfeld ist jetzt schon von zahreichen GefäBellenhaufen und -häufchen durchsetzt, welche oft die beschriebenen Beziehungen zum Entoderm aufweisen. Die Schnittbilder entsprechen im allgemeinen denen der Abb, 14 des vorigen Stadiums, nur sind die einzelnen Anlagen z. T, etwas zellenreicher geworden. und ist das Mesoderm, in das sie von unten her sich eingebettet haben, zu einer mehr zusammenhängenden blattartigen Schicht ge. schlossen, als dies bisher in dieser Region der Fall war.

Ein Fortschritt gegenüber dem Stadium der Textabb. B besteht darin. daB diese Crefäanlagen sich jetzt auch weiter caudal bis zum eigentlichen Hinterrand des Blastoderms nachweisen lassen. Dieser letztere ist schon in seinem lateralen thschnitt in einen flachen Umwachsungsrand ruckgebildet. so daß nur mehr seine mediale, an den Embryo angrenzende Hälfte den Bau des ursprünglichen dicken Randwulstes beibebalten hat, etwa wie in Textabb. $\mathrm{C}$. Bei dem einen der beiden Embryonen dieses Stadiums ist die GefäBbildung median bereits auf den Randwulst vorgerückt und reicht hier bis nahe an den Embryo heran, wie der durch den Hinterrand geführte Quersehnitt der Abb. 15 zeigt. Wärend weiter vorn die Gefabzellengruppen schon von ihrer Umgebung abgesetzt erscheinen, sind sie innerhalb des dicken Mesoderms des Pandwulstes noch in ihrem frühesten Entwicklungszustand begriffen, insofern sie nur leichte Ferdichtungen innerhaJb dieses Blattes darstellen. Bezeichnend ist aber auch hier ihre Lage in der tiefsten Schicht des Mesoderms, in das sie sich von unten her einschieben $(\mathrm{Abb} .15)$, als ob sie ein ihr fremder Bestandteil wären. In der Tat steht die abgebildete Zellengruppe $g^{2}$ an 2 Stellen mit dem unterliegenden Entoderm in Zusammenhang, einmal in Abb. 15 durch einen schmalen Stiel und dann wieder einige Schnitte weiter hinten, nach vorübergehender Abtrennung. Hier (Abb. 16) endet der Zellenstrang im Entoderm, indem er die charakteristische Form einer gegen den mesolermalen Randwolst vordringenden Knospe $(k n)$ annimmt.

Die GefäBzellengruppen des Randwulstes sind nur in geringer Zahl vorhanden und oft trheblich schwächer als die abgebildeten, so daß diese gesamte GefäB. anlage des eigentlichen Hinterrandes weit hinter der Blutinselkette der vorderen Keimscheibenhälfte zurïcksteht. Die größten derselben kann man noch als kleine oder rudinentäre Blutinseln ansprechen (s. u.). Daß solche aber überhaupt am Hinterrand zur Entwicklung gelangen, ist, wie gezeigt werden wird, für die morphologisehe Auffassung der ersten GefäBbahnen ron Bedeutung.

4. Am hinteren Keimscheibenumfang bildet sich ein Umwachsungsrand ans; womit das duftreten der Randrime daselbst vorbereitet wird. Die rudimentären Blutinseln des Hinterrandes setzen sich in den Embryo fort, wo das erste Anlagestïck der Yena subintestinalis und das Zellenmaterial fïr die hintere Dottervene ans ihnen entstehen.

Bei Embryonen mit 13 und $14 \mathrm{Ur}$ w $\mathrm{r}$ bel $\mathrm{n}$ und Anlage einer ersten Visceraltasche sind in nerhalb des Embryos die ersten GefäBzellen, die Herzzellen, aufgetreten. Doch soll diese Anlage erst in Kap. II beschrieben werden. Hier beschränken wix uns auf das extraembryonale Blastoderm des Stadiums und beginnen mit dem 
Vorderen Mesoderm-oder GefäBfeld. Dieses hat sich wieder verbreitert und eine Vermehrung seiner GefäBzellengruppen erfahren. Unter den letzteren trifft man jetzt zum erstenmal einige wenige, die sich schon zu durchgängigen Endothelrohrstückchen geformt haben. Anch die Entodermeinsenkungen an der Oberfluche des Dotters haben entsprechend der Verbreiterung der GefäBzone zugenommen. Der Inhalt der Blutinseln beginnt sich zu lockern. In bezug auf die Entstehung ihrer endothelialen Wandschicht und die Ablöstung von ihrem Mesodermüberzug verweise ich anf meine Angaben im Hertwigschen Handbuch (S. 1099). Das Dotterentoderm zeigt jetzt ein umgekehrtes Verhalten als zu Beginn der Mesodermentwicklung: Es zieht sich nur im Bereich der mesodermfreien Zone mehr und mehr za einem dünnen einschichtigen Epithel aus, in der GefäBzone dagegen, wit Ausnahme von deren Randabschnitt, erscheint es höher und meist $1-2$ reihig, am höchsten unterhalb der Blutinseln und namentlich an den Rändern der Blutinselgruben. An diesen Stellen ist auch das Merocytenlager unterhalb des Dotterentoderms am mächtigsten entwickelt. Utber den Zusammenhang des letzteren mit den Blutinseln und die Möglichkeit einer nachträglichen Zellenabgabe an diese habe ich mich im Hertwigschen Handbuch S. 1109-1912 so ausfübrlich ausgesprochen, daB ich hier diesen Punkt übergehen kann.

Im hinteren Mesoderm- oder GefäBfeld trift man vorn zunächst die "einbiegenden" Blutinseln. Sie liegen, die mesodernfreie Zone von hinten umsäumend, in verschieden weitem Abstand vom Seitenrand der Keimscheibe. oft meirere nebeneinander in der gleichen Querschnittsebene. Infolge der Verbreiterung der GefäBzone durch Auswachsen des Blastoderms erscheirren sie jetzt dem Embryo relativ genähert, in Wirklichkeit halten sie aber noch den gleichen seitlichen Abstand zu ihm ein, nach wie vor von ihm getrennt durch einen fast gefäBlosen Mesodermstreifen, der vorne schon Cölomlücken entwickelt hat $\left(c^{\prime}\right.$ in Abb. 19) und median und vorwärts in die inzwischen entstandene Perikardialhöhle des Embryonalkörpers, $c$ in Abb. 19, übergeht. Dieser Stroif ist das auf den Dotter seitlich ausgewachsene axiale Mesoderm (s. u. Kap. II. S. 37). Die ,einbiegenden" Blutinseln sind, obwohl sie meist zu den kleineren Exemplaren der großen Inseln gehören, doch entsprechend ihrer etwas späteren Entstehung noch solid.

Im übrigen finden sich im hinteren Mesodermfeld noch die auf S. 12 erwähnten zellenürmeren GefäBanlagen in allen Größenabstufungen. Die schwächeren, für blutleere Endothelröhren bestimmten Anlagen beginnen schon zum Teil, sich in HohlgefäBe umzugestalten. Die zellenreicheren dagegen sind noch kompakt. Sie finden sich außer in der caudalen Fortsetzung der großen Blutinseln vorwiegend in der Nähe des Hinterrandes im Bereich des sich hier auflösenden oder schon aufgelösten Randwulstrestes, wie gleich näher gezeigt werclen soll. Die gröberen unter ihnen stellen Übergangsformen zu den eohten Blutinseln des Vorderseitenrandes dar. Diese rudimentären Inseln sind auf das hintere Mesodermfeld beschränkt, niemals begegnet man ihnen im vorderen Feld. In letzterem sind stets nur grobe typische Inseln in einer Peibe und zu beiden Seiten derselben dünne, $1-2$ reihige Vorstufen leerer Gefäße vorhanden.

Das Dotterentoderm bildet im hinteren Gefäbfeld ein einschichtiges Platten- 
epithel, nur im Bereich der kleinen und gröBeren GefïBanlagen ist es höher und stellenweise zweischichtig. Häufig steht es mit ihnen in Verbindung, wie in. vorderen Felde.

Am eigentlichen Hintorand der Keimscheibe ist lie Entwicklung einen wichtigen Schritt vorwärts gegangen insofern, als der aufgewulstete Umschlagsrand (palingenetischer Urmundrand) sich jetzt auf die axiale Embryonalanlage zurückgezogen und einem flachen Cmwachsungsmand Platz gemacht hat. Ein Vergleich der Textabb. A und B mit C und D zeigt, wie dieser Vorgang im Oberflächenbild der Keimscheibe zum Ausdruck kommt. In A umfabt der Randwulst noch die hintere Halfte der Keimscheibe, in B ist er auf deren caudales Drittel. auf die hintere Mesodermzone, beschränkt. Bei C stellt er jederseits nur mehr einen kleinen nach hinten ausgebogenen Lappen dar, welcher das Caudalende der Axialanlage mit dem Umwachsungsrand verbindet, in welch letzteren er sich noch allmählich verliert. In $A b b . D$ sind diese

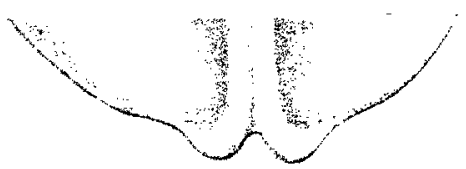

Abb. C. Hinteres Ende eines Enbry von Torp. marnor. mit $2 \mathrm{~mm}$ Läige.

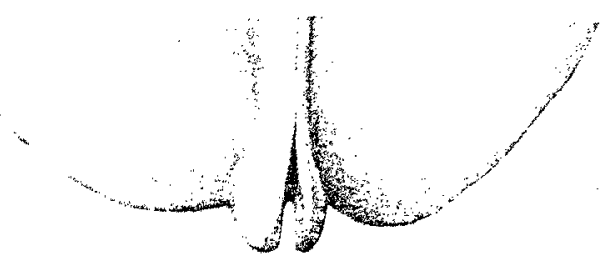

Ably. D. Das Glaiche von rinem Embrgo fin Tolp) maxaor, mit 3 mm luange.

Caudallappen im hinteren Ende der Axialanlage vollig anfgegangen und nun scharf vom Umwachsungsrand abgesetzt. Auch haben sie sich wie die übrige Embryonalanlage steil aufgerichtet und heben sich schon dadurch vom hinteren flachen Keimscheibenrand, den sie nummehr caudal weiter überragen, deutlich ab.

Wie sich diese Umgestaltung im Innern vollzogen hat, kann hier nur kurz angedeutet werden. Im vorderen Gebiet des halblxeisförmigen Hinterrandes der Textabb. A, wo ein nur schwacher Randwulst sich ein wenig über den Dotter aufgerichtet hatte, wächst der Keimscheibenrand von seiner Anheftungsstelle auf dem Dotter, indem er diese seine Verbindung beibehält, einfach aus und verflacht sich dabei. Weiter hinten und medial dagegen, seitlich von der axialen Embryonalanlage, wo ein viel dickerer Randwulst das Urdarmdach bildet, wird ex median in den Embryo einbezogen (S. 5), wobei der ihn fortsetzende düne Umwachsungsrand sich ihm sehrittweise nachschiebt, bis er zuletzt an die axiale Embryonalanlage heranreicht (Textabb. B-D).

Diese Einverleibung von Randwulstmaterial in die axiale Anlage ist duroh Experimente am Squalidenei ron mir (Rükert 1891) $)^{1}$ ) und $\mathrm{Kopsch}$ (1898) dargetan worden. Weiter unten werde ich zeigen, daf man auch durch Vergleichung von Querschnitten durch den Hinterrand aufeinanderfolgender Ent-

1) Meine kurze Mittelung ist in der Diskussion zu einem auf der Versammhung der Anatom. Gesellschaft zu Müchen gehaltenen Fortrag won His niedergelegt. Ioh habe im AnsehluB an dieselbe damals auch die von mir operierten Embryonen nebst den zugehörigen Abbildungen der Versammlung demonstriert. Die betreffenden Abbildungen gedenke ich noch nachträglich zu veröffenthehen, da sie die instruktiven Abbildungen von $\mathrm{K}$ opsch zu exgïnzen geeignet sind. 
wicklungsstadien die Aufuahme des Randwulstmesoderms in den Embryo erkennen kann. Wie freilich die Grenze zwischen dem sich abflachenden Randbezirk und dem in die Axialanlage eintretenden verläuft, ist noch nicht ermittelt. Dazu bedürfte es genauerer, eigens auf diese Frage gerichteter Durchsehneidungsund Zerstörungsexperimente des Randes.

Betrachten wir den so umgewandelten Hinterrand auf Querschnitten. Wir beginnen mit dem Schnitt der Abb. 20. Fr entstammt einem Embryo mit 14 Urwirbeln und exster Visceraltasche, der also etwas jünger ist als derjenige des Modells der tbb. I Tafel I. Der Lage nach entspricht er dem Selmitt der Abb. 15 der zuvor beschriebenen Altersstute. In Abb. 15 war das Ektoderm des Hinterrandes noch verdickt und ging durch Umsehlag in ein gleichfall dickes primäres Randentoderm über (biker Rand der Abb. 15), das sich nach innen (vorne) zu unter Abspaltung eines niedrigen sekundären Entoderms in das starke Randmesodern fortsetzt. Dieses primitive Verhalten eines echten Trmundrandes hat nun dem der Abb. 20 Platz gemacht, in welcher alle 3 Keimblatter im Begriff sind, sich zu einem dïnnen und abgeflachten Cmwachsungsrand auszuziehen. Das Auswachsen wird auch hier wieder dadurch bewiesen. dab der Keimscheibenrand über die Ursprungsstelle des Mesoderms peripher hinausragt. DaB die Ausbreitung sich über den gesamten Hinterrand erstreckt, geht aus den weiter caudal geführten Querschnitten der Abb. 21 und 22 hervor. Abb. 22 entspricht der Stelle, an welcher der caudale Abschnitt der Embryonalanlage sich rom Dotter abhebt, um als freier Caudallappen die Keimscheibe nach hinten zu überragen. Der freie ventrolaterale Rand (Umschlagsrand) dieses Querschnittes wird später mit dem der gegenüberliegenden Seite sich median rereinigen, womit die woiter vorne gegen den Dotter geoffnete Embryonalanlage, Darmwand sowohl wie Körperwand, ventral zum VerschluB gelangen wird. Da, wo diese verschlossene Strecke sich nach vorne zu ventral eröffnet, befindet sich die hintere Wand des zunächst noch langen Nabels, des Hautnabels sowohl wie des mit ihm anfänglich zusammenfallenden Darmabels ( $=$ hintere Darmpforte). Man sieht nun aus Abb. 22, daß der dünne Tmwachsungsrand, der hier nur von den beiden Grenzblättern gebildet wird. bis dicht an diese Abtrennungsstelle des Embryo vom Dotter heranreicht.

Mit dieser Abflachung ist jetzt für den gesa m ten Hinterrand des Blastoderms die gestaltliche Unterlage für das Auftreten der Randrinne gegeben. Es braucht nur der dünne periphere Abschnitt des Dotterentoderms sich daselbst grubig einzusenken, dann ist die gleiche Entwicklungsstufe erreicht, wie sie am Vorder-Seitenrand seit dem Stadium der Abb. 11 existiert. An einzelnen Stellen des Hinterrandes wie z. B. bei $r$ in Abb. 21 ist dieser Zustand bereits eingeleitet, doch ist eine fertige Randrinne am caudalen Umfang der Keimscheibe erst im folgenden Stadium vorhanden.

Für die vorliegende Entwicklungsstufe ist noch der Zustand des mittleren Keimblattes a $m$ Hinterrand und die daselbst stattfindende Bildung solider GefäBanlagen zu betrachten. Schon im vorigen Stadium, in welchem der Hinterrand in seiner medialen Hälfte noch den Charakter eines Randwalstes besa $B$ ( $A b b, 15)$ und dementsprechend noch ein mehrschichtiges, wenn auch gegen früher bereits verdünntes Mesoderm aufwies, trafen wir dicht vor ihm 
auf jüngste Gefäbanlagen. Die Entstehung von solchen hat sich nun an dieser Stelle inzwischen etwas gesteigert. Es hat sich bis zum vorliegenden Stadium das Mesoderm des Hinterrandes noch weiter nach rückwärts ausgezogen, so dap es jetzt mit Ausnahme eines an den Embryo anschließenden kurzen Stückes definitiv $z u$ einer dünneren Platte reduziert ist (Abb, 20 und 21), wie sie am Vorder-Seitenrand schon längst existiert. Und während nun der Hinterrand mehr und mehr den Charakter des Vorderrandes annimmt, wandelt sich ein Teil seines Zellenmateriales zu blutbildenden Gefabanlagen um, wie ein Vergleich der Abb. 20 mit Abb. 15, dem entsprechenden Schnitt des vorigen Stadiums, demonstriert. Diese Anschwellungen mit ihren mundkernigen, syncytiumartig verbundenen Binnenzellen tragen den. Charakter kleinster, jugendlicher Blutinseln. Auch in bezug auf ihre Lage dicht am Rande des Blastoderms sind sie den echten jungen Blutinseln der Vorder-Seitenrandkette vergleichbar.

Noch deutlicher tritt dieses Verhalten an einzelnen alteren Fmbryonen zutage, wie die durch den hinteren Blastodermrand eines Embryo von 16 Urwirbeln geführten Querschnitte der Abb. 25 und 26 lehren. Der flache hintere Keimscheibenrand ist hier ähnlich wie im Oberflächenbild des gleichaltrigen Embryos der Textabb. D jederseits rom Embryo über dessen Anheftungsstelle candal im Bogen hinausgewachsen. Ein Querschnitt durch das hintere Ende einer solchen Blastodermvorbuchtung, also ein Tangentialschnitt des Hinterrandes (Abb. 26), zeigt in einem dünen Mesoderm 4 nebeneinander liegende kleine Blutinseln. Es ist dies genau das gleiche Bild, wie es die Blatinselkette des Vorder-Seitenrandes in fruherer Entwicklungszeit ebenfalls auf tangentialen Sehnitten, d. h. Querschnitten durch den Vorder- und Sagittalschnitt durch den Seitenrand, darbietet. Etwas weiter vome (Abb. 25) treffen wir, dem bogenförmigen Verlauf des Randes entsprechend, die Anschwellungen nur mehr an beiden Enden des Schnittes. Zwischen ihnen liegt das gewöhnliche dünne Mesoderm mit ein par kleinen Gefäßzellengruppen. Aber nur die Verdickung am seitlichen (in der Abbildung links gelegenen) Schnittrand kann als eine kleine Blutinsel gelten, diejenige des medialen, dem Embryo zugewandten Randes (rechts in der Abbildung bei $r w$ ) ist nur in ihren tiefen Zelschichten zu einer GefäBanlage verdichtet, während sie im übrigen noch aus jener indifferenten Mesodermmasse besteht, die sich einige Schnitte weiter vorn in die Seitenplatten des Embryos fortsetzt, in der gleichen Weise, wie dies in Abb, 20 oberhalb $g^{\mathbf{1}}$ für einen etwas jüngeren Embryo übersichtlich dargestellt ist.

Diese verspätet auftretenden letzten Mesodermanschwellungen wachsen nun nicht $\mathrm{za}$ den typischen großen Blutinseln heran wie die des Vorderseitenrandes, offenbar schon deshalb nicht, weil ihnen dazu die Zeit fehlt, denn sie schließen sich bald der schon im Gang befindlichen Differenzierung der übrigen Inseln und HohlgefäBe an. Sie liefern dabei nur, wie Abb. 30 zeigt, eine spärliche Anzahl Blutzellen, aber sie produzieren doch immerhin solche und vielleicht sogar noch mehr als die vor ihnen gelegenen Gefäßanlagen des übrigen Hinterrandfeldes. Thre Bedeutung liegt auf morphologischem Gebiet, insofern sie genetisch zu der Reihe der randständigen echten BIutinseln gehören. Sie unterscheiden sich von ihnen nur dadurch, daß sie, infolge der sich langsam vollziehenden Ungestaltung des Randwulstes in einem Umwachsungsrand, verspätet auf- 
treten und damit im Wachstum zurückbleiben. Daß ihr Erscheinen sich bis zur Umwandlung des freien Umschlagsrandes in einen mit dem Dotter verbundenen Unwachsungsrand hinauszieht, ist sehr bezeichnend, denn Blutanlagen können. nur in Verbindung mit dem Dotter und dem Dotterentoderm sich bilden, niemals aus einem frei auswachsenden (palingenetischen) Umundrand.

Diese Gefäßanlagen des Hinterrandes stehen nun in wichtigen Beziehungen zu solchen des Embryonalkörpers. Schon bei einem der Embryonen mit 8 Urwirbeln (S. 13 und Abb. 15 u. 16) ließen sich am Hinterrand der Keimscheibe jugendliche GefäBzellengruppen medianwärts bis nahe an den Embryo heran verfolgen. Sie fanden sich daselbst in der tiefsten Schicht bzw, unterhalb einer dicken, noch auf dem Dotter mhenden, aber schon in die Seitenplatten des Embryos sich fortsetzenden Mesodermanschwellung. Dieses Zellenlager wird in aer Folge bei der weiteren Ausbreitung des Mesoderms über den Dotter nicht mit aufgebraucht, d. h. nicht dünn ausgezogen, sondern bleibt, wenigstens in der Hauptsache, zunächst an Ort und Stelle erhalten als letzter Rest des ehemaligen. Randwulstes der Keimscheibe. In dieser Lage treffen wir es noch bei den in. Abb. 20 und 21 abgebildeten Querschnitten eines Embryo von 14 Urwirbeln (bei $r w$ ) und erkennen in seiner tiefen Schicht die GefaßBanlagen $\left(g^{1}\right)$ des vorigen Stadiums wieder. Diese haben sich gegen früher nur wenig weiter entwickelt. Diejenige von $A b b .20$ zeigt schon eine Lichtung und stellt damit eine der ersten sich höhlenden Endothelröhren der Keimscheibe dar, diejenige ron Abb. 21 lehnt sich an eine entodermale Zellenknospe an, als ob sie sich von ihr abgeschnürt hätte. Es läßt sich hier sehr schön der Anschluß dieser GefäBanlagen an die letzten Blutinseln des seitlich angrenzenden bereits verdünnten Hinterrandes $\left(g^{2}-g^{4}\right.$ in Abb. 20$)$ demonstrieren.

Und der Mesodermwulst selbst? Verfolgt man ihn in der Querschnittsserie caudal, so bemerkt man (Abb. 22), daß er als ventraler angeschwollener Teil der Seitenplatte in das Bereich des Embryos einbezogen ist. In seiner inneren. der Darmwand zugewendeten Schicht ist eine noch junge, aber ganz deutliche GefäBzellengruppe zu sehen (si), welche der Lage nach $g^{1}$ der Abb. 21 entspricht. und die letzte in der Reihe der von uns über Abb. 20 und 21 bis hierher verfolgten GefäBanlagen des Hinterrandes ist. Sie ist, wie schon aus ihrer nachbarlichen Beziehung zur späteren ventralen Darmwand ersichtlich, nichts anderes als die erste Anlage der Vena subin testinalis und stellt, abgesehen von den in diesem Stadium ebenfalls schon aufgetretenen Herzzellen, die erste Gefäßzellengruppe des embryonalen Körpers dar.

Während der Weiterentwicklung (Textabb. D) wird auch der noch auf dem Dotter gelagerte Mesodermwulst der Abb. 20 und 21 in den Embryo einbezogen, also ein vorn and seitlich von Abb. 22 gelegener Teil des Wulstes. Dies zeigt Abb. 20, ein der Lage nach dem Schnitt der Abb. 20 entsprechender Querschnitt durch einen älteren Embryo von 18 Urwirbeln und 2 Visceraltaschen. Man erkennt hier, daß diese Cmlagerung dadurch zustande kommt, daß das vorher niedrige Darmohr sich in dorsaler Richtung streckt. Dabei wird an seiner sich aufrichtenden Seitenwand der Mesodermwulst emporgehoben und in vertikale Stellung gebracht, so daß er jetzt einen verdickten ventralen Abschnitt der embryonalen Seitenplatte darstellt. Damit kommen die an seiner Innenfläche 
entstandenen GefaBanlagen ( $g^{\mathrm{I}}$ in $\mathrm{Ab}$. 20 a. 21) ebenfalls in den Embryo hinein und bilden nun ein weiteres Stück der Subintestinalvenenanlage (si Abb. 29), welches dasjenige der Abb. 22 des vorigen Stadiums nach vorne zu fortsetzt.

Das ehemalige laterale, jetzt untere Ende des Mesodermwulstes reicht immer noch ein kurzes Stück auf den Dotter. Die Gefaßanlagen, welche aus diesem Teil hervorgehen und somit die Verbindung derjenigen des Dotters mit der Subintestinalvene hestellen, entsprechen dem späteren Verbindungsgefäls zwischen dem Sinus terminalis und der Subintestinalvene, nämlich der weiter unten näher zu beschreibenden, hinteren Dottervene" (hd in Abb. 29). Der abgebildete Schnitt trifft diese Venenanlage gerade, wo sie sich mit den Zellen der Subintestinalvene nach aufwärts zusammenhängt, also an der Stelle der Mündung der späteren hohlen Dottervene in die Subintestinalvene. Diese Stelle liegt 4 Urwirbel vor der caudalen dbtrennung des Embryos vom Blastoderm, der hinteren Hautnabelwand, und der mit diesem Punkt zur Zeit noch zusammenfallenden hinteren Darmnabelwand (- hintere Darmpforte s. S. 16). Die Zellengruppe der Subintestinalvene laBt sich von $A b b .29$ an noch um $11 / 2$ Urwirbel nach vorn verfolgen, von da ab sind dann nur mehr vereinzelte Gefaßzellen zur Seite der Darmwand zu finden, die einer anderen, in Kap. III zu besprechenden Anlage. angehören. Nach rückwäzts hat sich dagegen die Anlage der Vene seit dem Stadium der Abb, 20-22 nicht wesentlich weiter entwickelt, $\mathrm{d}$. h. sie ist mit Sicherheit noch nicht merklich über die der früheren $A b b .22$ entsprechende Stelle der hinteren Darmpforte hinaus nachzuweisen.

Ihrer Struktur nach ist die beschriebene Subintestinalvenenanlage noch vorwiegend solid, nur an einzelnen Stellen hat die Rohrbildung bereits eingesetzt. Auffallend ist ihr Zellenreichtum und ihre dichte Beschaffenheit, wodurch sie sich von den übrigen blutleeren Gefäßanlagen, namentlich denen des Embryonalkörpers, unterscheidet. Sie steht auch hierin den kleinen Blutinseln des Hinterrandes, deren Fortsetzung in den Fmbryo sie bildet, nahe. Nicht selten findet man sie in dieser frühen Entwicklungsstufe in Gestalt von kugligen Zellenhaufen, die im Innern des ventralen Seitenplattenwulstes einen beträ.chtlichen Raum einnehmen. Man könnte auf die Vermutung kommen, daß diese kräftigen Anlagen nicht bloß einem Endothelrohr, sondern auch einzelnen Blutzellen den Ursprung geben, doch habe ich aus ihnen immer nur ein leeres, freilich ungemein weites Rohrstück hervorgehen sehen. Mit dem Entoderm zeigt ibr Zellenmaterial, nur so lange es noch auf dem Dotter liegt, Verbindungen (s. oben), worin sich ebenfalls eine Ubereinstimmung mit den übrigen GefäBanlagen des Blastoderms ausspricht. Sobald es aber einmal in den Embryo einbezogen ist, gehört es ausschließlich dem mittleren Keimblatt an. Nirgends im Embryo läbt sich der mesodermale und zugleich lokale Ursprung von Gefäßen so deutlich demonstrieren als an dieser ersten, zellenreichen Subintestinalvenenanlage des Embryonalkörpers.

Ehe wix weitergehen, wollen wir eine Übersicht über die Gesamtheit der an den Querschnitten beschriebenen GefäBanlagen dieses Stadiums mit Hilfe der Abbildung eines Plattenmodells (Tafel $1, \mathrm{Abb} .1$ ) zu gewinnen suchen. Die rekonstruierte Keimscheibe gehört zu eimem Embryo mit 16 großen Urwirbeln, 
2 Visceraltaschen, von denen die zweite noch vollständig vom Mesoderm gedeckt ist, und einem im Bereiche des Hinterhirns bis zur Herzanlage nach rückwärts geschlossenen Neuralrohr.

Die durch eine weiße wellige Linie begrenzte mesodermfreie Zone (mf) ist von Gefäßanlagen völlig entblößt. In der sie vorn und seitlich umgebenden vorderen Mesodermzone ist noch die einreibige Kette der großen Blutinseln in bisheriger Anordnung wie in Textabb. B erhalten. Die Inseln sind ungleich stark, ein Teil von ihnen hat sich unter Aufnahme von Flüssigkeit und beträchtlicher Lockerung des Zelleninhalts ausgeweitet. Sie setzen sich in Ausliufer fort, welche solide Anlagen blutleerer Endothelröhren darstellen, zum Teil a ber wohl noch mit den Blutinselrändern bei weiterer Eröffnung von deren Lumina konfluieren werden. Zu beiden Seiten der Inselkette sind Gefäßzellengruppen aufgetreten, das Naterial für blutleere Gefaße (in der Abbildung schwarz wie die Blutinseln). Einige dieser Anlagen sind bereits in Hohlgefäße umgewandelt oder im Begriff, das zu tun (blau in der Abbildung). Peripher schließt die Zone mit der Randrinne (gelb) ab. Diese letztere erstreckt sich über den ganzen Vorder- und Seitenrand der Keimseheibe nach hinten, nur den eigentlichen Hinterrand noch frei lassend. Sie ist hier recht flach, was durch Strichelungen der Abbildung angegeben ist, und melrfach durch vollständig verstrichene Stellen unterbrochen.

In der hinteren Mesodermzone schließt sich an das mesodermfreie Feld nach rückwärts jederseits das Dottercölom $\left(c^{\prime}\right)$ an, der die Perikardialhöhle auf den Dotter fortsetzende einheitliche, aufgeblähte Raum. Seine obere Wand buchtet sich nach aufwärts, die untere mit dem anliegenden Dotter und Dotterentoderm gegen die Thefe zu aus. Dieser Leibeshöhlenabschnitt ist im vorliegenden Stadium noch wenig umfangreich. Rechts ragt er kaum bis in die Mitte der hinteren Mesodermzone nach rückwärts. Links ist er noch kleiner, etwas kranial verschoben und durch den Embryo großenteils verdeckt.

Im Bereich des Dottercöloms sind abgesehen von dessen Rändern nur vereinzelte GefäBzellen (schwarze Punkte) vorhanden. Lateral und hinten ist das Dottereölom im Begriff, in das ungespaltene Mesodermgebiet sich weiter auszubreiten in Form von vorerst noch getrennten, kleinen Leibeshöhlenspalten. Solche erstrecken sich auch an der Grenze des seitlichen Embryonalrandes und des Dotters über das Bereich der Perikardialhöhle weit hinaus nach hinten, viel weiter als die übrigen Mesodermlücken. In der vorderen Mesodermzone finden sich nur kleine schwache Cölomlücken, und zwar an den Rändern der Blutinseln.

Die soliden Gefäßanlagen der hinteren Mesodermzone bestehen außer den medial einbiegenden letzten großen Blutinseln aus kleinen und kleinsten Inseln die sich bis zum Hinterrand des Blastoderms erstrecken, wo sie in dem noch erhalten gebliebenen Rest des Randwulstes (grau in der Abbildung) oder unter ihm liegen und $\mathrm{ihm}$ folgend median in dem. Embryo sich fortsetzen als gleichfalls solide z. T. noch im Mesoderm steckende Anlagen der Vena subintestinalis. Im übrigen ist das Feld von den gleichen zerstreuten GefäBzellen und Zellenketten durchsetzt wie die übrige Mesodermzone. Diese zweifellos blutleeren Gefäßanlagen haben sich auch hier schon an einigen Stellen zu kleinen Gefäßröhrchen (blau in der Abbildung) umgebildet. 
5. Die Randrinne tritt auch am hinteren Keimscheibenrand ant. Die Inlagen der Sabintestinalvenen und der hinteren Dottervenen werden za Hohlgefäßen.

Die hier zu schildernden Entwicklungsvorgänge spielen sich während der Zeit der Ausbildung der dritten Visceraltasche ab. Es soll zunächst ein Uberblick über den Zustand des gesamten extraembryonalen Gefaßssystems in dieser Entwicklungsperiode an Hand eines weiteren Modells (Tafel I, Abb. 2) von einem Embryo mit eben beginnender Ausbuchtung der dritten Visceraltasche und 21 Trwirbeln gegeben werden.

In der vorderen Mesodermzone fallen zunähst die Blutinseln durch ihr stürkers Volumen auf. Sie verdanken dies der inzwischen weiter fortgeschrittenen Flüsigkeitsaufnahme und Zerstreuung ihrer Inhaltszellen, nur die hintersten gegen den Embryo einbiegenden Inseln zeigen noch die ursprüngliche, mehr kompakte Beschaffenheit. Die Inseln verästeln sich in jetzt ebenfalls hohl gewordene Fortsätze, die, soweit sie Blutzellen als Inhalt führen, mit den gleichen schwarzen Farbenton wie die Inseln selbst wiedergegeben sind. Nach außen und innen schließen sich an die Inseln blutleere Endothelröhren an (blau), die vielfach in offener Verbindung mit den bluthaltigen Auslihufern der Inseln stehen, entsprechend ihrer ersten Entwicklung als dünnere, letzte Fortsetzungen dieser Gebilde. Zwischen den blutleeren Gefäßen liegen, ebenfalls innen sowohl wie außen von den Inseln, wandungslose Rinnen (gelb) der Dotteroberflkche, die peripher mit der Randrinne abschließen. Diese lacunären primitiven Gefäßbahnen (s. S. 10) sind an dem Yodell der Abb. 1 nicht wiedergegehen, sie waren hier sehr undeutlich, offenbar infolge artifizieller Ablachung bei der Konservierung des herausgeschnittenen Dotterstückes. Aber, daß sie auch hier vorhanden sind, zeigen zahlreiche Mesodermbrücken, die sich häufig zu den Rändern solcher Rinnen herabsenken und sich mit deren Entodermuberzuy verbinden.

In der hinteren Mesodermzone liegt das jetzt umfangreichere Dottercollom $c^{\prime}$ auf der rechten Seite in ganzer Ausdehnung frei zutage, während es links durch den in dieser Richtung amgebogenen Embryo zum Teil verdeckt wird. Auch hier ist es wieder auf der linken Seite mit dem ganzen hinteren Blastodermabschnitt in kranialer Richtung versehoben.

Die Armut des Dottercöloms an GefäBanlagen fält jetzt gegenüber der reichen Vascularisierung des übrigen Mesodermgebietes noch mehr in die Augen als bisher. Die Anlagen beschränken sich immer noch auf vereinzeite GefäBzellen in dem engen Spaltraum zwischen dem visceralen Mesoderm und dem Dotterentoderm (schwarze Punkte in Abb. 2). Es erklät sich dies Verhalten aus dem Umstand, daB das Mesoderm des Dottercoloms kein peripheres, vom Dotterentoderm delaminiertes ist, sondern ein trei auf den Dotter ausgewachsener Teil des axialen Mesoderms. Ich sehe hierin cinen der vielen Belege für meine Auffassung von der Abstammung der DottergefaßBe aus einem vom Dotterentoderm sich abspaltenden Zellenmaterial.

Die das Dottercölom unmittelbar umgebende Kette leerer GefäBanlagen soll in Kap. II behandelt werden.

In der GefäBzone des hin teren Mesoder m feldes finden sich verstreut die kleinen Blutinseln. Ein Teil dieser GefäBanlagen hat sich aber seit dem Stadium der Abb. $l$ in leere Endothelröhren umgewandelt. Gegen den Hinterrand 
zu und in der Gegend des jetzt nahezu verschwundenen Randwulstes findet man die Anlagen noch fast durchweg kompakt oder erst im Beginne ihrer Hohlung begriffen, entsprechend ihrer späteren Entstehung. Wie sich diese Gefäßzellengruppen gegen den Erabryo $z u$ in die vorn hohle (blau), hinten noch solide (schwarz) Anlage der Subintestinalvene fortsetzen, ist ersichtlich.

Die Randrinne (gelb) ist nun auch am eigentlichen Hinterrand aufgetreten, aber sie erscheint daselbst noch unterbrochen und großenteils noch recht flach (gelb gestrichelt).

Wir verfolgen nun an $Q$ uerschnitten das Hohlwerden der Vena subintestinalis nebst der hinteren Dottervenen und deren weitere Ausbreitung. Daza wählen wir zunächst einen Embryo von 26 Urwirbeln [unter ihnen 20 Rumpfsegmente $^{1}$ ] und 3 Visceraltaschen, deren dritte ihre Mesodermumhüllung noch nicht völlig verdrüngt hat.

Der Schnitt der Abb. 37. welcher demjenigen der $A b b .29$ des vorigen Stadiums entspricht, trifft gerade den Ubergang der hinteren Dottervene in die Subintestinalvene ( $h d$ und si). Das Verbindungsstück, das vom Dotter zum Darm emporsteigt, stellt ein weites Endothelrohr dar, neben dem Kopfsinus das erste und mächtigste des ganzen Embryos, denn das Herz und die Venensohenkel desselben sind zu dieser Zeit erst in der Lumenbildung begriffen und noch eng. tuf der linken Körperhälfte (rechts in der Abbildung) erscheint das GefäB ein wenig weiter als rechts, auf weleher Seite der Ubergang der Dottervene in die Subintestinalis 2 Schnitte hinter dem abgebildeten liegt.

Hinter dieser Verbindungsstelle wird die Subintestinalvene enger (Abb. 38). Auf der linken Seite liegt das Rohr, was oft und auch schon in der soliden Anlage zu beobachten war, ganz im Innern des Mesoderms und ist noch nicht vollständig eröffnet. Noch vor der hinteren Darmpforte geht es in den ursprünglichen soliden Zustand über (Abb. 39) und ist in dieser Form nach hinten bis zu der schon jetzt kenntlichen Kloakenanlage zu verfolgen. Sie liegt auf dieser Strecke bekanntich, wie z. B. aus den Querschnitten eines alteren Embryos (Abb. 47-49) zu ersehen ist, am ventralen Endabschnitt der Seitenplatte, also jener, dem ehemaligen Umschlagsrand der Keimscheibe entsprechenden Stelle des Embryos (Abb. 22), an welcher' wir die Vene zuerst auftreten sahen. Die nach hinten zu erheblich kleiner werdende Zellengruppe bricht förnlich aus diesem Teil des Mesoderms heraus, indem sie Lücken hinter sich zurückläßt. Nach vor $n$ von ihrer Mündung stellt die Subintestinalis ein sofort enger werdendes, aber offenes Endothelrohr dar, das schon nach wenigen Schnitten authört. Sie hat also in dieser Richtung sich seit dem vorigen Stadium nur ausgehöhlt, nicht verlängert und wächst auch weiterhin nicht merkbar nach vome aus.

Sohließlich haben wir noch die hintere Dottervene zu berücksichtigen. Die Randrinne des hinteren Keimscheibenumfanges hat sich seit der Altersstufe der $A b b .2$, Tafel I vervolständigt. Sie erstreckt sich jetzt medial bis zur An-

1) Von jetzt ab lassen sich die Rumpfsegmente yon den mitotischen Koptsegmenten mit Hilfe der zwischen Trwirbel $t w$ und $x$ (nach Furbringers Terminologie) stattindenden $\mathrm{K}$ reuzung der Nervenleiste abgrenzen. Im vorliegenden Stadium erweist sich der erste große, hinter der 3. Visceraltasche gelegene, mitotische Urwirbel, mit welchem meine Zählung beginnt, als Kopfsomit $u$. Es sind also zu dieser Zeit noch 6 mitotische Kopfsegnente vorhanden. Später reduziert sich ihre Zahi anf 4 . 
des Herzens bei Torpedo in morphologischer und histiogenetischer Hinsicht.

heftungsstelle des Embryos an den hinteren Blastodermand, endet aber daselbst nicht, sondern setzt sich in Begleitung des Embryos ein kurzes Stück weit nach vorn fort. Sie liegt auf dieser Strecke beiderseits von der Anheftungsstelle der embryonalen Darmwand an den Dottex (Abb. 38 and $39 m$ ). Hier läBt sie sich mehr oder weniger deutlich nach vorn bis zu der Stelle verfolgen, wo das oben beschriebene noch solide, jetzt offene Anlagestück der hinteren Dottervene (Abb. $37 h d)$ nach aufwärts in die Subintestinalvene umbiegt.

Wärend die übrige am. Keimscheibenrand gelegene Rinne noch für längere Zeit wandungslos bleibt, erhält dieses neben dem Embryo nach vorn verlaufende Fndstück derselben bald nach seinem Erscheinen eine epitheliale Auskleidung. Es treten Zellengruppen in ihm auf, welche jenen oben beschriebenen soliden Gefäbanlagen entsprechen, die am hinteren Blastodermand entang bis zur Anlage der $V$. subintestinalis sich erstrecken. Hinten im Bereich der caudalen Darmpforte (Abb. 39 linke Seite) ist aus diesen Zellen schon ein Endothelrohr gebildet $(h d)$, das aber noch eng ist und die Rinne, in der es liegt, bei weitem nicht erfiult. Nach vorn zu hat es sich weiter ausgedehnt (Abb. 38 linke Seite) und füllt die Rinne schon aus. In diesem Zustand mündet es noch weiter vorn in die darüber gelegene, jetzt gleichfalls weit offene Subintestinalvene (Abb. 37).

So bildet sich hier das Endothelrohr innerhalb der Fortsetzung der Randrinne nach demselben Modus, wie wir überall bisher Gefaße entstehen sahen, nämlich aus sogenannter solider Anlage, d. h. aus GefäBzellensträngen, die sich später höhlen. Wie bei zahlreichen DottergefäBen, geschieht die Entwicklung auch hier in einer prifformierten Rinne des Dotterentoderms.

Das so entstandene paarige Gefäßstück darf man nun nicht mehr zum Sinus terminalis selbst rechnen, weil es nicht am Keimscheibenrand liegt. Es ist das Verbindungsstük der Randrinne mit der Vena subintestinalis and muB daher als ein vom Dotter zum Embryo ziehender GefuBstamm den Namen Dotter. vene, und zwar im Gegensatz zu einem später (Kap. II) zu beschreibenden zweiten derartigen Venenzug die Bezeichnung, hintere Dottervene erhalten.

Wie sich die hintere Dottervene vom in die Vena subintestinalis ergie $B$ t, wurde oben beschrieben. Es ist dem nur nachzutragen, daß hinter der in $A b b .37$ abgebildeten Mündung noch eine zweite Kommunikation aufgetreten ist (Abb. 38 rechte Seite), die übrigens schon in der soliden Anlage des vorigen Stadiums kenntlich war.

Peripher hängt die Dottervene mit anderen Gefäßen zusammen, die seitlich von ihx vor dem hinteren Blastodermrand sich entwickelt haben und zum Teil noch unfertig sind. Diese NachbargefaßBe, die Dottervene selbst und das zuerst gebildete Stuck der Venasubintestinalis sind somit sämtlioh Produkte der oben beschriebenen Kette der letzten GefäBanschwellangen des Hinterrandes (Abb. 1, Tafel I und $A b b .20$ ).

6. Ausbildung der definitiven, mit GefäBepithel ausgekleideten, Fena teminalis. Weitere Fntwicklung der Vena subintestinalis und der hinteren Dottervenen.

Wir beenden den Abschnitt I mit dem Entwioklungsstadium ron 4 Visceraltaschen. Von 8 untersuchten Embryonen dieses Stadiums ist bei zweien die zweite Visceraltasche schon im Durchbruch begriffen. Die Zahl der Crwirbel beträgt 
32-34, was einer Ziffer von 28-30 Rumpfsomiten in diesern Stadium entspricht. Es wurde won jetzt ab bei allen Embryonen der erste Rumpfsomit Iestgestellt und als Ausgangspunkt für die Zählungen genommen.

Eine allgemeine Orientierung über das Verhalten des Blastoderms in diesem Stadium soll mit Hilfe des Plattenmodells der Tafel I, Abb. 3 gegeben werden. Die Blutinseln sind hier fast durchweg in blutzellenhaltige HohlgefäBe umgewandelt, die mit den übrigen, den blutleer angelegten, Gefäßen ein zusammenhängendes dichtes Netz bilden. Das Kaliber von dessen einzelnen. GefäBstücken ist ein ungleiches. So lassen sich z. B. die ehemaligen Inseln z. T. noch als erweiterte Bahnen des Netzes wieder erkennen, doch trifft man solche tusweitungen auch unter den blutleer angelegten Gefäßen. Hingegen ist für die Inseln charakteristisch ihre stärkere Fülung mit Blutzellen. Diese letzteren werden offenbar von ihren Brutstätten ganz allmählich abgeschwemmt, denn. in den blutleer angelegten Gefäßen werden sie in geringerer Zahl angetroffen. Aber dafür haben sie sich schon über die ganze GefäBzone verbreitet und sind bis in den Embryo vorgedrungen, wo sie im Herzen, in den Mandibulararterien, der Subintestinalis und ziemlich zahlreich im Kopfsinus zu finden sind. Die hintersten großen Inseln der Fette sind gemäB ihrer späteren Entstehung in der Entwicklung zurückgeblieben, ihre Zellen füllen noch dicht gedrüngt das Lumen aus, und auch ihre untere Endothelwand ist noch unfertig. Doch gelten diese speziellen Angaben nur für die vorliegende Keimscheibe, denn bei den verschiedenen gleichaltrigen Objekten dieses Stadiums ist die Auflösung der Blutzellenmasse ungleich weit vorgeschritten.

Uber den AbschluB der Area vasculosa nach innen gegen die mesodermfreie Zone soll an anderer Stelle gehandelt werden. Nach a u Ben folgt auf das Netz der Endothelrohren die Pandrinne. Sie läßt sich im Gegensatz zu dem Modell der Tafel I, Abb. 2 am Hinterrand der Keimscheibe bis zum Embryo verfolgen, in dessen Bereich sie, wie oben beschrieben, im Bogen nach forn umbiegt, gedeckt von dem im Modell weggenommenen Ekto- und Mesoderm. In diesem ihren kurzen Endstück ist ( $\$$. S. 23) bereits die hintere Dottervene als HohlgefäB aufgetreten, was rechts in $A b b .3$ zu erkennen ist. Die Vene - blau - deckt zum Teil das Ende der gelben Randrinne zu. Wie sich die Dottervene in die Subintestinalvene des Embryos fortsetzt, ist aus der Abbildung ebenfalls zu ersehen.

Am Boden des Dottercöloms sind gleichtalls HohlgefäBe anfgetreten. aber spärlicher als in der GefäBzone. Die in letzterer vorhandenen Cölomlücken haben namentlich in der Cimgebung der ehemaligen Blutinseln an Ausdehnung gewonnen.

Verfolgen wir zunächst die weitere Entwicklung des Randgefabes an Querschnitten. Bei den jüngeren Embryonen unseres Stadiums, zu denen auch derjenige der $A b b$. 3 gehört, zeigt diese Anlage noch die bisherige Beschaffenheit der offenen Lacune ( $\mathrm{Ab}$ b. $40 \mathrm{rr}$ ), die Rinne ist im allgemeinen sogar stärker abgeflacht und verstrichen als früher. Blutzellen fehlen in ihr noch völlig. Es weist dies auf die an den Schnitten leicht feststellbare Tatsache hin, daß die Randrinne mit den Hohlgefaßen des Blastoderms nicht in offener Verbindung steht.

Noch im Verlauf dieses Stadiums erscheint nun an Stelle der Rinne der mit GefäBepithel ansgekleidete und blutzellenhaltige, definitive Sinus terminalis, 
der dann den Namen einer Ra ndvene verdient und sich in die vorher innerhalb der Rinne gebildeten hinteren Dottervenen und damit in die Subintestinalyenen fortsetzt. Dieses Gefäß ist in dem Modell der Abb. 4, Tafel I vom jüngsten Embryo des Stadiums mit 5 Visceraltaschen, auf das ich in Ermangelung eines zweiten Modells aus dem vorliegenden Stadium hier vorgreifend verweise, in seiner ganzen Ausdehnung zu uberblicken. Sein spezielles Verhalten ist aus dem Querschnitt der Abb. 41 eines noch etwas älteren Embryos zu ersehen.

Wie entsteht die Randvene? Diese Frage hat mir, bevor ich ihre Lösung fand, nicht geringe Schwierigkeiten bereitet, weil ich von der anscheinend selbstverständlichen Vorstellung ausging, daß die lacunäre Randrinne sich in das endothelbegrenzte GefiBrolr umgestalte.

Das Ungewöhnliche an dem Vorgang der Randvenenbildung besteht darin, daß dieses Endothelrohr nicht wie die bisherigen Gefäße des Blastoderms und des Embryonalkörpers (Herz, Subintestinalis, Aorta) in ,solidem" Zustand angelegt wird. Solche Gefäßzellenketten und stränge, die bei der ersten Entstehung der Dottergefäße teils als Ausläufer der Blutinseln, teils frei, so z. B. auch innerhalb des Endstückes der Randrinne als Anlagen der hinteren Dottervenen, auftraten, vermiBt man an der Stelle dex zu erwartenden Randvene, in der Pandlacune, gänzlich. Tnd doch könnten sie bei der Bildung eines so kräftigen GefäBes, wie es die Randvene ist, nicht übersehen werden. Nur ganz vereinzelte, stark abgeplattete Zellen trifft man am Boden der Rinne and andere nicht so abgeflachte Elemente an der Untertläche der sonst dinnen Mesodernidecke und ebenso an dem der Rinne zugewandten Rand eines benachbarten Endothelrohres. Von diesen spärlichen Zellen habe ich früher (Rü̈ckert 1903 tund im Hextwigschen Handbuch I, S. 1108) die Randvene abgeleitet unter der Annahme, daß sie allmählich einen vollständigen Wandbelag der Rinne ausbilden und damit diese in ein Endothelrohr umwandeln. Ich kann ibre Beteligung an der Bildung des letzteren auch jetzt nicht ausschließen (s. unten), aber daß sie eine entscheidende Rolle bei dem Vorgang spielen, nehme ich jetzt nicht mehr an, und zwar aus verschiedenen Grüclen, unter anderem auch deshalb, weil man niemals Zwischenstufen zwischen diesen vereinzelten Zellen und dem fertigen Gefäb findet.

Das gänzliche Fehlen von zweifellosen Vorstufen des Endothelrohres innerhalb der Randrinne hat mich zu der Auffassung geführt, daß dieses Gebilde uberhaupt nicht selbständig in der Lacune sich entwickelt, sondern daß es von den benachbarten, fertigen HohlgefäBen aus in sie vordringt. Bei Durchmusterung der Querschnittsserien $\mathrm{kam}$ ich zunärbst zu der Ansicht, daß dieser Vorgang in einem Yorsprossen von einzelnen HohlgefäBen in die Rinne bestehe, die dann zum Ringgefäß konfluieren müßten. Übersichtlicher noch als die Schnitte zeigt das Modell der $A b b .3$, Tafel I solche Vorbuchtungen der Gefäle gegen die Rinne. Aber wäre dem so, dann müßten zur Zeit der Randvenenbildung irgendwo an dem ausgedehnten Blastodermrand doch einmal die getrennten Sprossen der einzelnen HohlgefäBe und ein Durchbruch derselben ineinander zu sehen sein. Das ist aber niemals der Fall. Nach Verlauf einer ganz kurzen Zeit, noch während des Stadiums von 4 Visceraltaschen, bei Embryonen, die gar nicht oder nur um 1 Urwirbel alter sind als derjenige des Modells der $\mathrm{Abb}, 3$, ist die fertige Ping- 
vene wie mit einem Schlage in Erscheinung getreten als ein un unterbrochen über den ganzen Rand durchlaufendes blutzellenhaltiges Gefäß. wie es im Modell der Abb. 4 für das spätere Stadium von $\tilde{5}$ Visceraltaschen abgebildet ist.

Diese Tatsachen führen zu folgender Auffassung der Entstehung der äuBeren Ringvene: Nicht getrennte Gefäßsprossen, sondern der gesarate in sich geschlossene Rand des GefäBnetzes der A. vasculosa schiebt sich peripher gegen die Stelle der bisherigen Rinne vor, wobei dessen $z$. T. stark vorspringende Schlingen und blinde Buchten seiner Ausbreitung über eine ausgedehntere Fläche entsprechend sich allmählich strecken und ausgleichen. So stellt also die Vene am Blastodermrand von Anfang an einen in sich geschlossenen Ping dar, welcher aber noch durch seinen geschwungenen Verlauf (Abb. 4) seine Entatehungsweise aus dem Randteil des Netzes erkennen läBt. Diese Vene ist somit nicht durch Umgestaltung der vorher vorhandenen lacunären Rinne entstanden, etwa durch Umscheidung derselben mit GefäBzellen, sondern sie ist eine von ihr unabhängige Bildung, die an ihre Stelle getreten ist, um sie zu ersetzen.

Weon man diesen Entwicklungsvorgang einmal verstanden hat, dann erkennt man auch dié Vorstufen des definitiven Sinus terminalis an den Schnittserien. Solche Keimscheiben zeigen ein sehr wechselvolles Bild ihres Randbezirkes, das mir ganz unverständlich war, solange ich an eine Umwandlung der Pandlacune in ein Epithelrohr geglaubt hatte. Uber einer Anzahl von Schnitten nämlich liegt hier das fertige endothelbekleidete und blutzellenhaltige Gefaß dicht am Rande, wie in $A b b .41$ eines älteren Embryos, nur mit dem Unterschied, daß die Vene noch nicht so voluminös ist als in der Abbildung. Solche Strecken des Randes wechseln nun mit anderen $a b$, welche noch die ursprüngliche Randrinne erkennen lassen, die freilich gegen früher im allgemeinen flacher geworden $(r r$ in $A b b .40$ ) und stärker verstrichen ist, eine Rückbildung, die nebenbei bemerkt, offenbar durch die jetzt stattfindende Ansammlung des Blutplasmas in dem Endothelröhrennetz bedingt ist. Hier möchte man zunächst glauben, daß die Randwene noch nicht einmal in ihren Anfängen angelegt sei, was man' aber angesichts der übrigen Querschnitte wiederum nicht annehmen kann. In Wahrheit ist auch hier die Randrene (rs in Abb. 40) schon rorhanden, aber noch micht bis zum Rande vorgeschoben.

Die auffallende Tatsache, daß die Pingrene nicht wie die ersten Gefäße im Embryo und auf dem Dotter aus einer, soliden" Anlage, d. h. aus einer Gefäßrellenansammlung, entsteht, erklärt sich daraus, daß ihre Bildung schon in eine etwas spätere Zeit fällt in welcher der Austritt des gefäßbildenden Zellenmaterials aus dem Keimblattverband und seine lebhafte Eigenvermehrung im wesentlichen bereits abgelaufen ist. Dieser erste, ich möchte sagen stürmische, Verlauf der GefäBbildung erstreckt sich auf dem Dotter sowie im Embryo nur über die Zeit, bis die soliden Anlagen sich in offene Endothelröhren umgewandelt haben. Auf diese erste Periode folgt dann eine zweite, in welcher das GefaBzellenmaterial nicht mehr gruppenweise auftritt, sondern höchstens in Form einzelner Zellen, ein Umstand, der nebenbei bemerkt, die Untersuchung der GefäBbildung von da ab exschwert, zumal nun auch bald danach innerhalb des Embryos die ersten Mesenchymzellen erscheinen, von denen sich die gefäßbildenden Zellen micht unterscheiden lassen, außer, nachdem sie die für sie 
charakteristische starke Abplattung erfahren haben. Für diese zweite Periode kommt vor allem eine Ausbreitung der Gefäße durch Auswachsen der blinden Enden der schon fertigen Endothelröhren in Frage.

Wenn der Randsinus den Zustand der $A b b, 41$ erreicht hat, ist seine histiogenetische Ausbildung im wesentlichen vollendet. Ich habe ihn auf Schnitten bis zu Embryonen mit 61 Urwirbeln verfolgt und ihn bis dahin im allgemeinen streng randständig gefunden. Wenn auch der auswachsende Blastodermrand hier und da einen Vorstoß über den Sinus hinaus macht, so handelt es sich dabei um einen viel schmäleren Randstreifen als denjenigen, der im Zwischenstadium zwisehen der Randrinne und der Randvene durch Verstreichen der letzteren torübergehend aufgetreten war. Auch ist er dann nicht mehr dreiblätrig. sondern besteht aus einigen dünnen, der oberen Dotterfliche unmittelbar angehefteten Ektodermzellen, zu denen am Rande des Sinus noch ein paar Entodermzellen als tiefe Schicht hinzutreten können. Bei noch älteren Embryonen ragt das den Dotter umwachsende Blastoderm, wie die Oberflächenbetrachtung solcher Eier zeigt, stets mittels eines Saumes über die Randvene hinaus (s. Rüokert 1921). Ob dieser den zuletzt beschriebenen Bau besitzt, kann ich. da ich ihn auf Schnitten nicht mehr systenatisch untersucht habe, nicht mit Sicherheit angeben, vermute es aber.

Die hintere Dottervene erhält während der weiteren Entwicklung einen Zuwachs an threm caudalen Ende. Solange der Embryo noch am hinteren Blastodermrand angeheftet ist, biegt der Randsinus von hier aus unmittelbar in den Embryonalkörper ein, indem er an der Anheftungsstelle unter dessen Ektodermüberzug gelangt. Diese Fortsetzung des Sinus, die Dottervene, liegt daher anfänglich auf ihrer ganzen, zu dieser Zeit noch kurzen Verlaufsstrecke intraembryonall). Später dagegen erstreckt sich die Keimhaut caudal über die Anheftungsstelle des Embryos hinaus. Auf welche Weise dies zustande kommt, wurde kürzlich von mir (Rückert 1921) dargelegt. Während nach der bisherigen Ansicht hierbei die 2 Hälften des hinteren Blastodermrandes in der Mittellinie zu einer ,Dottersacknaht" (H. Virchow) sich vereinigen sollen, habe ich gezeigt, daß dies nicht der Fall ist, daß vielmehr der hintere Blastodermrand ohne eine solche Crmlagerung seiner Teile einfach nach hinten auswächst, indem er sich sukzessive von der hinteren Anheftungsstelle des Embryos an den Dotter (hintere Nabelwand oder Hautnabelwand) entfernt. Dabei muB die hintere Dottervene sich entsprechend verlängern oder genauer ausgedrückt: Zu ihrer anfünglichen intraembryonalen Verlaufsstrecke muB mit dem Abrücken des hinteren Blastodermrandes von der hinteren Nabelwand ein extraembryonaler Abschnitt hinzutreten. Dieser letztere ist im vorliegenden Stadium von 4 Viscexaltaschen erst bei einem Teil der Embryonen gebildet, und er ist auch da noch sehr kurz, ton der Lange kaum eines Urwirbels, so daß er in der stark verkleiner-

1) Der Ausdruck ,intraembryonal" könnte angefochten werden, weil die Vene in Wirklichkeit dem Dotter aufruht, beiderseitig von der Anheftung des Darms an diesen und von einem Abschnitt des Ektoderms gedeckt wird, der sich rom Embryonalkörper auf den Dotter umschlägt (Abb. 37 und $38 \mathrm{hl}$ ). Aber im Gegensatz zu dem caudal vom Embryo gelegenen extraembryonalen Abschnitt des GefäBes befindet sich der intraembryonale doch im Bereich des Embryos, wenn auch an der Anheftungsstelle desselben an den Dotter. 
ten $A b b .3$ unseres Plattenmodells noch nicht in die Augen fallt. Im Stadium der Abb. 4 ist er schon kenntlich, und später mit der weiteren Umwachsung des Dotters gewinnt er selbstverständlich eine mächtige Längenausdehnung.

Der intraembryonale Abschnitt der Dottervene befindet sich im vorliegenden Stadium von 4 Visceraltaschen nicht mehr wie früher (vgl. $A b b, 37$ u. 38) zu beiden Seiten der Anheftungsstelle des Darms an den Dotter. denn der Darm hat sich inzwischen in caudo-kranialer Richtung vom Dotter abzuschnüren begonnen. Letzterer Vorgang verläuft in der Weise, daB die seitlichen Darmwände sich mit ihrem ventralen Abschnitt gegeneinander einfalten bis zur medianen Berühung und Verklebung, also zur Bildung eines Darmstiels wie ihn $\mathrm{Abb} .39$ vom vorigen und $\mathrm{Abb} .45(h s l)$ vom vorliegenden Stadium zeigen. Sodann trennt sich der für den Embryonalkörper bestimmte Teil des Darmquerschnittes als geschlossenes Rohr ab (Abb. 46) und läBt dabei unter sich als leistenförmigen Rest den bisherigen Stiel, den wir nun ,hinteren Darm. rest: $\left.(h r)^{1}\right)$ nennen, auf dem Dotter zurück. Dieser hat meist die Gestalt einer nach unten offenen Falte, wie in $A b b, 46$ oder eines unpaaren Septums, wenn die Verklebung seiner beiden Blatter bis zum Dotter herabreicht, wie in $A b b .45$, wo dio Leiste übrigens noch nicht durchtrennt ist. Infolge dieses Vorgangs bleiben die Dottervenen unterhalb des abgeschnürten Darms auf dem Dotter zurück. wo sie jetzt $z u$ beiden Seiten des Darmrestes liegen (hd in Abb. 46).

Das über ihnen gelegene Stück der Subintestinalvenen aber gelangt durch die Abschnürung aus der ursprünglich rein seitlichen in eine ventrale Lage zum Darmrohr ( $s i$ in $\mathrm{Abb} .46$ ), woselbst die beiderseitigen Gefäße durch kein Hindernis mehr getrennt, einander zur Vereinigung zustreben. So erreichen diese Venen auch in ihrem mit dem Dotter anfänglich verbundenen kranialen Anfangsstück die ihnen zukommende ventrale Stellung zum Darm, die sie in dem über die Keimscheibe hinausgewachsenen caudalen Rumpfabschnitte (Abb. 47 u. 48), gemäB ihrer Entstehung aus den ventralen Endstücken der Seitenplatten, von Anfang an eingenommen haben.

Diese für die Weiterentwicklung des vorliegenden Venenabschnittes makgebende caudo-kraniale Abnabelung des Darms stand im vorigen Stadium von. 3 Visceraltaschen erst in Vorbereitung. Der Schnitt der Abb. 39 aus jenem Stadium traf die Verlötungs- und spätere Durchschnürungsstelle des Darms, also die hintere Wand des noch weiten Darmnabels oder, wie wir kürzer sagen, die hintere Darmpforte. Zugleich fiel auf der linken Seite des Embryos, wie die Figur zeigt, auch die Abschnürung des Ektoderms, also die hintere Wand des Hautnabels, in den Schnitt. Es hatte also die Darmanschnürung zu jener Zeit gerade erst an der hinteren Hautnabelwand eingesetzt, oder mit anderen Worten: Hintere Hautnabel- und hintere Darmnabelwand (= hintere Darmpforte) trafen noch zusammen. Dies ändert sich bis zum vorliegenden Stadium von 4 Visceraltaschen. Die caudo-kraniale Abnabelung des Darms ist bei den einzelnen verschieden weit entwickelten Embryonen dieses Stadiums um 1-4 Urwirbel vorgerückt, ohne daß ihr eine Abschnürung des Ektoderms gefolgt wäre. Um die Länge von 4 Urwirbeln liegt also jetzt bei den ältesten Embryonen des Sta-

1) Uber den hinteren Darmrest als Beweismittel gegen die Annahme einer Dottemaht bildang s. Ruekert 1921. 
diums yon 4 Visceraltaschen die hintere Darm pforte vor der hinteren, ,Hautnabelwand" oder, wie wir der Kürze wegen sagen, der ,hinteren $\mathrm{Nabel}$. wand"1). In dieser Ausdehnung sind also die vorher seitlich vom Darm gelegenen vorderen Abschnitte der Subintestinalvenen in eine ventrale Lage zu ihm gelangt. Wie sie sich hier weiter entwrickeln, soll in Kap. V dargestellt werden.

Die $\$$ ubintestinalvenen reichen kranial nach wie vor ein wenig über die Einmündung der Dottervenen, welche durch 2-3 Eröfnungen geschieht, hinaus. Dann endet dieser ihr kurzer kranialer Stumpf, indem er enger wird, blind. Auch caudal hat sich ihre Anlage seit dem vorigen Stadium nicht wesentlich weiter ausgedehnt, aber sie ist num hohl geworden (Abb. 47, 48 u. 49), und zwar bei dem einen der Embryonen bis zur Kloake (Abb. 50 ), bei dem anderen nicht ganz bis zu dieser Stelle.

Es ist damit die Entstehung eines e inheitliehen hinteren Venenzuges, der sich aus der Randvene, der hinteren Dottervene und der Subintesti. nalvene zusammensetzt, bis zum Zustand eines durchlaufenden HohlgefäBes verfolgt. Dabei haben sich genetische Beziehungen dieses Gefäßrohres zu den Blutanlagen ergeben, erstens seines Dotterabschnittes, des Sinus terminalis, der in seinem Vorlïufer, der Randrinne, zeitlich unmittelbar nach und örtich unmittelbar neben der Blutinselkette angelegt wird, wie ein AbfluBrohr für das dort entstandene. Blut, und zweitens seiner embryonalen Abschnitte der hinteren Dottervene und der Subintestinalvene, die als eine Fortsetzung der Blutinselreihe des hinteren Blastodermrandes in das Innere des Embryonalkörpers auftreten. Man wird daher, wenn wan für den neuen Begriff dieses gesamten Venenzuges nach einem Namen sucht, ihm die Bezeichnung $\mathrm{H}$ ä malve ne geben dürfen.

\section{Zusammenfassung.}

An der ringförmigen Mesoderm-oder Gefäßzone der Keimscheibe von Torpedo muB ein vorderes Feld, welches die zentrale, jedoch etwas exzentrisch nach vorn verschobene, mesodermfreie Zone vorn und seitlich umgibt, ron einem hinteren, schon von Anfang an etwas breiteren Feld unterschieden werden.

Im vorderen Mesodermfeld entsteht zur Zeit der Abgliederung der exsten Urwirbel eine in Bogen verlaufende Reihe randständiger Blutinseln, die mit Rücksicht auf ihr späteres Wachstum und den Umstand, daB sie weitaus die Hauptmasse des Blutes liefern, als die groBen oder ty pischen Blutinseln bezeichnet werden können. Die Kette tritt zuerst am Vorderrand der Keimscheibe auf und greift von da rasch an deren Seitenrand nach rückwärts bis zum Vorderrand des hinteren Mesodermfeldes, in dessen Bereich sie in das Innere der Keimscheibe einbiegt, um seitlich vom Erobryo in einiger Entfemung von ihm zu enden. Das letztere geschieht neben dem ebenfalls schon zum hinteren

1) Als hintere Darm pforte soll im folgenden immer die Stelle bezeichnet werden, an welcher der caudal abgeschnürte Darm nach vom mit dem Dotter ventral in Zusammenhang tritt, gleichguiltig, ob diese Verbindung offen ist, ähnlich wie in Abb. 39 oder infolge einer Verklebung der Darmwände geschlossen, wie in Abb. 45. Also ,hintere Darmpforte" bedeutet für die späteren Kapitel immer caudale Abschnürungsstelle des Darms vom Dotter. 
Mesodermfeld gehörigen, auf den Dotter hinausgewachsenen axialen Mesoderm, welches später die blasig autgetriebene extraembryonale Perikardialhöhle (Dottercölom) liefert.

Die erste Anlage der Blutinseln erscheint, bevor das periphere Mesoderm am Keimscheibenrand sich von dem primären, mait dem Dotter verbundenen und gegen den Keimscheibenrand zu stäker geschichteten Dotterentoderm abgespalten hat. Die Inseln nehmen also ihren Ausgang vom primären Dotterentoderm. Dieses Blatt ist durch Umschlag mit dem gleichfalls etwas verdickten Randektoderm verbunden, doch ruhen beide Blätter im Bereich der vorderen Keimscheibenhälfte bekanntiich dem Dotter flach auf oder nur wenig über ihn sich emporwulstend.

Daß die ersten Blutanlagen schon innerhalb des primären Entoderms kenntlich sind, wurde von allen jenen Forschern nicht beachtet, welche dieselben aus dem Mesoderm ableiten.

Die Differenzierung des mittleren Blattes geschieht durch Delamination, indem die oberflächlichen Schichten des pirimären Entoderms und mit ihnen die jungen Blutanlagen sich als peripheres Mesoderm von einer auf dem Dotter zurückbleibenden, meist nur einreihigen Zellenlage, der sekundären oder definitiven Dotterentoderm, abspalten.

Aber die Blutinseln gelangen auf diese Weise nur vorübergehend in das Mittelblatt, denn sie werden bald darauf wieder aus ihm ausgeschaltet, dadurch, daB sich an ihrem oberen Umfang Mesoderm von ihnen abtrennt.

Bald nach dem Erscheinen der Blutinseln senkt sich an dem jetzt dün ausgezogenen Keimscheibenrand (Umwachsungsrand) der peripher an sie angrenzende Teil des Dotterentoderms grubig in den Dotter ein. Die Gesamtheit dieser durch abgeflachte Stellen mehr oder weniger voneinander getrennten Vertiefungen (,Randgruben") bildet eine Rinne, die Pandrinne, den Vorläufer des Sinus terminalis. Diese frühzeitig entstehende RandgefäBanlage erstreckt sich über das ganze vordere Mesodermfeld, d. h. über den vorderen und den anschließenden größeren Abschnitt des seitlichen Keimscheibenrandes. Sie tritt zeitlich unmittelbar nach den Blutinseln auf und örtlich dicht neben ihnen, wie ein zur Aufnahme des neugebildeten Blutes bestimmter Abfuhrkanal. Bei den Sauropsiden behält der Sinus diese Lage bei, infolgedessen die von den Inseln sich ablösenden Blutzellen direkt in ihn hineinfallen. Bei Torpedo aber rückt er alsbald, da er an den vorwachsenden Keimscheibenrand gebunden ist, mit dessen Ausbreitung von den Blutinseln ab.

Später treten in der sich verbreiternden vorderen GefäBzone zu beiden Seiten der Blutinselkette neue GefäBanlagen auf. Es sind dies erstens weitere rinnenartige Einsenkungen des Dotterentoderms, also wandungslose provisorische Gefäßräume, wie solche für den Dotter von Petromyzon, der Teleostier und Amphibien bereits bekannt sind. Dann folgen Anlagen für blutleere Endothelröhren in Gestalt von GefäBzellenhäufchen und Strängen, welch letztere sich häufig in die Blutinseln verfolgen und somit als seitliche Ausläufer derselben feststellen lassen (Abb. 1). Auch für diese Gefäßanlagen kann man eine Delamination aus den unter ihnen gelegenen, verdickten, oft knospenartig vorragenden Stellen des Dotterentoderms erkennen. Soweit 
uber ihnen das Mesoderm sich, entsprechend dem vorgerückteren Entwicklungszustand, schon $z u$ einem geschlossenen Blatt differenziert hat, treten sie im Gegensatz zu den Blutinseln nicht in dessen Verband ein, sondern lagern sich nur von unten, mehr oder wenige innig, an dasselbe an, stellen also dann rein entodermale Bildungen dur. Wie die Blutinseln sich in die vom Entoderm überkleidete Dotteroberfläche einsenken, so lagern sich auch die Anlagen der leeren Gefäbe zumeist in Gruben und Rinnen dieser Unterlage ein, zum Teil wohl in die schon präformierten Vertiefungen, zum Teil in solche, die sie sich erst graben. Es steht ein Teil der blutleer angelegten GefüBe des vorteren Mesodermfeldes primär, d. $h$. von der ersten soliden Anlage an, mit den bluthaltigen Anlagen, den Blutinseln, in Zusarmmenhang. Indem nun dieselben unter sich und mit den anderen, anscheinend selbständig entstandenen, blutleeren Anlagen in Verbindung treten und der ganze Anlagenkomplex hohl wird, bildet sich ein zusammen. hängendes Netz von Gefäßröhren (Abb. 2 u. 3).

Im hinteren Mesodermfeld schlagt die Entwicklung der Blutgefaße zunächst einen anderen Weg ein. Es wird hier am Keimscheibenrand nicht eine Reibe grober Blutinseln gebildet wie im vorderen Feld, und zwar zweifellos deshalb nicht, weil der daselbst durch den Urmundspalt vorn Dotter abgehobene Umschlagsrand (palingenetischer Urmundrand, im Gegensatz zu dem mit dem Dotter verbundenen cenogenetischen Urmundrand der vorderen Keimscheibenhälfte) zu einer solchen Funktion ungeeignet ist. Blutinseln gehen nur yon einer mit dem Dotter rerbundenen oder verbunden gewesenen Keimschicht aus.

Aber vor dem randständigen Darmspalt, gegen das Keimscheibeninnere zu, ist das Entoderm auch im hinteren Mesodermfeld von vornherein mit dem Dotter in Verbindung. Es besteht hier ein Dotterentoderm, und das rom Rand dahin vorwachsende Mesoderm ergänzt sich aus ihm durch Delamination. So kommt es auch hier zur Entwicklung von GefäBanlagen, die freilich schon in ihrem soliden Anfangszustand zellenärmer sind als die typischen randständigen Blutinseln des vorderen Feldes, aber doch vielfach kräftiger als die dort später auftretenden blutleeren Anlagen (Abb.1). Sie liefern leere Endothelröhren (Abb. 2) und dazwischen solche mit nur spärlichen Blutzellen (= kleine Blutinseln) und stellen so eine Zwischenstufe dar zwischen den zweierlei scharf getrennten Produkten des vorderen Feldes, den großen typischen Blutinseln und den blutleeren Endothelröhren. Auch diese Anlagen bilden sich gleichzeitig mit denen des vorderen. Mesodermfeldes and in Verbindung mit ihnen zu einem Netz von HohlgefäBen um (Abb. 3, Tafel I). Ein solches erstreckt sich somit über den gesamten mesodermhaltigen Bezirk der Keimscheibe und erfüllt ihn ziemlich gleichmäßig mit Ausnahme des spärlicher vascularisierten Bodens des Dottercöloms. Unter dem Einfluß der einsetzenden Herztätigkeit oder vielleicht auch ohne diese durch selbständige Kontraktionen der Dottergefäße werden die Blutzellen ganz allmählich aus den Inseln in das übrige Netz eingeschwemmt und alsbald (schon in Abb. 3) dem Embryo zugeführt.

Inzwischen sind am Rand des hinteren Mesodermfeldes, insbesondere an dessen Hinterrand, wichtige Entwicklungsvorgänge abgelaufen. Mit dem caudalen Auswachsen desselben hat sich das hintere Mesodermfeld stärker 
verbreitert als das vordere, womit periphex neue GefäBanlagen zu den alten hinzugetreten sind. Dabei wurde der vom Dotter abgehobene dicke Umschlagsrand (Randwulst) allmählich in caudomedian fortschreitender Richtung cluroh eine mit dem Dotter verbundene flache Randformation (Umwachsungsrand), wie sie in der vorderen Keimscheibenhälfte schon von Anfang an vorhanden war, ersetzt und so die Vorbedingung für das Auftreten randständiger Blutinseln auch für den Hinterand erfült (Abb. 1 3. 2). In der Tat sind nun solche Bildungen als letzte Gefaßanlagen des hinteren Mesodermfeldes aufgetreten. Sie haben zunächst in einem mehrschichtigen vom Randwulst übriggebliebenen Mesodermlager ihre Entstehung genommen $(A b b .15$ a. 16), das, wie vorher in der vorderen Gefäß. zone, unmittelbar innen von dem auswachsenden Rand zurüokgeblieben war (Abb. 1 u. 2). Infolge ihres verspäteten Erscheinens konnten sie aber nicht zu den mächtigen Inseln des vorderen Mesodermfeldes heranwachsen, sondern blieben auf der Stufe kleiner Blutinseln stehen. Morphologisch aber gehören sie as randständige Inseln zu jenen, sie stellen einen, infolge der vorausgegangenen Umgestaltung des Randwulstes verspäteten, rudimentären Abschnitt der Blutinselkette dar.

Diese kleinen Blutinseln des Hinterrandes setzen sich nun median gegen den Embryo zu in ein neben diesem gelegenes dickes, noch auf dem Dotter ruhendes Mesodermlager fort (Abb. 16, 20, 21 und Abb. 1), welches den letzten Rest des Randwulstes darstellt. Man sollte erwarten, dab diese in seiner tiefsten Schicht in Verbindung mit dem Dotter entstandenen Gefäßzellenhaufen ebenfalls noch randständige DottergefüBe, sei es mit oder ohne Blutzellen, bilden. Dies ist aber nicht der Fall : Dieser Mesodermwulst mitsamt seinen GefäBzellengruppen wird vielmehr durch dorsale Aufrichtung des bis dahin flachen-Darmrohres mit in die Höhe gehoben und so der Seitenwand des Embryos einverleibt, um dessen Seitenplatten ventral zu exgänzen (vgl. Abb. 22 und Abb. 16). Dadurch kommt das Gefäßmaterial seitlich neben den Ventralteil des Darms zu liegen und hiefert hier das erste Anlagestück der Venas ubintestinalis (Abb. 22 und Abb. 1). Diese entsteht somit aus einer Fortsetzung der Blutinseln des Hinterrandes, aber nicht etwa durch Einwachsen des Zellenmaterials vom Dotter in den Embryo, sondern durch eine in dieser Richtung erfolgende lokale Abspaltung desselben von seinem Mutterboden.

Die Subintestinalis breitet sich im Embryonalkörper nur ganz wenig nach vorn, in der Hauptsache aber rasch nach rückwärts (Abb. 2) in das über die Keimscheibe caudal hinauswachsende freie Caudalstück des Embryo, dessen „Hinterrumpf:; aus, wobei ihr Zellenmaterial aus einem entsprechenden Teil des mittleren Keimblattes, nämlich dem vom ehemaligen Umscblagsrand stammenden ventralen Ende der Seitenplatte seinen Ursprung nimmt. Auch durch seine mächtigen, kompakten Gefäßzellengruppen läßt das zuerst gebildete Stück der soliden Venenanlage die Verwandtschaft mit den kleinen Blutinsein des Dotters erkennen und unterscheidet sich durch dieses Merkmal von der Anlage aller übrigen Gefäßröhren des Körpers einschließlich derjenigen des Herzens.

Wenn der Hinterrand der Keimscheibe nach Abgabe der rudimentären Blutinseln und durch Auswachsen dünn geworden ist, tritt auch an ihm die 
Randrinne auf. Diese Bildung war an dem flacheren Vorder- und Seitenrand des Blastoderms schon früzeitig erschienen, am Hinterrand aber war ihre Entstehung durch den Randwulst naturgemäB verzögert (vgl. Abb. 1 mit Abb. 2). Thre Ausbildung daselbst geht nur allmählich, und zwar entsprechend dem Schwund des Randwulstes in medianer Richtung, gegen den Embryo zu, vor sich.

Der Ersatz der die gesamte Keimscheibenperipherie alsdann begrenzenden Rinne durch ein epitheliales GefäBrohr, die definitive Vena terminalis, erfolgt erst erheblich später gegen Ende des Stadiums mit 4 Visceraltaschen, also bei Embryonen, die etwas älter sind als derjenige der Abb. 3. Dabei kommt die Vene nicht dadurch zustande, daß die Rinne, wie ich früher annahm, sich mit Epithel auskleidet, sondern sie tritt als eine Neubildung auf, und zwar in folgender Weise:

Die Gesamtheit der Randschlingen, mit welchen das hohl gewordene Gefäßnetz der Area rasculosa peripher abschlieBt (Abb. 3), schiebt sich gegen den Rand der Keimscheibe d. h. an die Stelle der Rinne vor, deren Platz einnehmend, gleicht dabei thre Biegungen allmählich aus und streckt sich so zu einem kontinuierlichen, anfänglich noch wellig verlaufenden Ringgefaß $(\mathrm{Abb}$. 4 ). Erst jetzt findet sich Blut in dem Gefäß vor, während die Rinne solches niemals besaB, also nicht in Verbindung mit dem GefaßBnetz des Dotters gestanden war.

Wenn die Randrinne am hinteren Keimscheibenrand die Anheftungsstelle des Embryos erreicht hat, endet sie nicht an dieser Stelle, sondern breitet sich zu beiden Seiten des Embryos noch ein Stück weit nach vome ans in Begleitung der Gefäßzellengruppen, die vom Keimscheibenrande nach vome sich zur Anlage der Subintestinalvene erstrecken. Diese Rinne sowie die aber ihr befindlichen noch soliden Gefäßanlagen liegen von außen gesehen noch intraembryonal, d. h. gedeckt von der Umschlagsstelle des embryonalen Ektoderms in das Dotterektoderm auf dem Dotter zu beiden Seiten der Anheftung des Darms an den letzteren. Diese Anlage wird zum Verbindungsrohr der Vena terminalis mit der Subintestinalvene, zur Dottervene, oder, wie wir mit Rücksicht auf eine zur Zeit noch vorhandene ,vordere Dottervene" vorerst sagen müssen, zur , hinteren Dottervene“". Die Umgestaltung ihrer Anlage in ein hohles Epithelrohr geschieht im Gegensatz zur Bildung der Vena terminalis dadurch, daß die solide Anlage sich höht und sich dabei in die Rinne legt und sie ausfüllt. Dies geht frühzeitiger vor sich als die Entstehung der Randvene, nämlich vor Schluß des Stadiums mit 3 Visceraltaschen, gleichzeitig mit der Höhlung der soliden Subintestinalvenenanlage, mit der sie von Anfang an zusammenhängt.

Die Subintestinalvene selbst wird allmählich in kranio-caudaler Richtung hohl, so daß im Stadium von 4 Visceraltaschen ihre bis zur Kloake reichende Anlage bis fast zu dieser Stelle in ein Endothelrohr umgewandelt ist.

So stellt die hintere Dottervene schon gemäß ihrer ersten Entstehung ein Verbindungsgefä $B$ rwischen dem Pandsinus und der Subintestinalis dar. Denn thre Rinne füht von der Randrinne zur Subintestinalis, und thr Zellenmaterial setzt die kleinen Blutinseln des Hinterrandes in die solide Anlage dieser Vene fort. Und nachdem die Anlage hohl geworden ist, stellen die Randvene, die hintere Dottervene und die Subintestinalvene einen dem Dotter und dem Embryo gemeinschaftlichen, einheitlichen Gefißßug dar. Derselbe steht in Verbindung mit den Blutablagen, insofern sein Dotterabschnitt als Sammelgefäß für das 
neugebildete Blut und sein intraembryonaler Abschnit, die hintere Dottervene + Subintestinalvene, als Fortsetzung der randständigen Blutinselkette angelegt wird. Für den neuen Begriff dieses gesamten Venenzuges ist ein neuer Name erforderlich. Wegen seiner Beziehungen zu den Blutanlagen schlage ich für ibn die Bezeichnung Hämalvene vor.

Zwischen dem Stadium yon 3 und dem von 4 Visceraltaschen hat sich ein vor der hinteren Hautnabelwand (= caudaler Anheftungsstelle des Embryos an den Blastodermrand) gelegener Darmabschnitt in caudo-kranialer Richtung vom Dotter abgeschnürt, und zwar bis zu einer Länge von 4 Urwirbeln bei den älteren Embryonen des Stadiums von a Visceraltaschen. Um diese Strecke ist also die hintere Darmabelwand (= hintere Darmptorte), die vorher dicht an der hinteren Hautnabelwand gelegen war, nach vorne gerückt, ohne dab ihr zunächst eine Abtrennung der übrigen embryonalen Blätter, des Ekto- und Mesoderms, gefolgt wäre (Abb. 46). Infolge dieser Abtrennung des Darms rücken die bisher seitlich von ihm gelegenen Subintestinalvenen an seinen frei gewordenen ventralen Umfang und kommen damit in die gleiche Lage zu ihm, welche sie an dem freien, den Dotter caudal überragenden Hinterrumpf des Fmbryos von vomherein als Produkte der ventralen Enden der Seitenplatten eingenommen haben. Sie verdienen also jetzt auch in diesem ihren kranialen Anfangsstück den Namen ,Subintestinalvenen":

Die hinteren Dottervenen behalten dagegen ihre Lage bei, nur befinden sie sich nicht mehr zu beiden Seiten der Darmanheftung an den Dotter, sondern beiderseits von einer bei der Darmabschnürung auf dem Dotter zurückgebliebenen Leiste bzw. Falte, welche wir den "hinteren Darmrest" nennen. Wenn später der caudale Blastodermrand auf dem Dotter nach rückwärts über die hintere Nabelwand (Hautnabelwand) hinauswichst, kommt ein extraembryonales Stück der hinteren Dottervene zu dem bisherigen intraembryonalen $A b$. schnitt hinzu. Es verläuft als paarige Fortsetzung des Sinus terminalis vom hinteren Blastodermrand neben der Medianebene beiderseits der sog. "Dotternaht" auf dem Dotter nach vorn zur Nabelwand und gewinnt später bei der Umwachsung der Dotterkugel dureh das Blastoderm eine mächtige Längenentwicklung gegenüber dem stets kurz bleibenden intraembryonalen Abschnitt.

Kapitel IT.

\section{Die Entwicklung des Herzens, der vorderen Dotteryenen und des inneren Ringgefabes der Keimscheibe.}

1. Stadium der ersten Viseeraltasehe. Iuftreten der Gefäßzellen der Mandibulararterien, des Herzens und der vorderen Dottervenen als durchlaufende paarige Längskette.

Die Entwicklung der mit dem Herzen primär verbundenen vorderen Venenbahn setzt bei den auf $\mathrm{S} .13$ besprochenen Torpedoembryonen mit 13 und 14 Ur. wirbeln ein. Hier findet sich die erste Anlage des Herzens in der von mir im Jahre 1888 (Rückert 88) zuerst beschriebenen und von Rabl (89 und 92) bald darauf bestätigten Anordnung vor, nämlich in Cestalt spärlicher, zu beiden Seiten der Kopfdarmhöhle gelegener Gefäßzellen. 
Der spätere Kiemendarm ist zu dieser Zeit daran kennthch, daß sich sein dorsaler Abschnitt seitlich ausbuchtet (Abb. 17 und 18). Sein vorderes Stück liegt frei über dem Dotter mit geschlossener ventraler Wand (Abb. 17), während sein caudaler Teil sich ventral gegen den Dotter zu eröffnet, wobei seine nach abwärts konvergierenden Seitenwände, bevor sie ihren Ansatz am Dotter erreichen, sich wieder auseinander spreizen (Abb. 18). Die Stelle, wo diese beiden Abschnitte des Kiemendarms ineinander übergehen, ist die "Wordere Darmpforte". Ich werde mit Rücksicht auf die späteren Stadien denjenigen Teil der ventralen Darmwand, der sich daselbst zum Dotter herabsenkt, als vordere Darmnabelwand bezeichnen oder, da der Leibesnabel für das Folgende unberücksichtigt bleiben kann, der Kürze wegen als, wordere Nabelwand "1). Im vorliegenden Stadium hat die später an dieser Stelle in caudaler Richtung erfolgende Abschnürung des Darms rom Dotter noch nicht eingesetzt, die vordere Nabelwand vertaut noch nahezu senkrecht herab zum Dotter.

Im vorderen den Dotter frei überragenden Teil des Kiemendarmes ist die erste Anlago einer ersten Visceraltasche schon festzustellen (Abb. 17) durch eine starke Verdünnung bzw. vollständige Tnterbrechung der die seitliche Ausbuchtung überzichenden mesodermalen Seitenplatten. Unmittelbar hinter dieser Stelle liegt die rordere Nabelwand, die in dem an 4 bb. 17 sich anschließenden Schnitt schon angeschnitten ist. In dem caudal folgenden, also mit dem Dotter verbundenen Teil des Kiemendarms (Abb. 18) ist das Mesoderm der Seitenplatten noch nirgends verdrüngt, so daß von gesonderten Anlagen weiterer Kiementaschen hier noch nichts angedeutet ist. Die Seitenplatten eröffnen sich daselbst zur Perikardialhöle (c).

An der Wand dieser beiden Abschnitte der Kopfdarmhöhle, zwischen ihrem Entoderm und dem viscernlen Mesoderm, sind im vorliegenden Stadium die ersten Herzzellen zu erkennen. In dem vor dem Dar m nabel gelegenen Abschnitt des Darms (ma in Abh. 17) befinden sie sich am ventro-lateralen Umafang des geschlossenen Darmrohres an den unteren Enden der hier noch weit voneinander getrennten Seitenplatten. Dieser vorderste pa arige Teil der GefäBanlage entspricht, wie später gezeigt werden soll, den späteren Gabelästen des Truncus arteriosus, also den Mandibulararterien, einer Anlage, die ihre paarige Beschaffenheit dauernd bewahrt. Sie besteht aus einigen spärlichen kleinen GefäBzellen, die teilweise noch in Abspaltung aus der Splanchnopleura begriffen sind. Nach vorne lassen sie sich noch nicht bis an das vordere Ende des Darms verfolgen. Sie gehen in dieser Pichtung zuletzt ganz im Mesoderm auf und sind dann nur an ihrer geringen Größe und ihrer dichten Aneinanderlagerung in der ventraten Ecke der Seitenplatten zu erkennen. Nach rückwärts erstrecken sie sich bis zur vorderen Nabelwand, wo sie sich in die Anlage des Herzens selbst fortsetzen.

Von der Nabelwand an nach hinten liegt die Zellengruppe ( $h z$ in $A b b .18$ ) naturgemäß nicht mehr am freien ventralen, sondern am seitlichen Umfang der bis zum Dotter herabreichenden Kopfdarmhöhle. Diese eigentliche Herzanlage ist auf dem Querschnitt etwas zellenreicher als die Anlage der Mandibulararterien und breitet sich in dorsoventraler Richtung stärker aus.

1) Uber die hintere Darmpforte und hintere Nabelwand vgl. 8.16 und 29. 
Ihre Zellen, meist seitlich mehr oder weniger abgeplattet, hängen teilweise untereinander zusammen und stehen gleichfalls noch vieltach mit ihrem Mutterboden, dem Visceralblatt des Perikards, in Verbindung, was darauf hinweist, daß ihr Austritt aus diesem Blatt noch im Gang ist.

Die Herzzellen lagern fast sämtlich einer seitlich eingebuchteten Stelle der Darmwand an, welche den oberen rundlichen Teil des Querschnitts (= Fortsetzung des vorderen abgetrennten Darmabschnittes) von einem ventralen dreieckigen trennt. Nur vereinzelt ragen sie über diese Bucht dorsal hinaus. Da an dieser Einsohnürungsstelle später die Abtrennung des Darmes erfolgt, so müssen auch die Herzzellen ihrer jetzigen Lage entsprechend alsdann an die ventrale Wand des abgeschnürten Rohres zu liegen kommen.

Nur im hintersten Abschnitt der gesamten Anlage, wo die Perikardialhöhle sich bis zum Dotter herabsenkt ( $c$ in $A b b .19$ ), um in einen auf dem Dotter in Entstehung begriffenen Abschnit der Leibeshöhle $\left(c^{\prime}\right)$ überzugehen, rücken die GefäBzellen mit der herabtretenden Splanchnopleura ebenfalls gegen den Dotter herunter. Die der Herzanlage entsprechende seitliche Einbuchtung der Darmwand steht hier etwas tiefer als weiter vorn. An dieser Stelle liegen (Abb. 19 bei hz) die letzten Herzzellen.

Von da senken sich jedoch weitere Gefübzellen bis zum Dotter herab (vd in Abb. 19). Diese spärlichen kleinen Elemente stehen hier noch alle in Verbindung mit der Splanchnopleura, die Anlage befindet sich hier also auf einer noch etwas jüngeren Entwicklungsstufe als weiter vorn. 'Der von der Herzanlage zum. Dotter herabtretende Zellenzug stellt das Material für das Anfangsstück der vorderen Dottervenen dar. Wir bezeichen diesen Abschnitt des Gefäßes, weil er noch der Darmwand anliegt, als in traembryonalen Teil des Dottervenenstammes, im Gegensatz zu dem auf dem Datter verlaufenden, später zu beschreibenden extraembryonalen Absehnitt.

Dicht hinter der zum Dotter herabtretenden Zellengruppe endet die an der Ausbuchtung ihres dorsalen Abschnittes kenntliche Anlage des Kiemendarms, indem der Darmquerschnitt aus der $\Omega$-Form in eine dreieckige $\wedge$ übergeht.

Die beschriebene Gefäßanlage gehört zu den ersten, die innerhalb des Embryos auftreten, denn es ist im vorliegenden Stadium nur beiderseits vom vorderen Chordaende eine kleine Gruppe von Aortenzellen vorhanden als Vorläufer der Kopfsinusanlage und im h nterea Rumpfabschnitt an einer ganz umschriebenen Stelle eine die Anlage der Vena subintestinalis vorbereitende Verdichtung in den Seitenplatten (s. Abb, 22).

Aus dieser Darstellung geht hervor 1 , daB gemeinsam mit der ersten Herzanlage der Stamm der Mandibulararterien entsteht, indem die Abspaltung der GefäBzellen von der Stelle des späteren Herzens aus nach vorne in das Gebiet des ersten Visceralbogens sich erstreckt, 2. daß gem einsam mit der ersten Herzanlage der intraembryonale Stammteil der vorderen Dottervenen sich bildet, indem die Abtrennung der Gefäßzellen von hinteren Ende der ersten Herzanlage aus ventral zum Dotter herabgreift. Der intraembryonale Stamm der vorderen Dottervenen stellt also schon seiner ersten Anlage nach eine caudale Fortsetzung des Herzens gegen den Dotter z u dar; 3 . diese eimheitliche GefäBanlage tritt in ihrer gan- 
zen Längenausdehnung paarig auf, es existiert also in der ersten Anlage kein unpaarer vorderer Abschnitt der Herzanalge. Die nächste Ursache für die paarige Entstehung der Herzanlage selbst ist in dem Umstand gegeben, daß sie in ihrer ganzen Lüngenausdehnung an einem ventral mit dem Dotter verbundenen Darmabschnitt entsteht. 4. Das erste Zellenmaterial dieses gesamten paarigen GefäBzuges stammt aus dem Visceralblatt des Mesoderms. 5. Es gehört zu dem frühesten, welches innerhalb des Embryo frei abgespalten erscheint.

Was jetzt vor allem interessiert, ist die Frage, ob diese ersten Gefäßzellen des Embryonalkörpers mit solchen des Dotters in Verbindung stehen. Um hierüber Klarheit zu erhalten, müssen wir zunächst die Topographie der die Herzanalge umgebenden Tele ins Auge fassen.

In der ganzen Längenausdehnung der eigentlichen Herzzellengruppe und noch caudal etwas über sie hinausgreifend, ist in den Seitenplatten des Embryos die Leibeshöhle (Perikardialhöhle) aufgetreten. Im vorderen Bereich der Herzanlage (Abb. 18) erstreckt sich der Hchlraum, wie wir gesehen haben, nicht bis zum Dotter herab. Die ihn umschließenden Seitenplatten reichen abwärts nicht über das Gebiet des Embryonalkörpers hinaus, sondern grenzen gegen den Dotter $z u$ an die mesodernfreie Zone der Keimscheibe $(m f)$ an. Aber weiter hinten (Abb. 19) dehnen sie sich seitlich auf den Dotter aus und bilden hier ebenfalls eine Leibeshöhle, die im vorliegenden Stadium noch aus einzelnen Lücken $\left(c^{\prime}\right)$ besteht.

Die letzteren konfluieren aber in einer nur wenig älteren Entwicklungsphase unter sich und mit der embryonalen Perikardialhöhle zu einem einheitlichen, großen und blasig aufgetriebenen Hohlraum, der schon bei Oberflächenbetrachtung der Keimscheibe durch sein opakes Aussehen auffallt. Es ist dies die schon in Kap. I auf S. 14 und 20 beschriebene extraembryonale Leibeshöhle oder das Dottercölom. Dasselbe breitet sich, wie die Modelle (Abb. 1 und $\left.2 c^{\prime}\right)$ zeigen, in lateraler Richtung nur über reichlich ein Drittel der vom Embryo zum seithichen Blastodermrand reichenden Strecke aus und reicht auch in späteren Stadien nach rückwärts bei weitem nicht bis zum hinteren Keimscheibenrand. Es wird seitlich sowohl wie hinten von der Gefäßzone des hinteren Mesodermfeldes umfaßt.

So sind hier aus dem vom Mesoderm überkleideten Keimscheibengebiet jüngerer Stadien zwei wohlunterseheidbare Abschnitte hervorgegangen, die von den beiden aus versehiedenen Quellen stammenden Teilen des mittleren Keimblattes abzuleiten sind, dem axialen und dem peripheren Mesoderm.

Das axiale Mesoderm nimmt innerhalb des Embryos den gleichen Entwicklungsgang wie auBerhalb desselben. Es erzeugt durch früheitige Spaltung eine Leibeshöhle, die sich vom Embryo seitlich aut den Dotter fortsetzt, also in derselben Richtung sich ausbreitet, in welcher das Blatt vordem bei seiner Entstehung ausgewachsen ist.

Der an das Dotteroölom seitlich sich anschlieBende Mesodermabschnitt dagegen chrakterisiert sich dadureh als ,peripherer", dab er sich genau so verhält, wie das periphere Mesoderm es dort tut, wo es für sich allein auftritt, wo also seine periphere Abstammung nicht zweifelhaft sein kann, nämlich in der vorderen GefäBzone. Die gemeinsamen Merkmale sind erstens, daß dieses Mesoderm längere Zeit hindurch ungespalten bleibt, und zweitens, daß es schon. 
früh GefäBanlagen entwickelt, zuerst die Blutinseln und später das Material für blutleere Endothelröhren. Auch in letzterer Hinsicht steht es im Gegensatz zum axialen Mesoderm des Dotters, das sich anfänglich an dieser Gefübildung nicht beteiligt (s. Kap. I). Man kann daher die letztere Pugion eine Zeitlang als einen gefäBfreien Abschnitt des Dotters der Area vasculosa gegenüberstellen.

Caudal rom Dottercölom hingegen trägt das Mesoderm in der ga:izen Breite der Keimscheibe bis fast an den Embryo heran den gleichen Charakter wie in der Gefaßzone. Hier liegt eben offenbar ausschlieBlich peripheres Mesoderm vor, das vom Hinterrand aus nach vorne vorgedrungen bzw. bei der Rückwanderung des letzteren auf dem Dotter zurückgelassen ist. Zum mindesten läßt sioh hier ein auf den Dotter ausgewachsenes axiales Mesoderm zeiner Struktur nach nicht unterscheiden.

Entstehung der Fena vitellina anterior anf dem Dotter. Untersuchen wir nach dieser topographischen Ubersicht die an die Herzanlage seitlich sich anschließende Region des Dottercöloms auf Gefäßbildung. Hier ist im vorliegenden Stadium zwischen dem Visceralblatt der in Eröfinung begriffenen Leibeshöhle ( $c^{t}$ in Abb. 19) und dem Dotterentoderm noch ein freier Raum, der alle in ihm etwa vorhandenen GefäBzellen deutlich erkennen läBt. So kamn man verhältnismäBig leicht daselbst einen noch sehr feinen und jugendlichen Gefäßzellenzug ( $v d^{\prime}$ in $A b b .19$ ) auffinden, welcher den intraembryonalen Dottervenenstamm vom Darm auf den Dotter fortsetzt. Er besteht aus einigen wenigen sehr langgestreckten Elementen, die neben dem Embryo sich an das Dotterentoderm anschmiegen, während sie weiter seitlich frei in dem Spaltraum liegen und mit einer etwas zellenreicheren GefäBanlage $(r p)$ in die Area vasculosa sich fortsetzen. Die auf dem Dotter ruhenden Zellen bilden mittels feinster Fortsätze ihrer beiden Enden eine dünne ausgezogene Kette, die medianwärts mit der Anlage der vorderen Dottervene des Embryonalkörpers (vd) sich verbindet. Dies geschieht auf dem Schnitt in bemerkenswerter Weise dadurch, daß das untere Ende der von der Splanchnopleura des Embryos sich abspaltenden Zellenreihe sich in einen relativ langen, feinen plasmatischen Ausläufer fortsetzt, der schräg zum Dotterentoderm herabtretend in die diesem Blatt anhaftende erste Gefäßzelle des Dotters ubergeht. Diese sowie die folgende Zelle hängen nun aber mit dem Entoderm - wenn auch nur partiell - zusammen, aber unter ihnen liegen noch kleinere Elemente von der gleichen platten Form in zwei Schichten, die zweifellos noch dem Dotterentoderm angehören. Doch ragt die oberflächliche der zwei Schichten etwas über dessen Niveau vor und ist nach rechts schon vom übrigen Dotterentoderm abgegrenzt. Ich kann für dieses gesamte Bild keine andere Deutung geben, als die einer Abspaltung von GefäBzellen rom Dotterentoderm, eine Auffassung, die durch das Verhalten der nämlichen Stelle bei einem älteren Embryo (s. u.) bestatigt wird.

Diese noch ärmliche Gefäßzellenkette liegt unter dem vorderen Abschnitt der extraembryonalen Per"kardialhöhle, etwas hinter deren Vorderrand. Sie stellt die Anlage für das extraembryonale Stück des Dottervenenstammes dar, welches später (Abb.3) vom Embryo aus in querer Richtung unter dem vorderen Rand des Dottercöloms, hinter der mesodermfreien Zone lateralwärts läuft. So verhält sich die linke Seite des Embryos. Die rechte unterschei- 
det sich von ihr nur dadurch, AaB die GefäBzellen unter dem in Ausbildung begriffenen Dottercölom in noch geringerer Zahl vorhanden sind und sich nicht als zusammenhängende Kette verfolgen lassen.

Bei einem zweiten nur wenig jüngeren Embryo, der zwar die gleiche Urwirbelzahl, aber noch eine kleinere Perikardialhöle und weniger Herzzellen besitzt, finden sich an derselben Stelle wie in Abb. 19 gleichtalls einige Gefäßzellen; sie sind aber noch so spärlich, daß ich sie ohne Kenntnis des anderen Embryos kaum als Anlage des Dottervenenstammes angesprochen hätte.

So tritt gleichzeitig mit der fruhesten Anlage des Herzens und der mit ihm verbundenen Anlage des intraembryonalen Dottervenenstammes diejenige des extraembryonalen Dottervenenstammes auf. Beide stellen zusammen einen einheitlichen Zug dar. der bei seinem Ubertritt auf den Dotter nur zellenärmer wird. In diesem primären Zusammenhang könnte man eine Stütze für die alte $\mathrm{H}$ is sche Lehre des Eindringens der DottergefäBe in den Embryo erblicken. Dem widerspricht jedoch auf das bestimmteste die deutlich erkennbare lokale Entstehung der ersten im Embryo autretenden Gefaßzellen aus dem visceralen Mesoderm.

Das Zellenmaterial für das Ventralgefäß des Kopfes entsteht also auf die gleiche Weise wie dasjenige für das Ventralgefaßß des Hintermmpfes, die Vena subintestinalis, nur daß bei letzterer infolge des gruppenweisen Auftretens der Gefäßzellen ihre lokale Abspaltung aus den Seitenplatten viel augenfulliger ist. Hier ließ sich aus dem gleichen Grunde auch erkennen, daß der lokale Abspaltungsvorgang auf dem Dotter beginnt und von da an in den Embryo fortschreitet. Ein soleher Nachweis ist beim vorderen Gefäl3zug nicht möglich. Wie es seheint, tritt hier die Ablösung der Zellen zuerst im Embryo auf und greift von da auf den Dotter über, woselbst sie dann auffallenderweise unter Beteiligung des Entoderms erfolgt. Diese lokale Entstehung lïßt sich allerdings nur für einen schmalen neben dem Embryo befindlichen Abschnitt des Dotters verfolgen, während dic Herkunft der weiter seitlich sich anreihenden Zellen wegen ihrer geringen Zahl überhaupt nicht za ermitteln war. Die Moglichkeit, daß wenigstens diese letzteren im Spaltraum zwischen dem Dottercolom und dem Dotterentoderm auftretenden vereinzelten Elemente von der angrenzenden Gefäßzone aus eingewandert sind, ist daher nicht abzulehnen. Indessen $m u B$ bei solchen Erwägungen immer wieder daran erinnert werden, daB iuberall auf dem Dotter, wo das erste Auftreten von GefäBzellen überhaupt genaa zu erkennen ist, ihre lokale Abspaltung klar zutage liegt.

Ehe wir die weitere Entwicklung dex vorderen Dottervene vertolgen, wollen wir uns einen kurzen Uberblick über den Verlauf des späteren zum Endothelrohr ausgebildeten Gefäßes verschaffen. Die Vene biegt alsdann (Abb. 3, Taf. I) am vorderen Umfang des Dottereöloms nach vorn auf den Innenrand der vorderen Mesodermzone um, so daß sie nun die mesodermireie Zone allseitig umfaßt. Diesen nach vorn abbiegenden Teil des GefäBes will ich im Interesse der Beschreibung mit einem besonderen Namen belegen. Ich nemne ihn den vorderen Ast, weil das Gefäß da, wo es den yorderen Cölomand verläßt, einen zweiten zwisehen dem Colom und dem hinteren Gefaßfeld nach hinten verlaufenden, allerdings rasch vergänglichen Zweig, einen hinteren Ast, besitzt. Die Gabelung in die beiden Aste, die an der lateralen vorderen Ecke des Coloms 
erfolgt, ist auf der rechten Seite der Abb. 2, Taf. I gut zu erkennen. Sonach bleibt die Bezeichnung ,Sta $\mathrm{m} \mathrm{m}^{*}$ auf das den vorderen Cölomrand begleitende Gefäßstück reserviert - wenigstens so lange, als die beiden Aste noch kennthich sind.

Beim Embryo der Abb. 17-19 ist der vordere Ast noch nicht angelegt, d. h. es sind am Innenrand des noch schmalen und an Gefäßzellen armen vorderen Mesodermfeldes noch keine über längere Strecken durchlaufende Zellenzüge zu finden. Aber vereinzelte kleine Zellengruppen kann man an dieser Stelle schon mit Sicherheit als Gefäßanlagen feststellen. Sie sind teils frei, teils mit dem Entoderm in Verbindung, öfters auch mit dem Mesoderm, dessen freier Rand sich dann gewöhnlich zu ihnen herabsenkt und sich mit ihnen verbindet. Meist läßt sich aber jetzt noch nicht entscheiden, ob solche Zellengruppen GefäBanlagen oder Mesodermzellen sind. Das ist besonders dann der Fall, wenn sie etwas einwärts vom mittleren Blatt noch im Randgebiet der mesodermfreien Zone liegen.

Im Gegensatz zum vorderen ist der hintere Ast der vorderen Dottervene schon über längere Strecken angelegt, und zwar durch GefäBzellengruppen, die entsprechend der im allgemeinen stärkeren Ausbildung der blutleeren Anlagen der hinteren Gefäßzone zellenreicher sind als die zuvor beschriebenen. In $A b b .19$ ist dieser die hintere GefäBzone gegen die in Bildung begriffene extraembryonale Leibeshöhle abgrenzende Zellenstrang $(r p)$ dargestellt. Derselbe läuft nur eine kurze Strecke nach hinten und endet dam in Verbindung mit dem Dotterentoderm, während medial von ihm ein zweiter auftaucht, auf dessen medialer Seite weiter hinten wiederum ein neuer erscheint. So rücken diese Längszüge nach hinten zu allmählich näher an den Embryo heran, ohne ihn aber zu erreichen.

Literatur. Die vorstehende ausführliche Beschreibung dieses jüngsten Stadiums bestätigt die von mir früher (1888) gegebene kurze Darstellung vom ersten Auftreten der Herzzellen und erweitert dieselbe in mehrfacher Hinsicht, so $\mathbf{u}$. a. durch den Nachweis, daB die letztere Anlage caudal in Zusammenhang mit derjenigen der vorderen Dottervenen auftritt und rostral sich in die Anlage der Mandibulararterien verfolgen läßt.

Die Angabe Raffaeles (1892), daB die erste Anlage der Mandibulararterien von Torpedo zeitlich derjenigen des Herzens vorangeht, ist irrig. Auch beruht es auf einem MiBverstehen, wenn der genannte Autor aus meiner Arbeit (1888) eine solche Behauptung herausliest. In Wirklichkeit entstehen beide aneinandergrenzenden Abschnitte des GefäBsystems gleichzeitig, vielleicht die ersten Herzzellen sogar noch ein wenig früher als die ersten MandibulargefäBzellen, wenigstens war dies bei einem Embryo, der um einen Urwirbel jünger ist als der von mir beschriebene, der Fall.

\section{Stadium yon 2 Visceraltasehen.}

Infolge der kranio-caudalen Abschnärung des Darms voan Dotter wird aus der parigen eine un paare Herzanlage. Weiterentwicklung der Dottervenenanlagen.

Einen bemerkenswerten Fortschritt in der Herzentwicklung zeigt ein Embryo von 18 Urwirbeln, einem bis zu den Augenblasen vollständig geschlossenen Neuralrohr und zwei Visceraltaschen, von denen die zweite vom Ektoderm. noch durchweg durch eine ganz dünne mesodermale Zellenanlage getrennt ist. 
Bei diesem Embryo hat sich die Hexzanlage in kranio-caudaler Richtung weiter ausgebreitet und ist auch auf dem Querschnitt merklich zellenreicher geworden. Die wesentliche Cmgestaltung der bisherigen Form ist aber durch eine Rückwärtsverschiebung der vorderen. Darmpforte vor sich gegangen. Diese Verlagemung kommt schon bei flüchtiger. Durchmusterung der Querschnittserie dadurch zum Ausdruck, daß die vordere Darmnabelwand, die im vorigen Stadium noch unterhalb der damals vorbandenen einzigen Visceraltasche lag, jetzt hinter das Gebiet der zweiten Tasohe gerückt ist. Wir müssen den Vorgang und seine Folgen für die Herzentwicklung näher ins Auge fassen.

Schon im vorausgegangenen Stadium (Abb. 18 und 19) lieB die Seitenwand des noch mit dem Dotter verbundenen Absehnittes dex Kopfdarmhöhle von der Stelle der vorderen Nabelwand an nach rückwärts, unter der Mitte ihres dorsom ventralen Durchmessers, eine seitliche Einbuchtung erkennen, durch welche der Querdurchmesser des Rohres eingeengt erschien. Diese Einfaltung entsprach genau der Stelle, an welcher die ersten Herzzellen zwischen Darmwand and Perikardialhöhle aufgetreten waren. Im weiteren Verlauf der Entwicklung trennt sich an dieser Stelle der Darm des Embryonalkörpers als ventral geschlossenes Rohr (Abb. $\$ 8$ d) won einem auf dem Dotter zuruckbleibenden Rest, den wir , vorderen Darmrest ${ }^{\text {iI }}$ ) (vr) nennen wollen, ab. Der letztere stellt, wie belannt, eine kraniale nach vorn niedrig auslaufende blinde Bucht des ventralen Darmabschnittes dar, welche ebenso wie dieser zum Boden den Nahrungsdotter hat.

Wie sich die Abtrennung mechanisch vollaieht, ist hier schwerer zu eruieren als bei dem entsprechenden Forgang an der hinteren Darmptorte. Dort geht, wie auf $\mathrm{S} .28$ und an der $\mathrm{H}$ and der $\mathrm{Abb} .39$ und 45 gezeigt wurde, die Abschnutrung zweifellos in der Weise vor sich, daß die ventralen Teile der beiderseitigen Darmwände sich gegeneinander einfalten, median verkleben und sich dann vom geschlossenen Mitteldarm abtremnen. An der vorderen Darmpforte läBt sich eine solche. Verschmelzung der Seitenwände mit nachfolgender Durchreißung für die vorliegende Entwicklungsperiode noch nicht (s. S. 54) nachweisen. Ich möchte daher eher annehmen, daß der Vorgang hier in einer Abfaltung besteht, in der Weise, daß die den Kiemendarm vom Darmrest trennende, nach hinten konkave Falte in caudaler Richtung allmählich weiter vordringt und so die beiden Darm. abschnitte schrittweise trennt.

Der Effekt des Vorgangs für die GefäBanlagen ist jedenfalls in beiden Fällen der gleiche: wie er hinten eine mediane Vereinigung der Subintestinalvenen ermöglicht, so führt er vorn dazu, dab die paarigen Herzzellengruppen zu einem unpaaren Zellenhaufen ( $h$ in $\mathrm{Abb} .28$ ) zusammentreten, welcher die nun entstandene Lücke zwischen dem Kopfdarm und Darmrest ausfüllt. Die Herzzellen, deren $\mathrm{Zahl}$ zugenommen hat, sind noch vorzugsweise dorso-ventral gerichtet und im Gegensatz zu späteren Stadien ziemiich dicht gelagert.

Diese unpaar gewordene Herzanlage reicht nach rückwärts selbstverständlich genau so weit, wie die Darmabschnürung, d. h. bis zur Darmnabelwand (worderen Darmpforte).

1) Ich wähle diese Bezeichnung mit Rücksicht auf die analoge Bildung am hìnteren Ende des Blastoderms, den ,hinteren. Darmrest" (S. 28) und vermeide damit den früher (88) von mir gebrauchten zweideutigen Ausdruck "Dotterdarm". 
Verfolgt man die unpaar gewordene Herzanlage nach forne (Abb. 27), so sieht man, wie die beiderseitigen Leibeshöhlen sich ventral rom abgeschnürten Darm zur gemeinsamen Perikardialhöhle $(c)$ vereinigt haben und der hier niedrigere Darmrest (vr) in eine solide Leiste ausläuft. Die Herzanlage wird in dieser Richtung rasch zellenärmer und noch kompakter und, was besonders charakteristisch erscheint, sie plattet sich dorso-ventral ab $(t r)$.

An dieser Form läßt sich das Vorderstïck der unpaaren Anlage sehon jetzt mit Sicherheit als kranialer Abschnitt des Truncus arteriosus bestimmen. Denn erstens schließt es sich caudal unmittelbar an die paarig gebliebene Anlage der Mandibulararterien, die sich übrigens seit dem vorigen Stadium kaum merklich weiter entwiokelt hat, an, und zweitens gestattet die Abflachung dieses Gefa Babschnittes, die sich noch am ausgebildeten Endothelrohr über eine lange Entwicklungszeit erhalt, die Identifizierung des Truncus. Die dorso-ventral komprimierte Strecke des Lumens reicht dann bis in das Mündungsgebiet der dritten Visceralbogenarterie nach hinten, entspricht also, da schon mit der Einmündung der vierten Bogenarterie der Truneus endet ${ }^{1}$ ), dem gröBeren rostralen Teil des lezzteren.

Literatur: In meiner früheren Arbeit (1888) habe ich bereits angegeben, daß durch die Abschnürung des Darmes die zur Seite desselben paarig auftretenden GefïBzellengruppen sich zu einer medianen unpaaren Herzanlage vereinigen und daB die letztere durch caudales Fortschreiten dieses Vorganges sich nach hinten verlängert.

Trotzdem berücksichtigt Rabl in seiner später erschienenen Beschreibung der Herzbildung der Selachier (1889 und 1892) diesen wichtigen, die Herzanlage kausal gestaltenden Vorgang der Darmabschnürung nicht. Er nimmt vielmehr irrtümlicherweise an, daß die ersten zur Seite des, „Darmstiels" auftretenden Gefäßzellen, sich zu Strängen ordnend, um die Vorderwand des Darmstiels herum nach vome wachsen und hier sich zur Herzanalge vereinigen. Die Stränge bilden das Mündungsstück der ,Venae omphalo-mesentericae". Somit würde das Herz von den letzteren aus durch Vorsprossung entstehen.

Tch habe früher (1888) nur einen caudalen Abschnitt der Herzanlage durch Verschmelzung der ersten paarigen GefäBzellen entstehen lassen, indem ich annahm, daß die Abspaltung dieser Elemente am ventralen Umfang des abgeschnürten Darms nach vorne weiter greift und hier eine prim ä u n pa are Anlage erzeugt. Diese Auffassung wird jetzt duxch den Nachweis einer pri na är bis zu den Mandibulararterien sich ausdehnenden parigen Herzanlage (s. voriges Stadium) hinfällig, denn hiernach kann das im vorliegenden Stadium vorhandene unpaare flache Vorderstück der Anlage (Truncus arteriosus) nur, wie der übrige Herzzellenstrang, durch mediane Verschmelzung seitlich entstandener Zellengruppen gebildet sein, wenn auch eine umpare Entstehung durch ein Weitergreifen des Abspaltungsvorganges der Gefäßzellen gegen die Mittellinie zu vielleicht vorgetäuscht wird.

Die unpaare Entstehung hatte ich damals angenommen, weil an der fraglichen Stelle die ventrale Darmwand eine, bei Torpedo schwache und diffuse, mediane

7) Die 5. und 6. Visceralbogenarterie ergießen sich bekanntlieh durch das Mündungsstück der \pm in den Truncus. 
Verdickung bildet, die auffallend reich an Witosen und chromatisch zerfallenden Kernen ist. Auch ist ihre Abgrenzung gegen die Herzzellen keine durchwegs so scharfe, wie sonst. So habe ich fruher (1888) dieser Stelle des Entoderms eine wesentliche Beteiligung an der Produktion von Herzzellen zugesprochen, indem ich mich hauptsächlich auf Befunde bei Pristiurus, wo ich einen deutlichen. medianen Entodermwulst in Auflösung fand, stützte ${ }^{1}$. Ich gestehe, daB mir diese Deutung jetzt fraglich erscheint, nachdem ich innerhalb des Embryos sonst nirgends eine entodermale Entstehung von Gefäßzellen, die ich früher angenommen hatte, mit Sicherheit habe verfolgen können. Auch könnte es sich, wie aus der vorstehenden Darlegung hervorgeht, höchstens um einen nachträglichen entodermalen Beitrag zur Bildung des Truncus arteriosus handeln. Andererseits ist aber der bei Pristiurus sich auflosende Entodermwulst in meiner Erinnerung so deutlich, daB ich mich nicht entschließen kann, meine frühere Angabe zurückzunehmen, solange ich mich nicht bei Pristiurusembryonen von ihrer Cnrichtigkeit überzeugt habe. Ich lasse daher die Frage offen, bis es nir gelingt, des einschlägigen Entwicklungsstadiums von Pristiurus wieder habhaft zu werden.

Ob die Verschmelzung der paarigen Herzanlagen in ihrer ganzen Längenausdehnung nur durch die Darmabschnürung bedingt wird, läBt sich im forliegenden Entwicklungsstadium nicht mehr feststellen. Zvar reicht der Darmrest hiex bis unter die flache Truncusanlage nach vorne, aber daraus folgt nicht, daß schon von dieser Quersehnittsebene an eine Abnabelung tatsïchlich stattgefunden hat, denn hat sich der Darm einmal durchsohnürt, so unterliegen sein embryonaler und sein auf dem Dotter verbliebener Anteil unabhängig roneinander ihren eigenen Wachstumsverschiebungen.

Hingegen gibt über die Frage ein jüngeres Entwicklungsstadiam Aufschluß, bei welchem die Darmdurchtrennung soeben eingesetzt hat. Der Embryo, dessen Beschreibung ich hier einschalte, hat 16 Urwirbel. Unterhalb seiner noch unfertigen zweiten Visceraltasche beginnt, wie Abb. 23 zeigt, die Darmabschnürung. Nun liegt hier zwischen dem im kranialen Anschnitt getroffenen Darmrest (vr) und dem Embryonaldarm bereits jene flache Herzzellengruppe der späteren Abb. 27, die noch zum. Truncus wird. Sie erstreckt sich aber noch einige Schnitte weiter nach vorne in das Bereich des ursprünglich freien, $d$. h. nicht abgeschnürten Kopflarms. Man kann biernach sagen: daß die Herzanlage in ihrer ganzen Länge und dazu noch ein caudaler Abschnitt des Truncus arteriosus, durch die Darmabschnürung unpaar wird. Der übrige Truncus hingegen entsteht durch mediane Vereinigung jener paarigen Anlagen, die an dem freien, $d . h$. vor der Nabelwand gelegenen Teil des Kopfes (also wie in Abb. 17) aufgetreten war. Der Vorgang geschieht unter medianer Verschmelzung der beiden Colomhälften unterbalb des Darms.

1) Den gegen mich erhobenen Einwand, ich möehte die Entodermverdickung mit der Anlage der Thyreoidea verwechselt haben, muB ich zurickweisen. Die Thyreoidea entsteht erheblich später und auch weitor vorn in dem Zwischenraum zwisehen den Mandibulararterien. Ebensowenig entspricht die Verdickung, wie Raffaele (1889) meint, dem Rest eines Verbindungsstranges (tratto) zwischen Kopfdarm und Dotterdarm. Den medianen Entodernwwalst, welehem die Herzzellen innig angelagert sind, hat iabrigens RabI (le89) für Pristiurus bestätigt. 
Die erste Herzentwicklung von Tor pedo zeigt - abgesehen von der ziemlich fraglichen Entodermbeteiligung - eine groBe Ubereinstimmung mit derjenigen von Triton nach Mollier (Hertwigs Handbuch Bd. I, 1906). Auch hier ist anfanglich die Anlage durchlaufend paarig und setzt sich vome in diejenige der Mandibulararterien und hinten in die der Dottervenen (Darmlebervenen Göttes) fort. Die Verschmelzung beginnt gleichfalls hinter den Mandibulararterien, also am späteren Truncus arteriosus und schreitet von da nach hinten fort. Auch die Stelle; an welcher die ersten Herzellen auftreten, entspricht genau derjenigen der Selachier. Es ist der Hohlraum einer queren gegen das Darminnere gerichteten Entodermfalte zwischen Yund- und Leberbucht, der sich, ,langsam mit zunehmender Abhebung des Kopfes vom Dotter erweitert". Das ist offenbar die der vorderen Darmpforte entsprechende Entodermeinfaltung von Torpedo, welche den freien Kopfdarm vom Darmrest abgrenzt.

Was die viel diskutierte Frage der paarigen oder umpaaren ersten Anlage des Wirbeltierherzens anlangt, so läBt bei Torpedo die anfänglich parige Anlage des Organes einen phylogenetischen RückschluB auf einen Vorfahrenzustand mit durchlaufend paarigem Ventralgefä $B$ nicht $z u$, weil wegen der Dotterverbindung des Darms die ersten Herzzellen gar nicht anders als paarig - za beiden Seiten des zum Dotter herabreichenden Darmrohres - auftreten liönnen. Höchstens für den vorderen Abschritt des Truncus käme dieser Einwand nicht in Betracht. Hingegen seheint mir bei Amphibien (Triton) ein solches mechanisches Hindernis für eine primär unpaare Anlage des Herzens nicht vorzuliegen. Und trotzdern tritt auch hier die allererste Anlage nicht unpaar, sondern paarig auf (Mollier 1906).

So verhalten sich die Gefäßzellen rostral von der vorderen Darmnabelwand. Im Bereiche derselben begen sie noch genau so, wie früher (vgl. $A b b .10$ ), nämlich an der die weitere Abschnürung vorbereitenden Einfaltung der Darmwand. Nur hat auch hier ihre Zahl zugenommen. Beim Weitergreifen der Abnabelung wird auch dieser caudal noch paarige Abschnitt der unpaaren Herzanlage einverleibt werden.

Caudal von der Darmptorte werden die Zellen sofort sehr spärlich, lassen sich aber noch über einige Sohnitte verfolgen. Da sie hier noch in Abspaltung aus der Splanchnopleura angetroffen werden, muß man schließen, daß die Gefäß. zellenentwicklung in caudaler Richtung, wenn auch verlangsarat, noch im Weiterschreiten begriffen ist.

$\mathrm{Za}$ beiden Seiten der Darmpforte und ebenso etwas vor and hinter dieser Stelle senken sich wie bisher zerstreute GetäBzellen zum Dotter herab, eingezwängt in den engen Spaltraum zwischen dem Visceralblatt der Leibeshöhle und dem Darmrest und daher von ausgesprochen platter Form. Es ist dies die schon an Abb. 19 des vorigen Stadiums demonstrierte Anlage des intraembryonalen Dottervenenstammes. In Abb. 24 ist rostral von der Darmpforte auf der rechten Seite eines Embryo von 16 Urwirbeln eine Kette solcher Dottervenenzellen $(v d)$ zu sehen.

Die Anlage des extraembryonalen Dottervenenstammes ist in$z$ wischen ebenfalls zellenreicher geworden. Soweit die jetzt einheitliche Perikardialnöhle auf den Dotter ( $c^{\prime}$ in Abb. 28 links) sieh ausgebreitet hat, ist die Splanch- 
nopleura mit ihren abgeflachten Zellen dicht an das Dotterentoderm angedrückt, so $\mathrm{daB}$ die einzelnen, überdies meist abgeflachten Gefaßzellen, zwischen diese beiden Sohichten eingeklemmt, nicht so in die Augen fallen wie zuvor. Aber da, wo diese Elemente in der Mehrzahl beisammen liegen, heben sie die Splanchnopleura von der Unterlage ab und treten nun sehr deutlich hervor, zumal sie in solchen Zellengruppen mehr rundliche Formen bewahren. Solche etwas zellenreichere Anlagen finden sich namentlich neben dem Embryo der $\Delta b b .28\left(v d^{\prime}\right)$, und hier sowohl wie an weiter seitlich gelegenen Stellen kann man sie wiederum in Verbindung ruit dem Dotterentoderm sehen.

In $A b b .24$ ist von dem obenerwähnten etwas jüngeren Embryo mit 16 Urwirbeln dieses Verhalten bei stïrkerer VergröBerung wiedergegeben für die Zellengruppe $v d^{\prime}$, welche ibrer Lage nach den ebenso bezeichneten Zellen von Abb. 19 und Abb. 28 entspricht. Man sieht, daß die sonst ziemlich regelmäßig angeordneten Zellen des Dotterentoderms hier aus der Peihe geraten sind, ein Teil von ihnen ragt aus dem Blatt heraus und schiebt sich in den für die GefüBzellen reservierten Spaltraum zwischen Ento- und Mesoderm knospenartig vor, wobei auch, wie so oft an solehen Stellen, eine innige Anlagemung an das mittlere Blatt stattfindet.

Vom vorderen Ast der Vena vit, anter, vermiBt man noch eine über längere Strecken sich ausdehnende Anlage, nur ganz kurze Endothelröhrchen oder Vorläufer solcher Bildungen findet man, wenn man den Innenrand der vorderen GefäBzone absucht.

Die als hinterer Ast zu bezeichnende, dem 'Seitenrand der extraembryonalen Leibeshöle entlanglaufende GefäBzellenansammlung ist stärker geworden. Auf der einen Seite des Embryo ist sie auf eine lange Strecke als einheitlicher Zug zu verfolgen. Sie tritt hier, indem sie sehr zellenreich wird, mit der vom Seitenrand vorgeschobenen Blutinsel vorübergehend in Verbindung. Diese noch durchweg soliden Anlagen hängen häufig mit Wucherungsstellen des Dotterentoderms zusammen.

Auf der anderen Seite der Keimscheibe ist der Zellenzug nicht mit Sicherheit festzustellen, weil es hier nicht gelingt, das extraembryonale Cölom gegen das periphere Mesoderm scharf abzugrenzen. Caudal von der Stelle, wo beide zusammentreffen - es ist dies hier zufälig weit hinten - ist das erstere noch unfertig, a.h. es besteht noch aus Colomlücken. Da nun auch das periphere Mesoderm jetzt schon mit der Bildung solcher Hohlräume einsetzt, kann die Abgrenzung beider Mesodermabschnitte vorübergehend unmöglich werden.

$\mathrm{Um}$ zu zeigen, wie weitgehende individuelle Schwankungen in bezug auf die zeitliche Entwicklung der Dottervenen vorkommen, schalte ich die kurze Besprechung von zwei Embryonen ein, die in bezug auf die Urwirbelzahl, die Ausbildung der zwei Visceralteschen, den VerschluB des Medullarrohres, die Entwioklung des Herzens und namentlich der extraembryonalen Perikardialhöhle entschieden jünger sind, als der diesem Stadium zugrunde gelegte Embryo. Der eine derselben ist in $A b b .782$ des Hertwigschen Handbuches abgebildet, sein Neuralrohr ist, außer an seinewa vordersten Ende, noch im hinteren Fünftel des Körpers offen. Trotzdem ist hier die Anlage des Dottervenenstammes unter dem vorderen Rand der in Ausbildung begriffenen extraembryonalen 
Perikardialhöhle reicher an Zellen ais bei dem zuletzt beschriebenen Embryo, vor allem aber ist thr hinterer Ast schon ein über eine lange Strecke durchlaufendes, fast durchweg ziemlich geräumiges Hohlgefäß. Bei dem zweiten fast gleichaltrigen Embryo, bei dem mehr als ein Drittel des Neuralrohres caudal noch offen ist, besitzt das genannte Gefäß streckenweise gleichfalls schon eine, wenn auch viel engere Lichtung. Im Gegensatz hierzu ist bei dem ebenfalls etwas jüngeren Embryo des Modells der Abb. I die gesamte Anlage der vorderen Dottervenen noch stank im Rückstand, wie die genannte Abbildung zeigt.

\section{Stadium mit 3 Viseeraltaschen.}

Die Anlagen des Herzens und der vorderen Dottervenen bilden sich zu Endothelröhren um. Die Abteilungen des Herzrohres werden, mit Ausnahme des Sinus venosus, unterscheidbar.

In diesem Stadium, in welchem sich bei Embryonen zwischen 20 und 29 Urwirbeln ${ }^{1}$ ) die dritte Visceraltasche ausbildet, schreitet die Darmabschnürung nach hinten weiter fort. Bei einem Embryo ron 20-21 Urwir beln (Modell der $A b b .2)$ liegt die vordere Darmpforte unterhalb der angedeuteten dritten Visceraltasche, bei dem ältesten Embryo des Stadiums mit 29 Urwirbeln liegt sie um $3 \frac{1}{2}$ Urwirbel caudal von ihr. Dementsprechend verlängert sich die unpaare Herzanlage wiederum nach rückwärts.

In Gefolge der Darmabschnürung rückt die mediane Verschmelzung der beiderseitigen. Leibeshöhlen ebenfalls nach hinten weiter. Sie geht, wie aus Abb. 23 und 27 des vorigen Stadiums zu entnehmen war, zwischen Darm und Herzanlage einerseits und Darmrest andererseits vor sich. Auf diese Weise war bei jenen Embryonen eine einheitliche Perikardialhöhle nur unterbalb des vorderen abgeplatteten Abschnittes der GefäBanlage, also dem Truncus arteriosus, gebildet worden. Dieses Gefäßstück buchtet die obere Herzbeutelwand ventral etwas vor, bleibt aber auch späterhin extraperikardial liegen (Textabb. E 1 und 2 and $G 1$ and 2). Anders die caudal sich anschlieBende eigentliche Herzanlage, die sich durch ihre dorso-ventrale Ausdehnung (Abb. 28 des vorigen Stadiums) von jener unterscheidet. Thre durch die Herzbeutelverschmelzung bewirkte Abtrennung rom Darmrest ist in Abb. 32 für den jüngsten Embryo des vorliegenden Stadiums dargestellt. Hier bildet die dorsale Wand der Leibeshöhle, indem sie die GefäBanlage überkleidet, bekanntlich einen vom Darm frei herabhängenden länglichen Beutel: Das Visceralblatt des Perikardiums (v), das dann im weiteren Verlauf der Entwicklung nach vorausgegangenem ventralen Abrücken des Herzens vom Darm mittels eines kurzen Gelzröses, des Mesocardiums dorsale ( $m d$ in Textabb. F 2-4), an der Darmwand hängt. Noch am SchluB des vorliegenden Stadiums beginnt das Gekä̈se des in die Länge gewachsenen Herzrohres, nachdem es sich verdünnt hat, einzureißen, worauf die myoepikardiale Hülle mit ihrem Endothelrohr frei in die Perikardialhöble zu liegen kommt und damit die Moglichkeit zu ausgiebigen Biegungen erhält (Textabb. F 3). tasthe.

1) Der erste große, mit welchem die Zähinng beginnt, liegt dicht hinter der 3. Viscral- 
Wir verfolgen num die Entwicklung der ventralen Gefäßanlage des Kopfes an den einzehen Errbryonen des vorliegenden Stadiums.

Bei dem jungsten dieser Embryonen, bei welchem das 21. Crsegment in Abgliederung begriffen ist (Taf. I, Abb. 2), erseheint die Gefälanlage noch durchweg solid. Nur an stelle des Koptsinus ist eine ihn vorbereitende paarige Mesenchymlücke zu sehen, die sich in ein Paar ventrale, an der medialen Wand der Mandibularböhlen absteigende kurze Fortsätze auszieht. Die letzteren entsprechen den dorsalen Endstücken der Mandibulararterien, deren Zellenstränge schon vorher aufgetreten waren. In seinem übrigen Verlanf ist aber dieses erste VisceralbogengefäB noch durchaus solid. Es ist noch immer sehr zellenarm, also gegenüber dem sich msch entwickelnden Herzen, mit dem es nahezu gleichzeitig entstanden war, zurückgeblieben. Doch ist bei diesem jüngsten Embryo des Stadiums auch in der Herzanlage noch kein Lumen aufgetreten. Der Truncus (Abb. 31) und ein kranialer Herzabschnitt sind noch von kompaktem Gefüge, während nach hinten zu die noch ziemlich zellenreiche Herzanlage sich mesenchymatijs auflockert (Abb. 32).

Vom caudalen Anfangsstück der Mandibulararterien und vom Truncus setzen sich GefäBzellen an der seitlichen Darmwand nach aufwärts fort bis zu der Stelle, wo die Aortenzellen sich aus dem segmentierten Mesoderm jetzt abtrennen $\left(\mathrm{Abb} .31, a b^{3}\right)$. Sie liegen in dem engen Spaltraum zwischen Ento- und Mesoderm eingezwängt und sind dementsprechend meist seitlich abgeplattet. Am zahlreichsten sind sie ventral, wo sie von der Anlage des LängsgefüBes ausgehen, am spärlichsten etwa in mittlerer Höhe des Darmquerschnittes, während sie dorsal, wo sie mit den Aortenzellen zusammenhängen, an Zahl anscheinend wieder zunehmen. Sie sind schon im Stadium von zwei Visceraltaschen vorhanden, wenn auch in geringerer Menge, und sind zu jener Zeit sowie auch noch im vorliegenden Stadium zum Teil im Austritt aus dem angrenzenden Mesoderm begriffen.

Diese Zellen, die zwischen den Visceraltaschen, also im Bereiche der sich ausbildenden Fisceralbogen liegen, stellen die Vorläufer der späteren Visceralbogengefäße dar, und zwar beim vorliegenden Embryo sowie denen des vorigen Stadiums die Vorlaufer des zweiten und dritten Bogengefäßes. Es ist bemerkenswert, daß diese die Aorta mit dem VentralgefäB verbindenden ersten Anlagen der VisceralbogengefäBe durch ihre Lage nnmittelbar auf dem Darmepithel den DarmquergefäBanlagen des Rurptes völlig gleichen. Für die zu Endothelröhren ausgebildeten VisceralbogengefäBe gilt dies nicht mehr, denn diese verlaufen. von ihren beiden. Endstücken abgesehen, in nerhalb des Nesoderms der Visceralbogen, zwischen der medialen Wand des Coloms und einer weiteren dem Darmepithel unmittelbar aufliegenden Mesodermschicht. Wenn sie trotzdem von einigen Auturen als homodynam mit den DarmquergefäBen erk\}art worden sind, so entbehrte diese Ansicht bisher der tatsächlichen Begründung. Aber das eben beschriebene Verhalten ihrer Anlage beweist in der Tat, daB sie ron Darmquergefäßen abzuleiten sind.

Ein weiteres Argument für diese Auffussung finde ich in der später zu beschreibenden Tatsache, daß diese Zellenketten, wenn sie mit der weiteren Entwicklung des Kiemendarms im Bereiche des füften und dann des sechsten Bogens 
aufgetreten sind, sich von da caudal weiter verfolgen lassen über die Gegend der Leberanlage hinaus bis zur Vornierenregion, wo dann an ihrer Stelle die echten DarmquergefäBe (s. Rückert 1917) auftreten. Es besteht also in dex ersten Anlage eine Kontinuitat der beiderlei Quergefäße. Das abweichende Verhalten. der fertigen Visceralbogengefäße, d. h. ihr Verlauf innerhalb des Visceralbogenmesoderms und ebenso ihre Branchiomerie dürfte sich aus den besoncleren Bedingungen, unter denen sie sich am Kiemendarm entwickeln müssen, leicht erklären: genetisch sind sie auf das Mesoderm angewiesen, können also nur zwischen den Taschen, also branchiomer, auftreten und hier geraten sie durch die Massenentwicklung des Mesoderms der Visceralbogen in das Innere dieser Schicht.

Ein Embryo mit 22-23 Urwirbeln besitzt eine schon tiefe 3 . Visceral-

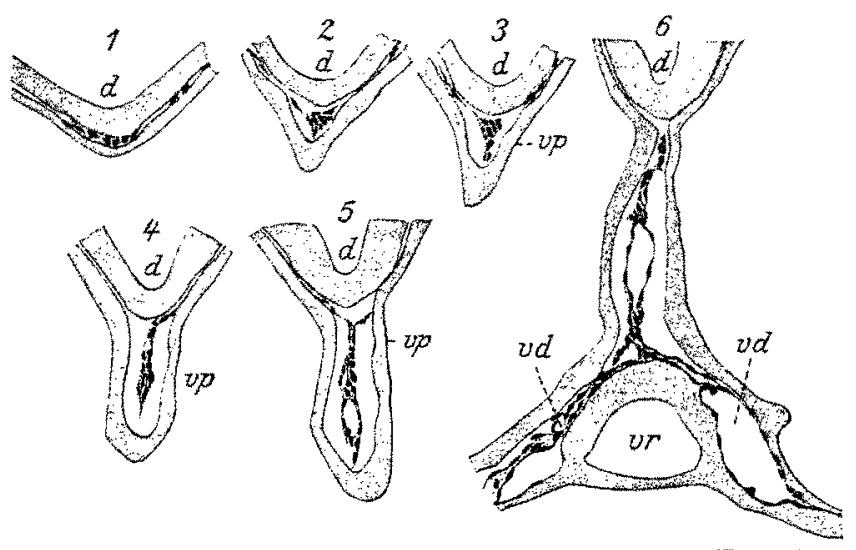

Abb. E. 6 Querschnitte durch dit Herzanlage eines Torpedoembryos mit 22-23 Urwirbelu und unfertiger 3. Visceraltasche. E $1-$ E $3=$ Durch die Anlage des Truncas atterios. - J $4=$ Durch die Anlage deg Bubus. - E $=$ Durch die Anlage des Ventrikels. -

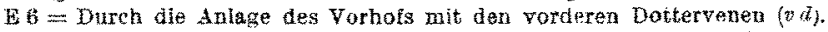
Darm $(d)$. Votderar Darmast $(u n)$. Viseerales Perikardiablatt $(y, p)$. tasche, die aber das Mesoderm erst an beschränkter Stelle verdrängt hat. Hier hat sich die Lumenbildung im rostralen dbschnitt der Mandibulararterien weiter ausgedehnt. Uber das Verhalten des Truncus und des Herzens ist aus der beistehenden Querschnittsskizze folgendes zu ersehen: Der vordere flache (Text. abbildung E 1) und dann sich ventral zur Keilforno (E 2 und 3) ausziehende Abschnitt hat seine bisherige Form und solide Beschaffenheit bewahrt. Dieser ganze Abschnitt fällt, da sich an das Ventralgefä $B$ von Textabb. E 3 seitlich die Zellenkette der 3. Visceralbogenarterie ansetzt, in das Bereich des Truncus. Hinter dieser Stelle erscheint der Querschnitt in ganzer Höhe seitlich total komprimiert (E 4), läßt aber schon die beiden seitlichen Endothelwände als solche einigermaßen erkennen und zwischen ihnen kein oder nur ein ganz kleines Lumen. Dieser Abschnitt ist hierdurch schon jetzt als Bulbus cordis kenntlich. Bis zu einem ganz späten Stadium, in welchem er bereits die histiogenetischen Merkmale des Bulbus aufweist, bewahrt er sich durch die geringere Ausweitung seines Lumens und dessen seitliche Kompression wnverkennbare Anklänge an diese Ausgangsform.

Weiter caudal (Textabb. E 5) tritt in dem dorsoventral sich verlangernden Zellenstrang das erste deutliche Lumen auf, das sich von da bis zum hinteren Ende desselben erhält, wobei es noch weiter wird (E 6). Das Lumen erscheint in dem hier mesenchymatös aufgelockerten Zellenhaufen diskontinuierlich, was auch schon weiter vorn in der bompakteren Anlage der Fall war. Von diesem 
caudalen Endabschnitt setzt sich das Herz ventral in die beirlen am Darmast absteigenden vorderen Dottervenen $(v d)$ fort. Aus diesem sich eroffnenden Teil der Herzanlage entwickeln sich Ventrikel und Vorhof. Der hintere größere, zur Zeit starker gehölte Abschnitt von E 6 wird dem Vorhof, derjenige von E 5 dem Ventrikel zufallen. Eine Grenze zwischen beiden Abschnitten läBt sich aber weder jetzt noch in den nächstfolgenden Entwicklungsstadien erkennen. Erst in erheblich spiterer Zeit wird eine solehe wahrnehmbar dadurch, daß das Rohr zum Aurikularkanal sich einzuschnüren beginnt.

Ein dem Sinus venosus entsprechendes Anlagestück laßt sich noch nicht von dem Vorhofsabschnitt unterscheiden and ist vielleicht auch noch nicht gebildet.

Es lassen sich also schon zu der Zeit der beginnenden Lumenbildung der Herzanlage die Unterabtelungen des fertigen Organs mit Ausnahme des Sinus venosus, also Truncus, Bulbus, Ventrikel und Atrium, identifizieren.

Daß das zeitliche Auftreten des Herzlumens individuell schwankt, lehrt ein anderer Embryo, der in bezug auf die Urwirbelzahl und die Entwicklung der 3. Visceraltasche dem beschriebenen nicht nachsteht, aber noch eine durchweg solide Herz- und Mandibulararterienanlage aufweist.

Bei einem Embryo von $26 \mathrm{Cr}$ r ir beln ( $=20$ Rumpfsomiten s. S. 22) ist der noch kleine Kopfsinus schon endothelial begrenzt, die Mandibulararterien sind weiter caudal gehöhlt als bisher. Die dorsalen Aorten im Kopf sind streckenweise schon als enge Endothelröhrchen aufgetreten, während dazwischen ihre Zellengruppen erst in Abtrennung vom axialen Mesoderm begriffen oder noch nicht unterscheidbar sind. Trotz dieses vorgeschrittenen Verhaltens der Kopfarterien steht das Herz noch auf der oben beschriebenen Stufe der Textabb. E.

Der älteste untersuchte Embryo des Stadiums von drei Visceraltaschen hat $29 \mathrm{Ur}$ wirbel and $23 \mathrm{Ram}$ p $\mathrm{s}$ somiten. An der 3 . Tasche ist das Mesoderm vollständig verdrängt, an der späteren Durchbruchsstelle der 2. das Entoderm schon rerdünnt. Das Neuralrohr erscheint nur mehr auf ein paar Schnitten zwischen den Augenblasen geöffnet. Hier besitzen die noch engen dorsalen Aorten im $K$ op f ein durchlaufendes Lumen, bis auf ihr rostrales Ende, das mit dem kleinen Sinus cephalicus noch nicht in offener Verbindung steht. Die Mandibulararterien sind bis zur Abgangsotelle der Zellenkette der 2. Visceralbogenarterie nach hinten hohl und dabei vorn weit, hinten noch eng, zuletzt werden sie solid. Aber schon nach kurzer Cnterbrechung tritt mit Beginn des unpaaren VentralgefäBes die Lichtung wieder auf. Der noch kurze Truncus ist also jetzt hohl. Auch am 2. und 3. Kiemenbogengefä $B$ setzt die Lumenbildung, und zwar ebenfalls an ihrem dorsalen Ende, ein. Dies gesehieht dadureh, daß die dorsalen Aorten sich ventral in die Zellenketten der Bogengefäßanlage hinein mit je einem kurzen Zipfel ausziehen. Caudal von der 3 . Visceraltasche erhebt sich vom Truncus der Zellenstrang eines 4. Bogengefäßes zu dem jetzt angelegten 4 . Visceralbogen.

Im Bulbas zeigt sich gegenüber Textabb. E die Bildung der Endothelwand fortgesehritten. Dieser vordere Herzabsehnitt ist wie immer seitlich komprimiert und an seinem kranialen Anfangsstück (Textabb. F l) total geschlossen. Nach hinten zu offnet sich sein Lumen, und zwar zunächst ventral (Textabb. F2), 
dann vollständig, so daß der Querschnitt elliptisch wird (Textabb. F 3). Das in der vorhergehenden Abbildung schon geschlossene Mesokardium verdünnt sich nach rückwärts und reißt aul ein paar Schnitte durch.

Auf dieser und der caudal folgenden Strecke tritt beim vorliegenden Embryo die erste Andeutung der späteren Krümmung des Herzrohres auf: In Textabb. F 2 und 3 ist die Herzanlage etwas nach rechts verlagert und diese Stellnng wird auch hinter der. Durchtrennungsstelle des Mesokardiums noch beibehalten, wie aus dessen schräger Richtung in Textabb. F $t$ ersichtlich ist, bis das - hier vielleicht zutälig - wieder verengte Endothelrohx sich zur weiten Vorhofsanlage ausdehnt. Die Verlagerung befallt, wie ein Vergleich wit alteren Stadien lehrt, den
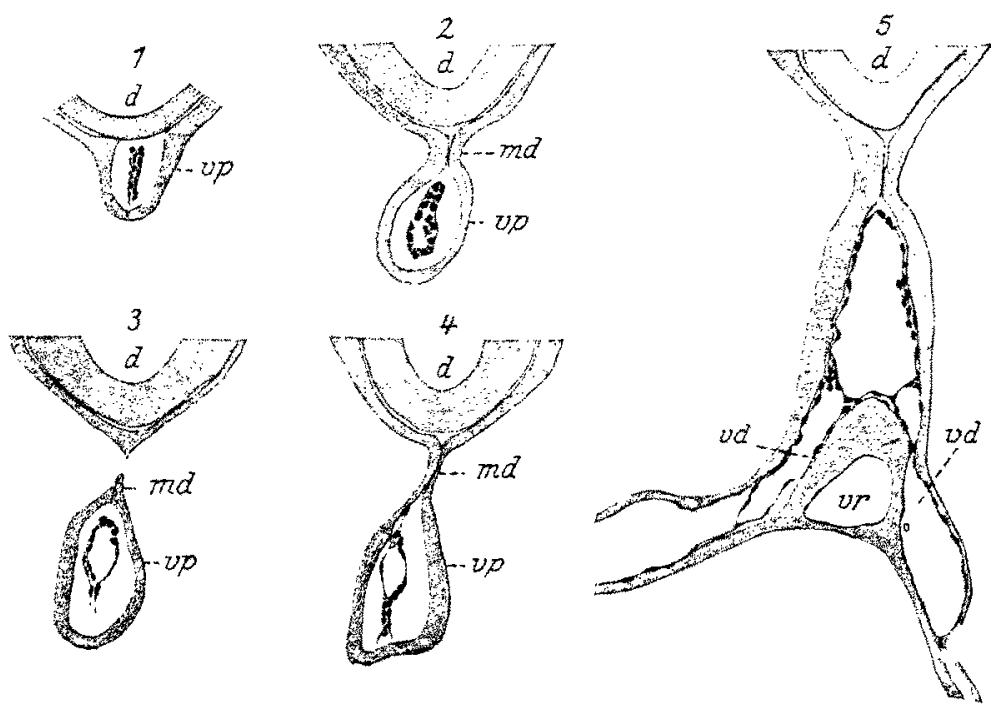

Abb. F. 5 Querschnitte durch die Herzanlage eines Torpedoembryos mit 29 Urwirbelu, darunter 23 Rumpfsomiten und fertiger 3 . Visceraltasche.

$F 1$ und $F 2=$ dureh den Bubus. - 3 und $74=$ durch den Ventrikel. $-55=$ dureh den Vorbof mit den $v d=$ vorderen Dottervenen. $m d=$ Mesocardium dorsale $d=$ Darm $v p=$ viscerales Perikardialblatt. vr $=$ porderer Darmrest.

caudalen Abschnitt des Bulbus und den kranialen des Ventrikels, die später bekanntlich nach rechts (und ventral) abgelenkt sind, während der folgende Teil des Ventrikels wieder gegen die Mitte (später bekanntlich bis auf die linke Seite) abbiegt, um in dieser Lage in den weiten Vorhof (Textabb. F5) überzugehen.

So liefert die erste auftretende Krümmung des Rohres eine Bestätigung für die Richtigkeit der oben durchgeführten frühzeitigen Untersoheidung der einzelnen Herzabteilungen. Bemerkenswert ist ferner, daß gleichzeitig mit dem Auftreten der Verbiegung das Mesokardium, und zwar ungefiahr in der Mitte der abgelenkten Strecke, durchzureißen beginnt. Es beweist dies die Berechtigung der Ansicht, daß der letztere Forgang grobmechanisch durch die Verlagerung des Rohres bedingt ist.

Die rorderen Dottervenen. Beginnende Verlagerung ihrer Mündungsstücke. In den vorausgegangenen Stadien war der das hintere 
Ende der Herzanlage fortsetzende parige Gefäßzellenzug, die Anlage des Anfangsstückes der Dottervene, in ziemlich senkrechter Richtung an der Seite der vorderen Darmpforte zum Dotter herabgetreten, wie aus $A b b .19$ und 28 ersichtlich ist. Diese Verlaufsrichtung ändert sich nun während des vorliegenden Stadiums. Infolge der caudal fortsehreitenden Darmabschnürung rückt unter gleichsinniger Verlängerung des Herzstranges die Abgangsstelle der Dottervenenzellen vom Herzende ebenfalls nach rückwärts. Dies bewirkt die im Gefolge der Darmabschnürung in caudaler Richtung vor sich gehende mediane Vereinigung der beiderseitigen Perikardialhöhlen (vgl. S. 46), dadurch, daß der mediane Teil dieser jetzt unpaaren Höhle sich zwi chen die am Darm hängende Herzanlage einerseits und den Darmrest mit den ihm aufgelagerten Dottervenenzellen. andererseits einschiebt ( $A b b .32)$ und so die Verbindung des Herzens mit den Dottervenen trennt und caudal verlagert. Infolge dieser Rückverschiebung ihrer Abgangsstellen wenden sich jetzt die auf dem Darmrest absteigenden Dottervenen statt der senkrechten einer schriag ventrokranialen Richtung zu. Sie verlaufen in einem nach vorne konkaven Bogen vom Herzen zum Dotter. DemgemäB werden sie auf dem Schnitt der $A b b .32$, welcher der Lage nach denjenigen der Abb. 19 und 28 entspricht, nicht mehr in ihrer Verbindung mit dem Herzen getroffen, wie in den letztgenannten Abbildungen, sondern erst weiter caudal. Hingegen sieht man sie in $\mathrm{Abb} .32$ auf dem Darmrest nach vorne verlaufen und sich dabei zum Dotter herabsenken. In vorliegendem Stadium ist diese Ablenkung der ursprünglichen Verlaufsrichtung noch geringgradig, später aber mit zunehmender Abnabelung steigert sie sich betrîchtlich.

Die Dottervenenanlage wird hohl. Im vorliegenden Stadium gestaltet sich die bisher fast durchweg noch solide, d. h. durch Gefäßzellen gebildete Anlage der Dottervene zu einem Endothelrohr um. Und zwar eilt auf diesem Wege der auf dem Dotter gelegene, größtere Abschnitt des Gefäßes den Embryonalgefäßen und dem Herzen voran, war doch schon bei Embryonen des vorigen Stadiums an den Asten der Vene eine beginnende Lumenbildung stellenweise zu erkennen. Dies Verhalten steht im Einklang mit der Tatsache, daß überhaupt auf dem Dotter frühzeitiger Hohlgefäße gebildet werden, als innerhalb des Embryonalkörpers. So findet man bei dem jüngsten Embryo unseres Stadiums (Nodell der $A b b .2$ ), der mit Ausnahme eines vorderen kurzen Endstückes der Mandibulararterien noch kein Lumen in den übrigen KopfgefäBen und im Herzen besitzt, schon über längere Strecken der Dottervene hohle Endothelröhren vor.

Am weitesten fortgeschritten ist in dieser Beziehung der am vorderen Cölomrand verlaufende extraembryonale Stammteil der Vene, dessen Endothelrohr, namentlich auf der rechten Seite der Abb. 2, nur wenige Unterbrechungen mehr aufweist.

Bei Betrachtung der genannten Abbildung fallt auf, daB rechts das uberdies umfangreichere Dottercölom sich weiter nach hinten ausbreitet und namentlich, daß es als Ganzes zugleich in dieser Richtung verlagert ist, wie die Stellung seines Vorderrandes beweist. Dieser Pand und mit ihm der Dottervenenstamm liegen also weiter hinten als links.

Dazu kommt noch folgendes: während links der vordere Cölomrand mit der Vene yom Embryo aus in querer Richtung bis zum Innenrand der Gefäßzone 
verlaufen, verlassen sie rechts diese Richtung, bevor sie die Area vasculosa erreicht haben und biegen nach hinten $a b$, so daB sich zwischen sie und die letztere Zone ein keilförmiger caudaler Zipfel des mesodermfreien Feldes von vorn einschiebt. Dementsprechend treten die GefäBzone und mit ihr die ,einbiegenden:" Blutinseln viel weiter caudal als links an den Colomrand heran. Es ist also rechts erstens das Cölom und zweitens in noch höherem Maße das vom Keimscheibenrand gegen das Cölom vordringende periphere Mesoderm nebst den in ihm enthaltenen ,einbiegenden:" Blutinseln nach rückwärts verschoben.

Solche Asymmetrien des Blastoderms kommen bei Torpedo ganz gewöhnlich vor. Namentlich eine einseitige Rückverlagerung des Dottercöloms habe ich oft und in einzelnen Fallen noch ausgeprägter vorgefunden als im vorliegenden. Sie wären an sich eine ziemlich gleichgültige Erscheinung, wenn sich nicht aus ihnen einige Rückschlüsse auf die Entwicklungsvorgänge im Blastoderm ziehen ließen. So ermöglicht die Anordnung der Abb. 2 noch im vorliegenden Stadium, in welohem das Dottercölom schon ausgebildet ist, nachträglich das Gebiet des axialen und des peripheren Mesoderms, die gewönlich ohne scharfe Grenze ineinander übergehen oder höchstens am vorderen Ende ihrer Berührungslinie sich trennen lassen, über eine lange Strecke gegeneinander abzugrenzen. Der laterale Rand des axialen Mesoderms ist hier, soweit als die mesodermfreie Zone sioh an ihm nach hinten ausbuchtet, freigelegt und damit als solcher kenntlich gemacht. Genau bis zu dieser Grenze hat sich das Cölom seitlich ausgebreitet. Man erkennt hier, daB das extraembryonale Cölom rom axialen Mesoderm in dessen ganzer Breitenausdehnung, und zwar a usschließlich von ihm, gebildet worden ist.

Ferner bedingt die Asymmetrie einen eigentümlichen Verlauf der Dottervene. Diese zieht auf der rechten Seite der Abb. 2 nicht in rein querer Richtung zum Innenrand der Gefäßzone wie links, sondern sie biegt stark nach hinten $a b$, um dann nach scharfer Knickung als vorderer Ast am Seitenrand des vorderen Mesodermfeldes wieder nach vome abzulenken. Sie beschreibt also einen auffallenden Umweg, der nur verständlich wird durch die eigentümliche Ausbreitung des Mesoderms. So liefert der vorliegende Fall ein schlagendes Beispiel für die allgemein gültige Tatsache, daß die Entstehung der Dottergefäße streng an die Ausbreitung des mittleren Keimblattes auf dem Doter gebunden ist. Wie im Embryo, so erscheinen auch auf dem Dotter die Gefäßanlagen aussehließlich im Bereich dieser Schicht. Niemals treten sie in der mesodermfreien Zone auf. Wenn es auch ofters, z. B. an Stellen des sich anlegenden vorderen Astes der Dottervene, den Anschein hat, als ob im Widerspruch mit dieser Regel GefäB. anlagen auf die nesodermfreie Zone übergreifen würden, so handelt es sich wohl in solchen Fällen nur um einzelne vorgeschobene Mesodermzellengruppen, welche die gleichzeitige Ausbreitung des mittleren Blattes und der Gefiasschicht vorbereiten. Man muß aus diesem Verhalten den Schluß ziehen, daß trotz der zweifellosen Beteiligung des Entoderms an der Bildung der bluthaltigen wie der blutleeren Dottergefäße auch irgendeine Mitwirkung des Mesoderms, zum mindesten dessen Anwesenheit bei diesem Entwicklungsvorgang unerläßlich ist.

Der vordere Ast der Dottervene ist nahe dem Stamm in seiner Entwick- 
lung am weitesten gedieben, im übrigen besteht er noch aus einer Anzahl kurzer Einzelstücke, deren Verbindung mit den Blutinsein aus der Abb, 2 zu ersehen ist.

Der hintere Ast $(A b b .2 \mathrm{rp})$ ist als Endothelrohr rechts ziemlich weit nach hinten entwickelt, links besteht er noch mehr aus getrennten Stücken und hebt sich daher von den benachbarten HohlgefäBen wenig ab.

Im Bereich des Dottercöloms finden sich noch keine Hohlgefäße, sondern nur spärliche zerstreute Gefäßzellen. Es verhält sich also der Dotter im Bereich des axialen Mesoderms auch in bezug auf die zeitliche Entwicklung der Gefäße ebenso wie der Embryonalkörper, der bei diesem Objekt noch keine Hoblgefäße besitzt.

Der vom Herzen am Darmrest absteigende in trae m bryonale Sta m m teil der Dottervene entwickelt sein Endothelrohr etwas später, ziemlich gleichzeitig mit dem Herzen selbst, wie der um zwei Urwirbel altere Embryo der Textabb. E zeigt. Auf dem Schnitt E 6 ist dieses Venenstücl gerade in der Lumenbildung begriffen. Es setzt sich ventral in den schon weit eröfneten Dotterabschnit der Vene fort. Von dem letzteren aus ist das Lumen auf der linken Seite am Darmrest ein Stück weit emporgedrungen. Letzteres Verhalten könnte den Eindruck erwecken, als ob der 2. Akt der Gefäßentwicklung, die Herstellung des Endothelrohres, vom Dotter aus in den Embryo hinein erfolge. Dies ist aber nicht der Fall. Man findet vielmehr gerade das Mundungsstück der Dottervenen, wie auch Textabb. E 6 zeigt, in der Entwicklung etwas zurückgeblieben gegenüber dem angrenzenden Vorhofsabschnitt. Die Lumenbildung im Herzen tritt unabhängig, wenn auch ziemlich gleichzeitig mit derjenigen des embryonalen Anteils der Dottervene auf. Das Verhältnis ist das nämliche, wie beim l. Akt der Gefäßentwicklung, bei der Bildung der Gefaßzellen. Auch diese schreitet, wie wir gesehen, nicht vom Dotter auf de Embryo fort, sondern tritt selbständig am Herzen auf.

Bei dem iltesten Embryo des Stadiums mit 29 Urwirbeln, darunter 23 Rumpfsegmenten, sind die am Darmrest absteigenden Venenstamme durchlaufend hohle Endothelröhren geworden. In Textabb. F 5 erscheinen sie zwar unterbrochen, aber nur weil ihre Mündung in das Herz nicht hier, sondern auf den caudal folgenden Schnitten getroffen ist. Man sieht, daB entsprechend dem bisherigen Verhalten ihr Lumen enger ist als das des angrenzenden Dotterstickes und das des Vorhofs.

GefäBzellen caudal vom Herzen. Während im torigen Stadium caudal von der unpaaren Herzanlage, zu beiden Seiten der hinteren Darmpforte, GefïBzellen angesamm' It waren, die dann bei der weiteren Darmabschnürung der Herzanlage einverleibt wurden, fehlen sie jetzt an dieser Stelle der bevorstehenden Darmabschnürung noch fast ganz, wie $\mathrm{Ab}$ b. 34 zeigt. Eine Neubildung ron Zellen. material für den weiteren Anbau des Ventralgefaßßes exfolgt jetzt offenbar sehr langsam. Hingegen sind ventral von der späteren Durchschnürungsstelle des Darms die Gefäßzellen schon in größerer Zahl aufgetreten ( $v d$ in $A b b .34$ ).

Auf dem an der vorderen Darmplorte geführten Querschnitt dex $A b b .34$ begegnen wir zum erstenmal einer Formveränderung des Darmrohres, die an dieser Stelle kurz erlatutert werden soll. In unserem Anfangsstadium von einer Visceraltasche hatte der Darm noeh in seiner ganzen Länge den von der Gastrulabildung übernommenen Ausgangszustand bewahrt, in welchem, wie aus Abb. 18 
54 Johannes Ruckert: Cber die Entwicklung der ersten Blutgefábe und

bis 22 ersichtlich, seine Seitenwände in einem beträchtlichen Abstand voneinander sich rentral am Dotter anheften, so daB die ventrale Wand des Rohres vom Dotter gebildet wird. Aber schon während der Ausbildung der 2. Visceraltasche beginnt das Verhalten sich zu ändern, insofern der Darm unter fortschreitender Abhebung des Embryo vom Dotter sich beträchtich dorsoventral in die Länge auszieht und sich dabei in seinem ventralen Absehnitt stark verdünnt, wie $A b b .34$ und 35 aus dem Stadium ron drei Visceraltaschen zeigen. Die Ansatzstellen der seitlichen Darmwände am Dotter nähern sich dabei einander stellenweise bis zur Berührung, und auch die dorsal angrenzenden dünnen Darmwände rücken dicht aneinander, streckenweise bis zur Verklebung, so daß dex ventrale Teil des Darmlumens zu einem. Spalt verengt oder ganz geschlossen wird. Dieser Vorgang beginnt hinter der vorderen Darmpforte und erstreckt sich in individuell wechselnder Ausdehnung nach hinten, doch öffnet sich in dieser jugendlichen Entwicklungsperiode das Rohr stets in einiger Entfernung vor der hinteren Darmpforte wieder in alter Weise ventral gegen den Dotter (Abb. 36-38). Auch in dorsoventraler Richtung unterliegt der Vorgang beträchtlichen individuellen Sehwankungen, die wohl durch zufüllige grobmechanische Einwirkung, z. B. den $Z$ ug, welchen der verschiebliche Embryo auf seine Unterlage ausübt, bedingt sein mögen. Aber die ventrale Verdünmung der Darmwände ist stets vorhanden, und auch den Spaltraum $z$ wischen ihnen findet man stets verengt mit Ausnahme jener Falle, in welchen das Darmlumen infolge ungeeigneter Behandlung stark aufgebläht, also künstlich verunstaltet ist. Erst spät, bei Embryonen mit fünf und sechs Visceraltaschen, wenn die Abnabelung über die Lebergegend hinaus in die Vornierenregion rückt, wird dieser ventrale verdünnte Teil der Darmwand. durchtrennt, im Gegensatz zu den jüngeren Stadien, bei welchen die Darmabschnürung dorsal von dieser Stelle vor sich gegangen war (vgl. Abb. 34).

\section{Stadium mit vier Visceraltaschen.}

Weitere Ausbildung der VisceralbogengefüBe und des Herzens. Fertigstellung der vorderen Dottervenen und des inneren Ringgefäßes.

Wir beschließen die Darstellung mit einem Stadium von vier geschlossenen $V$ isceraltaschen, weil in diesem die Entwicklung der vorderen Venenbahn des Eies im wesentlichen vollendet ist. Sieben quergeschnittene Embryonen dieser Altersstufe mit 28-30 Rumpfsegmenten zeigen folgende in den Hauptsachen übereinstimmenden Befunde.

Kopfsinus. Bei den meisten Embryonen des Stadiums von beträchtlicher Ausdehnung. Bei allen ist er mit Blutzellen erfüllt, nur ein Embryo, bei welchem er noch klein ist, macht eine Ausnahme.

Dorsale Kopfaorten paarig, durchlaufend hohl vom Kopfsinus an, im hinteren Abschnitt des Kiemendarms bei den jüngeren Embryonen noch eng.

Mandibulararterien jetzt durchlaufend hohl, bis zum Truncus art., bei den älteren Embryonen im allgemeinen schon von der Weite der Kopfaorten.

2. und 3. VisceralbogengefäB. Es beginnt die Bildung des Endothelrohres auch am ventralen Ende der ursprünglichen Zellenkette, und zwar als eine 
zipfelartige Ausbuchtung der Mandibulararterie für die 2. und des Truncus für die 3. Arterie, wie das in Textabb. G 1 und 2 für das letztgenannte GefäB zu sehen
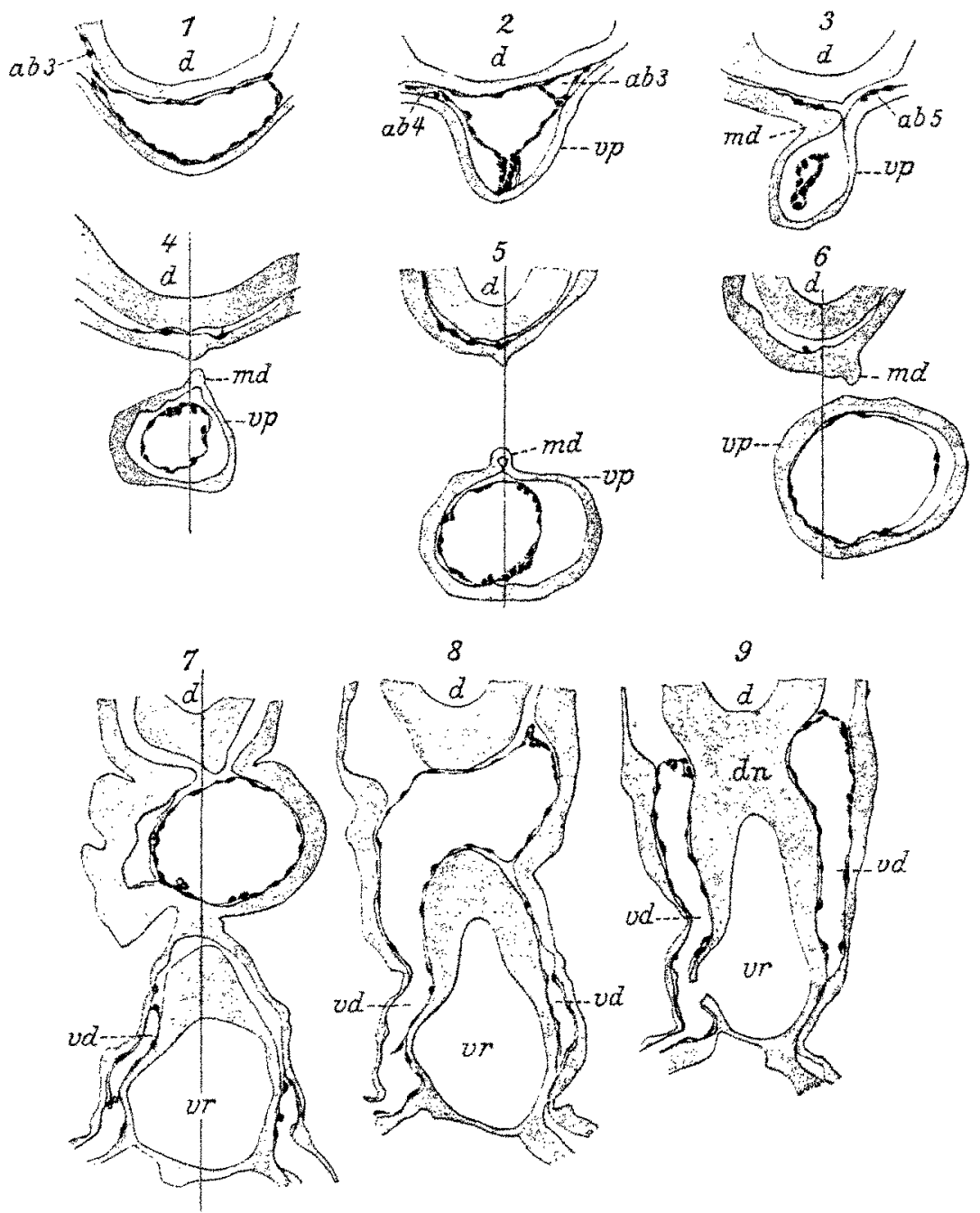

Abb. G. 9 Querschnitte durch die Herzanlage eines Turpedoembryos mit 35 Urwirbein und 29 Rumpfsomiten und mit 4 geschlossenen Visceraltaschen.

$\mathrm{Gl}=$ durch aen Trunc. arter. Abgangstelle des rechten 3 . Aortenbogens $a b z-102=$ durch den Trume. arter. Abganysstelle des 3 . linken Aortenbogens ab 3 und des rechten $t_{\text {t }}$ Aortenbogens $a b 4 .-63=$ đurch den kranialen Tell des Bulbus, ventral vom 4. Visceralbogen. Zellen des ă. Aortenbogens $a b$.

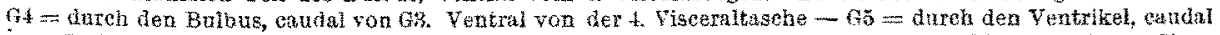

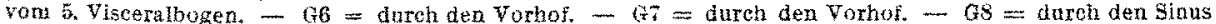

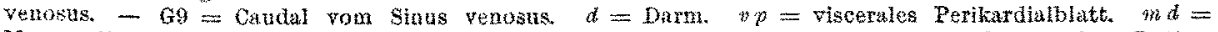
Mesoendium dorsale $d n=$ vordere Dammabeinand. $v r=$ vorderer Darment. $-v d=$ vordere Dottervenen. Die senkrechte Linie entsprioht der Medianebene und zeigt die seitlche Verlateruag des Herzens an.

ist. Der Ziplel setzt sich nach aufwärts in die GefäBzellenkette fort. Das dorsale Stück der Anlage als Aortenbucht ist übrigens noch nicht an allen Embryonen 
des Stadiums deutlich. Das die beiden Endabschnitte verbindende Rohrstück ist erst bei dem ältesten Embryo des Stadiums als HohlgefüP aufgetreten. Es liegt (s. oben) nicht auf der Darmwand, sondern im Mesoderm des Visceralbogens und stellt noch kein durchlaufendes Rohr dar.

Die Entwicklung des 4 . BogengefäBes (Abb. G2) geht in der gleichen Weise vor sich wie die der beiden vorigen, ist aber ihnen gegenüber noch etwas in Rückstand. Nur bei einem Teil der Embryonen sind das ventrale und dorsale Anlagestück schon in Höhlung begriffen.

Das 5. Bogengefäß. Bei allen Embryonen mit Ausnahme des jüngsten ist ein 5. Visceralbogen mehr oder minder weit angelegt und in ibm zwisehen Ento- und Mesoderm schon eine relativ kräftige solide Anlage eines 5 . KiemengefäBes, aber noch ohne jede Spur einer Lumenbildung (Abb. G 3). Der AnschluB der Zellengruppe an den Truncus ist noch unfertig, er wird hergestellt duroh Elemente, die dorsal vom abgeschnürten Herzen an der Ventralwand des Kiemendarms nach vorn zum ventralen Anlagestück des 4. Aortenbogens sich erstrecken und vielfach erst in Abspaltung vom Mesoderm begriffen sind (Textabb. G3 und 4). Auch caudal vom 5. Bogen ziehen sich schon Gefäßzellen an der Darmwand empor (Textabb. G 5).

Truncus arteriosus. Der schon am Ende des vorigen Stadiums hohl gewordene Truncus ist in Abb. $\mathrm{G} I$ und $\mathrm{G} 2$ für Embryonen mit vier Visceraltaschen abgebildet. Fr ist entsprechend seiner früberen soliden Anlage verbreitert und in Anlehnung an die ventrale Darmwand wurstförmig gekrümmt. Nach hinten zu zieht sich die Mitte seiner ventralen Wand nach abwärts in eine Spitze aus, in deren Bereich das Lumen noch ganz (Abb. G 2 ) fehlt oder mehr weniger verengt ist, so daß der Querschnitt dreieckige Gestalt erhält. Dies Verhalten kann sich schon von der Abgangsstelle des 3. Aortenbogens an geltend machen entsprechend dem soliden Zustand von Textabb. E 2 oder erst dicht vor dem 4 . Bogengefäß. Nur ausnahmsweise ist diese Enge im Truncus schon ganz ausgeglichen.

Bulbus cordis. Nach rückwärts von $A b b . G 2$ erstreckt sich die Querverengung vom ventralen Teil des Rohres auf dessen dorsalen Abschnitt, so daB bald der gesante Querschnitt die seitlich komprimierte Form der Abb. G3 annimmt, die aus der soliden Vorstufe der $\mathrm{Abb}$. F 1 abzuleiten ist und die für den Anfangsabschnitt des Bulbus charakteristisch ist. Hier ist bereits ein dünnes Mesokardium gebildet, das später durchreißen wird, wodurch der Bulbus auch in seinem vorderen Abschnitt frei in die Herzbeutelhöhle zu liegen kommt, im Gegensatz zu dem extraperikardial verbleibenden Truncus.

Die aus der ersten soliden Anlage stammende seitliche Kompression des vorderen Bulbusstückes dehnt sich bei den einzelnen Embryonen unseres Stadiums verschieden weit nach hinten aus, fehlt aber bei keinem ganz. Bei einem Teil derselben ist schon ein, wenn auch sehr enges, spaltförmiges Lumen gebildet, bei anderen tritt wenigstens über einige Querschnitte noch eine vollständige Berührung der Seitenwände zutage.

Nach hinten zu öfnet sich der Bulbus allmählich, $\mathrm{Abb}, \mathrm{G} 4$, wobei sein Querschnitt zunächst elliptisch und dann annähernd kreisrund wird. Das sich erweiternde Rohr lenkt, wie das schon am Schluß des vorigen Stadiums der Fall war, etwas nach rechts und bei einigen Embryonen auch deutlich ventral ab, 
wobei das Mesokardium durchtrennt wird. So geht dieser Abschnitt, immer noch ohne irgendwelche Grenze, in den Ventrikelteil über. Bei den älteren Embryonen des Stadiums senkt sich der letztere entsprechend seinem späteren Verhalten noch mexklich weiter und biegt dann nach links ab. So ist in Abb. G 5 das Endothelrohr wieder fast median eingestellt und das myoepikardiale Rohr bereits nach links ausgebogen. Auch gelangen diese beiden Schichten von jetzt ab miteinander in Berürung; am Ventrikel zunächst nur partiell, aber weiter caudal am Vorhof (vgl. $A b b . G 6-8$ ) in gröBerer Ausdehnung. Diese Anlagerung des Endothelrohres ist während aer ganzen späteren Entwicklungszeit charakteristiseh, zuerst für den Vorhof nebst Sinus venosus und später bei Embryonen mit 54 und besonders solchen von 60 Urwirbeln an auch für den Ventrikel, während am Bulbus ein weiter Abstand gegen das myoepiliardiale Rohr dann immer noch beibehalten wird.

Vorhof. Indem der Herzschlauch in unserem Stadium sich noch stärker erweitert, biegt er ziemlich rasch wieder nach aufwarts un und nähert sich damit dem Darm. Seine linkseitige Lage behält er in ausgesprochener Weise bei (Abb. G6). Dann gerit er in den Raum zwischen Darm und dem sich erhebenden Darmrest, wo er zwei Schnitte hinter $A b b, G 7$ an der Darmpforte endet, nachdem er sich abwärts in die beiden Dottervenen $(v d)$ eroffnet hat. Die Abgangsstelle der rechten Dottervene ist in Abb. G 8 zu sehen, während in Abb. $G 9$ die beiden Venen am kranialen Ansehnitt der vorderen Darmnabelwand, also dicht hinter dem Herzen, getroffen sind.

Das in Abb. G 8 durchschnittene hintere Ende des Herzens dürfte schon dem Sinus venos us entsprechen, denn es zeigt zwei Unterscheidungsmerkmale desselben rom Vorhof, die allerdings erst im folgenden Stadium mit fünf Visceraltaschen deutlicher werden: Sein Kaliber nimmt im vertikalen Durchmesser wieder $\mathrm{ab}$, und sein Mesodermmantel wird dicker. Die in ihn einrnündende Ductus Cuvieri sind allerdings erst im nächsten Stadium angelegt.

So sind jetzt alle späteren. Hauptabschnitte des Herzens kenntlich bis einschließlich des Simus venosus. Es kann daher bei der fortschreitenden $\mathrm{Ab}$ schnürung des Darms kein neuer Abschnitt des Herzens durch Verschmelzung paariger Anlagen angebaut werden wie zu Anfang der Herzentwicklung. Schon seit dem vorigen Stadium mit drei Visceraltasehen kann dieser Zuwachs nur ein geringer gewesen sein, denn sehon damals war der Vorhof als unpaares Gefä kenntlich, und er hat seitdem im Gegensatz zu den übrigen Herzabtellungen, insbesondere dem Bulbus, nur wenig an Länge zugenommen. Aber endgültig kommt die Verlängerung durch Versck roelzung paariger Anlagen erst zum Stillstand, wenn im Stadium von 5 Visceraltaschen die ventraie Leberkucht auftritt und sich zwischen die beiderseitigen Venen einschiebt (s. Kap. IV). Wenn trotzdem das hintere Ende des Herzens auch weiter hin fortfahrt, sich nach rückwärts zu verschieben, so ist dies somit jetzt nicht mehr durch eaudalen Anbau neuen Anlagematerials mit bedingt, sondern ausschlieBlich durch das zunehmende Längenwachstum des Pohres, dessen vorderes Ende (Truncus) fixiert ist. Das weitere beträchtliche Längenwachstum des Schlauches wird zwar durch dessen zumehmende Verbiegungen zum größeren Teil, aber doch nicht vollständig ausgeglichen, so daß immer noch eine bemerkenswerte Rückwärtsverlagerung seines caudalen Endes stattfinden muB. 
Da sich in den folgenden Kapiteln kein Anlaß mehr findet. auf die s pätere Entwicklung der VisceralbogengefäBe und des Herzens einzugehen, will ich hier noch ein paar einschlägige Tatsachen zusammenstellen, um der Beschreibung einen gewissen Abschluß zu geben:

Von dem 2. Visceralbogengefä $B$ ist bei Embryonen mit 39 und 41 Rumpfsomiten das kurze dorsale Anlagestück des Rohres noch vom ventralen getrennt, das letztere aber reicht weit nach aufwärts, da es sich mit den im Hyoidbogen entstandenen Endothelräumen vereinigt hat. Bei einem Embryo mit 43 bis 44 Rumptsomiten finde ich zum erstenmal das 2. BogengefäB rom MandibulargefäB bis zur dorsalen Aorta durchlaufend offen.

3. Bogengefä B. Bei einem Embryo mit 41 Rumpfsomiten treten auBer den bisherigen zwei hohlen Endstücken Endothellücken im Visceralbogenmesoderm auf. Bei dem Embryo mit 43-44 Rumpfsomiten sind sie mit dem ventralen Anlagestück konfluiert, und ist das letztere durch eine enge Kommunikationsstelle mit dem dorsalen verbunden. Bei einem Embryo mit 49-50 Rumpfsomiten dagegen ist diese Verbindung noch nicht geöffnet, dies ist erst bei 57 Rumpfsomiten der Fall, womit der 3 . Aortenbogen fertiggestellt erscheint.

4. BogengefäB. Bei einem Embryo von 43-44 Rumpfsomiten ist noch wie zuvor ein kurzes ventrales und ein noch kürzeres dorsales Endstück des Gefäßes offen und mit dem Truncus bzw. der Aorta in Verbindung. Bei 50 Rumpfsomiten dehnt sich das ventrale Anlagestäck ebenso wie bei der 3. Bogenarterie über reichlich $2 / 3$ des Visceralbogens nach aufwärts, ist aber mit der Aortenbucht noch nicht konfluiert. Erst bei einem Embryo mit 57 Rumpfsomiten ist diese Verbindung hergestellt.

5. Bogengefä $B$. Auch hier tritt das HohlgefäB in Form einer getrennten ventralen und dorsalen Anlage auf. Die ventrale ist bei dem Embryo mit 50 Rumpfsomiten ein kurzes Rohr, welches die Truncusmündung der 4. Bogenarterie caudal fortsetzt und sich bald in den zwischen ventraler Darmwand und Herzbeutel aufgetretenen GefäB- and Mesenchymzellen verliert. Es erhebt sich noch nicht in den 5. Visceralbogen. Die dorsale Anlage ist ein hurzes Aortendivertikel, das gegen den 5 . Visceralbogen eine Zellenkette entsendet. Bei 57 Rumptsomiten ist das Ventralstück in den Visceralbogen nach aufwärts vorgedrungen bis zum dorsalen Anlagestück, doch ist die Verbindung beider noch eng und ohne fertige Endothelwand.

6. Bogengefä 3 . Bei dem Embryo mit 50 Rumpfsomiten ist nur das dorsale Anlagestück vorhanden, aber besser entwickelt als dasjenige der 5 . Bogenarterie. Dieser Endabschnitt des 6. Aortenbogens kann sich schon sehr frühzeitig entwickeln. Bei einem viel jüngeren Embryo von ca. 41 Rumpfsomiten ist ex schon. als trichterförmiger Aortenzipfel vorhanden, der sich am caudalen Ende des noch kurzen 6 . Visceralbogens ventral in die einer DarmquergefaBanlage entsprechende subentodermale Zellenkette (S. 47) fortsetzt, ein Verhalten, das für die Ableitung der Visceralbogengefäße von DarmquergefäBen besonders in Betracht kommt. Bei dem Embryo mit 57 Rumpfsomiten ist auBer dem dorsalen auch ein ganz kurzes ventrales Anlagestück eines 6. Aortenbogens gebilctet, welches von dem ventralen Ursprungsstück des 5. Bogens zwischen Herzbeutel und unterer Darmwand ein kurzes Stück caudal verlanft, um sich daselbst im Mesenchym- 
gewebe zn verlieren. Nach aufwärts in den 6 . Visceralbogen dringt es noch nicht vor.

Trotzdem bei dem letztgenannten Embryo ein kurzer 7. Visceralbogen vorhanden ist, fehlt jetzt jede Spur eines 7 . Bogengefäßes.

Aus dieser Zusammenstellung geht hervor, daß die Endothelröhren der drei caudalen Visceralbogengefaßße sich in der gleichen Weise entwickeln wie die des 2. and 3. Bogens, nämlich aus einem kurzen dorsalen Anlagestück. das als Aortenbucht auftritt und einem ventralen, das ebenso von dem Truncus arteriosus (4. BogengefäB) bzw, von den Ursprungsstücken ihrer Vorgänger (5. und 6. VisceralbogengefäB) seinen Ausgang nimmt. Das ventrale dringt dann dorsal in den Visceralbogen nach aufwäts vor, entweder kontinuerlich oder - und das ist zum mindesten beim 2. Aortenbogen der Fall - diskontinuierlich, d. h. unter Vereinigung mit kurz zuvor innerhalb des Visceralbogens entstandenen Endothelräumen. Schließlich vereinigt es sich im dorsalen Viertel des Bogens mit dem dortenstück. Nur das 1. BogengefäB, die Mandibulararterie, macht hiervon eine Ausnahme, insofern seine Lichtung von der Anlage des Kopfsinus aus in ventrocaudaler Richtung gegen den Truncus arteriosus $z u$ entsteht.

Diese Beobachtungen stehen in direktem Widerspruch zu den Angaben Raffaeles (1892), nach welchen die VisceralbogengefäBe bei Torpedo ,weder vom Herzen, noch von den Aorten, sondern unabhängig, in der Nitte des Kiemenbogens entstehen" sollen. Der italienische Autor bezeichnet dieses Verhalten sogar als ein "Gesetz" und legt auf dasselbe aus theoretischen Gründen besonderen Wert, so u. a. deshalb, weil dadurch die Ra bl sche Auffassung von der Entstehung der Endothelien aus Endothelien widerlegt werde. Ich habe hierzu zu bemerken, erstens, daB auch ich beim 2 . Aortenbogen ein selbständiges Auftreten eines Lumens im Visceralbogen beobachtet habe und daß es mich nicht überraschen würde, wenn bei genauer Durchmusterung aller einschlägigen Stadien das gleiche auch beim 3 . bis 6 . Bogengefä $B$ gefunden würde. Aber sicher ist vorher schon ein ventrales und dorsales Anlagestück des Gefäßes vorhanden und dieses hat Raffaele übersehen. Was dann zweitens die Frage der Abstammung der GefäBendothelien anlangt, so kann dieselbe nicht durch das Auftreten eines HohlgefäBes, sondern nur durch die allerdings viel schwieriger zu verfolgende Entstehung der ihr vorangehenden, ,soliden "Anlage, also der GefäBzellen, entischieden werden. Auch diese erfolgt vom ventralen sowie vom dorsalen Lüngsgefäß aus.

Hingegen hat für den 2. Aortenbogen von Pristiurus schon Mollier (1906) den Beginn dex Lumenbildung vom ventralen und rom dorsalen Längsgefäß aus gesehen und als erste Anlage der 3 . Visceralbogenarterie einen ganz kurzen zelligen Ausläufer der ventralen und dorsalen Aorten. -

Was die spätere Entwieklung des Herzens anlangt, so wurde das Verhalten des Endothelrohres zum myoepikardialen Mantel für Sinus venosus, Vorhof und Ventrikel schon oben bis zu Embryonen von 60 Urwirbeln verfolgt. Hier ist nur noch über den $B$ albus nachzutragen, daß sein Endothelrohr auch weiterhin seitlich komprimiert und vom Myoepikardium durch einen Hohlraum abgedrüngt bleibt. Der Zwischenranm füllt sich später mit einem lockeren Gewebe, das die bekannten in das Lumen vorspringenden Balbuswilste bildet, 
aus denen schließlich die Klappenreihen hervorgehen. Auch die besonders starke Verengung des kranialen Endstückes des Bulbus erhält sich lange. Bei einem Embryo mit 54 Lrwirbein und 6 Visceraltaschen und einem solchen mit etwa 70 Urwirbeln traf ich daselbst die beiderseitigen Wände noch in loser Berührung. Bei anderen gleichaltrigen und jüngeren Embryonen waren sie nur durch einen engen Spalt getrent. Erst bei einem Embryo mit 73-74 Urwirbeln fand ich das Lumen erweitert, aber bei einem nur wenig jüngeren Embryo hinwiederum die frühere Enge noch deutlich erhalten.

Der seitlich komprimierte Bulbus der Torpedoembryonen zeigt eine auffallende Ubereinstimmung mit der Form dieses Herzabschnittes bei Neunaugen. Das Rohrstück legt sich hier bei den Embryonen als enger medianer Spalt an, der rechts und links von den Bulbuswülsten umschlossen wird, und dieser Zustand erhält sich durch die Larvenzeit bis zum ausgewachsenen Tier (Vialleto n 1903, Favaro 1913).

Aus der Vergleichung der jüngeren Torpedoembryonen mit den älteren geht. hervor, daß die Kaliberunterschiede der Hauptabteilungen des Herzens schon in dessen frühestem Entwicklungszustand, in welchem die Lumenbildung des Endothelrohres auftritt, präformiert sind. Der Vorhof legt sich von vornherein als weitester Abschnitt an, als etwas engerer der Ventrikel und als engster Teil der Bulbus, namentlich dessen kraniales Endstück, in welchem die Lumenbildung lange Zeit ïberhaupt ausbleibt.

Damit erledigt sich von selbst eine Frage, die von mehreren Untersuchern der Herzentwicklung aufgeworfen und verschieden beantwortet wurde: Eine der auffallendsten Erscheinungen an dew neu gebildeten Endothelrohr ist der beträchtliche Abstand desselben von seiner mesodermalen Hülle, dem späteren Myoepikardium, daher auf den Schnitten der Anschein einer Schrumpfung desselben erweckt wird. Besonders die Betrachtung des vorderen Bulbusstückes. ( $\nabla g l . ~ A b b . G$ 3) ist geeignet, diesen Eindruck zu erwecken. Die Gesamtheit der beschriebenen Entwicklungsvorgänge spricht aber entschieden gegen eine solche Annahme. Die Betrachtung unserer Abbildungen lehrt, daß schon die solide Herzanlage in ihren einzelnen Absehnitten ungleich zellenreich ist. Sie nimmt. von vorn nach hinten an Stärke zu und ihre Umwandlung zum Endothelrohr vollzieht sich sodann (Abb. E) in caudokranialer Richtung. In dieser blaht sich das Rohr ganz allmählich auf und legt sich an die myoepikardiale Wand an, ein Zustand, der in Abb. F und $G$ erst im Sinus- und Vorhofsabschnitt erreicht ist und am Bulbus überhaupt niemals eintritt, weil hier der Zwischenraum später durch das Gewebe der Wülste ausgefült wird. Die frühembryonalen $\mathbf{K}$ aliberunterschiede der einzelnen Herzabteilungen sind also keine zufälligen, wie sie es sein müBten, wenn sie durch ein Artefakt erzeugt wären, sie sind vielmehr durchaus gesetzmäßige und speziell im engen Bulbus auf den Endzustand gerichtete. Jede Abteilung zeigt in frühembryonaler Zeit ihre bestimmte Form und innerhalb gewisser Grenzen ihr bestimmtes Kaliber mit entsprechendem $\mathrm{A}$ bstand von der myoepikardialen Hülle.

Damit soll nicht in Abrede gestellt werden, daB durch Schrumpfen oder Kollabieren der Endothelwand eine noch weiter gehende Verengung des Herzlumens vorgetäuscht werden kann. Ein solches Artefakt wird man z. B. an- 
nehmen müssen, wenn man bei manchen Embryonen, deren Kopfsinus mit Blutzellen erfullt ist, die Seitenwände des vorderen Bulbusabschnittes auf einzelnen Gefäßen in totaler Berührung findet. Hier muß im Leben mindestens soviel Raum frei gewesen sein, als der Durchtritt der Blutzellen erfordert. Und namentlich in noch späterer Zeit, wenn der Kreislauf in vollem Gange ist, wird man dem vorderen Bulbusabschnitt eine besondere Ausdehnungsfähigkeit bei der Systole zusprechen müssen.

Die hier für Torpedo dargelegten Verhältnisse haben, soweit sich aus der vorliegenden Literatur beurtelen lïbt, allgemeine Geltung tür die Wirbeltiere. Ich verweise in dieser Hinsicht auf die Darstellung der Herzentwicklung bei Hochstetter (1906) und vor allem auf die genauen, über die gesamte Wirbeltierreihe sich erstreckenden Untersuchungen Favaros (1913). Eine der ältesten Beobachtungen auf diesem Gebiet stammt wohl von $\mathrm{His}$, der sehon 1868 und 1885 für das Hühnchen und den Menschen den Abstand des Ferzendothels vom Muskelschlauch festgestellt hat. Speziell für den Henschen haben nenerdings Tandler (1911 und 1913) and Mall (1912) diesen Gegenstand behandelt. Aus den Angaben der genannten drei Forscher entrehme ich, daß in den Hauptabteilungen des menschlichen Herzens im wesentlichen das glejche Verhalten zwisehen Endothel- und Muskelrohr besteht, wie ich es in entsprechend alten Stadien von Torpedo fand. Meine Befunde bei Selachiern gehen über die bei den übrigen Wirbeltieren erhobenen insofern hinaus, als sie zeigen, daß die Erscheinung schon in der frühesten Entwicklung, im soliden Zustand des Herzens und bei dessen Umwandlung zum Hohlschlauch, ihren Ausgang nimmt.

Dievordere Dottervene. Wiederintraembryonale Teil des Dotter. venenstammes zu: Seite der vorderen Darmpforte vom caudalen Ende des Herzens zum Dotter herabsteigt, geht aus $\mathrm{Abb}$. $\mathrm{G} 8$ und 9 hervor. Die beiden GefäBstämme sind noch von gleicher Stärke. Thre Ausdehnung an der seitlichen Darmwand erstreckt sich caudal über die Stelle hinaus, an der sie auf den Dotter übertreten. Hier ist inzwischen ein neues Stück an das alte hinten angebaut worden. Die Lage dieses caudalen Stückes am verdünnten ventralen Teil der Darmwand ist die gleiche wie diejenige der GefäBzellen in Abb. 34 des vorigen Stadiums, denn es ist aus diesen Zellen hervorgegangen. Und an diesen neugebildeten Rohrabschnitt schließen sich nach hinten wiederum GefäBzellen an, die einen weiteren caudalen Anbau der Venen vorbereiten.

Der extraembryonale Abschnitt des Dottervenenstammes (Modell der $A b b .3)$ stellt in seinem Verlaufe am vordere $\mathrm{Cölom}$ rand jetzt ein durchlaufendes, meist voluminöses und bluthaltiges Gefäßrohr dar. Während seine aus Zellenketten bestehende erste Anlage oft etwas hinter diesem Colomrand lag, reicht das ausgeweitete Rohr jetzt stets bis dicht an die Grenze gegen die mesodermfreie Zone vor.

Verfolgen wir zuerst den Venenstamm gegen seine Mündung. Von seiner queren, mehr oder minder gebogenen Verlaufsrichtung am vorderen Colomrand wendet er sich, dem Innenrand des nach vorn ausgebuchteten Coloms folgend, nach rückwärts und medial, also in eine direkt zum Herzen führende Richtung. Die beiderseitigen, nach hinten konvergierenden Venen umfassen auf diesem Wege ein dreieckiges Dotterfeld, das sich zwischen den vertieften Bodenflächen der 
beiden Leibeshöhlen plateavartig erhebt. Dieses Dreieck ist das hinten zipfelartig ansgezogene Endstück der mesodermfreien Zone (vgl. Rückert 1921, Abb. 1) und dementsprechend außer vom Ektoderm nur vom Dotterentoderm überkleidet. Gegen seine caudale Ecke zu erhebt sich das Feld stärker, denn hier faltet sich das Entoderm von seiner Dotterunterlage empor und bildet so den Darmrest. Dieser läuft nach vorne zu unmerklich aus, wobei er sich oft in eine linke und rechte meist solide Entodermleiste gabelt, die dann die Seitenränder des nach vorn breiter werdenden Plateaus begrenzen. Somit kommt die in den Seitenrand des Plateaus eingegrabene Dottervene nach hinten zu unmittelbar lateral neben einen Gabelast des Darmrestes zu liegen, falls ein solcher vorhanden ist, und setzt sich dann weiter caudal auf den seitlichen Umfang des ungeteilten Darmrestes fort, an welchem sie schlieBlich zum Venenende des Herzens emporsteigt. Der ganze, am Darmrest entlang ziehende Abschnitt der Vene ist, wie wir gesehen haben, durch die Abschnürung des Embryos vom Dotter entstanden.

Auf der beschriebenen caudomedian verlaufenden Strecke zeigt der Dottervenenstamm weitgehende individuelle Schwankungen in seiner Länge und Richtung, und zwar nicht nur zwischen Embryonen der gleichen Altersstufe, sondern auch zwischen den beiden Seiten des nämlichen Embryos. Dieselben sind, ebenso wie das oben (S. 52) beschriebene weohselnde Verhalten des am vorderen Colomrand verlaufenden Gefapabschnittes, hervorgerufen durch eine entsprechend ungleiche Ausbreitung des Dottercöloms in kraniocaudaler Richtung. Steht der Vorderrand des Cöloms ungewöhnlich weit hinten, dann ist der sagittale, rückläufige Abschnitt des Venenstammes verkürzt und umgekehrt. Am Modell der Abb. 3 reicht, ebenso wie an dem der Abb. 2, die an ihrer grabigen Dottereinbuchtung kenntliche Leibeshöhle mit der ihren Vorderrand umsäumenden Dottervene auf der linken Seite weiter nach vorn als rechts. Das Sagittalstück des linken Venenstammes ist daher länger als das rechte. In einem weiteren sehr ausgesprochenen Fall dieser Art, welcher in der Querschnittserie der Abb. G zu finden war, ist die Asymmetrie eine umgekehrte. Es ragt hier auf der rechten Seite der vordere Cólomrand mit dem von ihm gedeckten queren Dottervenenstiick bis in die Querschnittsebene des 2. Visceralbogens nach vorn, also noch vor Textabb. G 1 und vor das vordere Herzende. Links dagegen taucht dieser Cölomrand erst hinter dem fünften = letzten Visceralbogen zwischen Abb. G 5 u. 6 auf, und das unter ihm gelegene quere Stück der Dottervene erscheint erst an der vorderen Nabelwand bei Abb. G 9. Dieses Gefäß wendet sich daher in seinem weiteren Verlauf überhaupt nicht nach rückwärts wie sonst, sondern biegt umgekehrt, um den Darmrest noch vor der Nabelwand zu erreichen, nach vorne zu diesem ab. In $\mathrm{Abb}, \mathrm{G} 7$ ist es an dessen linker Seite (rechts in der Abbildung) getroffen. Von hier verläuft es dann am Darmrest in der gewöhnlichen Weise - allerdings nur ein kurzes Stück - nach rückwärts, indem es dabei zum Sinus venosus emporsteigt ( $\mathrm{Ab}$. G 8 und 9). Das Gefä $B$ beschreibt also auf seinem Verlauf zum Herzen eine Biegung mit vorderer Konvexitat.

Diese sonderbare Schlingenbildung der nach hinten verlagerten Vene, die bei so außergewöhnlich starker Rückverschiebung des Dottercöloms zutage tritt, kann nur durch die Wirkung der Darmabschnürung erklät werden. Sie bildet 
daher: wenn wir dessen überhaupt noch bedürften, einen greifbaren Beleg dafür, daB ein solcher Vorgang tatsächlich stattgelunden hat.

Der hintere Ast der Dottervene ist nicht zu weiterer Ausbildung gelangt. Es ist aus ihm ein von dem seitlich angrenzenden Netz der Area vasculosa nicht unterscheidbarer geschwungener GefuBzug hervorgegangen, welcher diese Zone gegen den Seitenrand des Dottercöloms abgrenzt. Von ihm sowie vom Stamm der Dottervene, also von der Seite sowohl wie von vorne, sind HohlgefüBe unter das Dottercolom vorgedrungen, durch welche der bisher gefaBlose oder gefäBarme Boden dieses Leibeshöhlenabschnittes sich zu vascularisieren beginnt.

Im Gegensatz zum hinteren hat sich der vordere Ast der Dottervene, der jetzt die einzige Fortsetzung des Stammes darstellt, weiter ausgebildet. Es hat daher keinen Sinn mehr, ihn noch als Ast der Vene zu bezeichnen. Das Gefäßstück zieht am Seitenrand der mesodermfreien Zone nach vorn und zeigt zu dieser Zeit einen auffallend geschwungenen Verlauf durch einzelne in die mesodermIreie Zone vorspringende Bögen und Sprossen. Dies ist besonders am Vorderrand der mesodermfreien Zone der Fall (Abb. 3), so daß hier die beiderseitigen Venen durch einen noch indifferenten Teil des GefäBnetzes der Area vasculosa roneinander getrennt sind, also noch nicht den späteren geschlossenen Ring bilden. Auch am Seitenrand der mesodermfreien Zone haben sich die Dotterrenen noch nicht vollständig aus dem Netz herausdifferenziert. Es gilt dies nicht sowohl für das rechte GefäB, das bis auf eine einzige dünne Stelle sich durch sein Kaliber schon deutlich aus dem übrigen Netz heraushebt, wohl aber für das linke.

Es geht aus dieser Darstellung hervor, daß der innere Gefäßring der Torpedokeimscheibe ebenso, wie das äußere Pinggefäß (S. 26), sich aus den das Netz der Area vasculosa abschließenden Randschlingen und -sprossen herausdifferenziert. $\mathrm{Ob}$ dies nur durch Streckung und Ausweitung der einzelnen Schlingen geschieht, wie beim äußeren Ringgefä $B$ oder ob daneben auch eine Verschmelzung einzelner Netzteile zu Hilfe kommt, ließ sich nicht entscheiden.

Die beiden primären venösen Abzugsbahnen der GefäBrone des Dotters, der äußere Venenring und der zur Zeit noch nicht geschlossene innere GefaBring entstehen also nicht etwa dadurch, daB eine solche GefäBanlage von irgendeinem zuerst entstandenen Abschnitt aus in der Richtung ihres späteren Verlaufes auswächst, sei es Ton der Peripherie aus gegen den Embryo oder umgekehrt, sondern sie bilden sich durch Vereinigung von lokal nebeneinander auf dem Dotter entstandenen Bestandteilen der Area vasculosa. Der den Ring mit dem Embryo verbindende Stamm (hintere Dottervene, Stamm der vorderen Dottervene) entsteht dagegen unabhängig von den Randschlingen des Tetzes, aber ebenfalls in loco auf dem Dotter.

Im weiteren Verlauf vereinigen sich die noch getrennten worderen Enden der beiden Dottervenen miteinander im Bogen am vorderen Rand der mesodermfreien Zone, so daß ein die Area vasculosa vollständig abschließendes in neres RinggefäB gebildet wird. Ich habe diesen geschlossenen inneren Venenring im

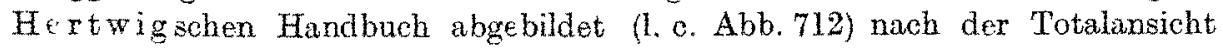
einer aufgehellten Keimscheibe, ron welcher der Dottex abgepinselt war und habe ihn neuerdings an den Quersehnittserien von 2 Keimseheiben des Stadiums der 
Abb. 3 wieder verfolgt. (Ruckert 1921, S. 208.) In der vorliegenden Arbeis ist der Ping erst für den jüngsten Embryo des nächstfolgenden Stadiums (Modell der Abb.4) dargestellt. Hier ist er durch sekundäre Eröffnung der rechten Dottervene in die Aorta bereits arteriell geworden, wenn die neue Verbindung auch noch eng ist (s. Kap. IV).

Literatur: Uber die vorderen Dottervenen des Selachierblastoderms und deren Entwicklung ist außer einigen Angaben, die ich gelegentlich in anderen Arbeiten gemacht habe (1906 und 1921) nichts bekannt.

Es soll nun zum Schluß das Längenwachstum des Herzens und des über ihm gelegenen Darm- und Kopfabschnittes für die bisherige Entwicklungszeit betrachtet werden. Wahrend in unserem Ausgangsstadium (Abb. 17-19), in welchem der Hinterkopf sich vom Dotter noch nicht abgeschnürt hatte, die paarige Herzzellengruppe nur die halbe Länge besaß wie der davor gelegene Kopfabschnit, weist im Stadium von vier Visceraltaschen das Herz einschließlich Truncus arteriosus fast die gleiche Länge auf wie jene vordere Koptregion. Ein entsprechendes Verhältnis ergibt sich auch, wenn man den im Bereich des Herzens gelegenen Darmabschnitt mit dem davor befindlichen vergleicht. Es geht darans hervor, daß das auf die zuerst auftretende Kiementaschenbuch $t^{1}$ ) folgende Kiemendarmstück ebenso wie das ihm anhaftende Herz relativ, d. h. im Verhaltnis zum übrigen Kopf, betrachtich an Liange zugenommen hat.

Wenn man nun verfolgt hat, wie die Abschnür ung des Darms vom Dotter eine Verlängerung des Herzens und Kopfdarms nach hinten bedingt, so wird man zunächat geneigt sein, in dieser caudal fortschreitenden Abnabelung die einzige Ursache für diese auffallende Längenzunahme zu suchen. Diese Annahone wäre aber nicht richtig. Es muß vielmehr die Tatsache auffallen, daß der bei der Abschnürung auf dem Dotter zurückbleibende Darmrest mit dieser Verlängerung nicht gleichen Schritt hält, was er doch müßte, wenn die Längenzunahme des Kopfes nur durch die Abnabelung bedingt wäre. Einige Daten mögen dies belegen. In unserem zweitjungsten Stadium, dem der $\mathrm{Abb}$. 23, beginnt der Darmrest als solide Leiste unterhalb der 2. Visceraltasche, in unserem SchluBstadium dagesen bei dem einen Embryo unterhalb, bei dem anderen erst hinter der 4 . Visceraltasche und in dem später zu schildernden Stadium von fünf Visceraltaschen hinter der fünften. Es geht daraus hervor, daß der sich abschnürende Kiemendarm durch beträchtliches Eigenwachstum sich über den auf dem Dotter zurückbleibenden Darmest nach vorn verlängert, and zwar in der Weise, daB am jeweiligen caudalen Ende dieses Darmstückes neues Material angebaut und dadurch der davor gelegene Abschnitt vorgeschoben wird. Letztere Verschiebung macht das Herz, dessen Truncusende dem Kiemendarm anhaftet, mit. Später genügt dann die Längenzunahme des Darmstückes dem noch stärkeren. Wachstumsdrang des Herzens bekanntlich nicht, der Herzschlauch beginnt sich zu falten. Dabei bleibt ûbrigens das Längenwachstum des Kiemendarms immer noch hinter dem des Neuralrohres zurück, wie sich nicht nur aus der Krümmung des letzteren, sondem besonders deutlich aus der Konvergenzstellung der Visceraltaschenand -bogen nach der ventralen Seite za ersehen läBt.

1) Diese exste Bucht umfaßt das Gebiet der 1. und vielleicht noch dar 2. definitiven Fisceraltasche. 
Man könnte gegen das Vorgetragene einwenden, daß das vordere Ende des Darmrestes keine sichere Marke abgibt für die Stelle, an welcher die Abnabelung zuerst eingesetzt hat, denn diese nach vorn auslaufende Entodermfalte könnte an ihrem vorderen Ende, etwa durch Zug des sich verbreiternden Blastoderms. zum Verstreichen gebracht werden. Aber dann sind doch immer noch die zu beiden Seiten des Darmrestes zur Darmpforte rückläufigen Dottervenenabschnitte vorhanden, die in loco erhalten bleiben ${ }^{1}$ ). Sie liefern einen ganz einwandfreien Gradmesser für die erfolgte Abnabelungsstrecke insofern, als die letztere unter keinen Cmstünden länger sein kann als der rückläufige GefäBabschnitt. Das genügt abex für die Beurteilung, denn das Venenstück wird im Einzelfalle verschieden lang gefunden, aber niemals so ausgedehnt, daß man die Verlängerung des Kiemendarms mit der tatsächlich stattfindenden Abschnürung des Kopfes vom Dotter allein erklären könnte.

\section{Zusammentassung.}

\section{Herz nebst Mandibulararterien und intraembryonalem Inteil der vorderen Dottervenen.}

Die erste Anlage des Herzens tritt auf bei Torpedoembryonen mit 13 bis 14 Urwirbeln und einer einzigen Kiemenbucht in Gestalt einer Anzahl ron kleinen, meist abgeflachten Zellen, die, zwischen dem Entoderm und dem Visceralblatt der Perikardialhöhle eingezwängt, zu beiden Seiten der vorderen Darrapforte liegen in der Höhe einer Horizontalebéne, an welcher später die Abschnürung des Darms vorn Dotter erfolgen wird (Abb. 18).

Diese Herzzellengruppe setzt sich einerseits nach vorne auf den frei über dem Dotter gelegenen Absehnitt des Kopfes fort, wo sie seitlich am ventralen Darmumfang, gedeckt von dem ventralen Ende der Seitenplatten (Abb. 17). zellenärmer werdend, sich allmählich im Mesoderm verliert. Dieser Teil der Anlage stellt den caudalen Abschnitt der Mandibulararterien (ersten Aortenbogenpaares) vor.

Andererseits senkt sich die Herzanlage an ihrem caudalen Ende zu beiden Seiten des Darms hinab zum Dotter, gedeckt von der hier gleichfalls zum Dotter herabreichenden Perikardialhöle (Abb. 19). Aus diesen ebenfalls zellenärmeren Teil der Anlage gehen die, das Herz caudal fortsetzenden vorderen Dottervenen hervor, und zwar die intraembryonal gelegenen Stam mteile dieser Getaße.

So tritt das Herz z us m men mit dem angrenzenden Teil der Mandibular. arterien und dem Stam der Dotterrenen als eine einheitliche durchweg parige Anlage auf. Die lokale Entstehung derselben durch Abspaltung der Zellen aus dem visceralen Mesoderm laBt sich zu dieser Zeit noch feststellen. Fur eine Einwanderung derselben vom Dotter kann dagegen keine Beobachtung angeführt werden.

1) Eine Verkürzung des rückdäufigen Venenstückes wäre nur in der Weise denkbar, daB der peripher angrenzende, am vorderen Colomrand entlang verlaufende CrefäBabschnitt zarückverlagert würde. Diese Verschiebung müBte jedoch der Colomrand, da an ihm die Vene stets vorgefunden wird, mitmachen. Eine solche gleichzeitige und gleichmäßige Rückwanderung der beiden Gebilde wäro aber eine absurde Annahne.

Zeitschr. Q. d. gos Anat. I. Abt. Bd. 6 . 
Bei Embryonen mit zwei getrennten Visceraltaschen und $16-18 \mathrm{Cr}$ wirbeln ist der anfänglich paarige GefäBzellenstrang in seinem mittleren für den Truncus arteriosus und das Ferz bestimmten Abschnitt durch mediane Verschmelaung umpar geworlen. Die Vereinigung ist vorne, in dem uber die Nabelwand frei hina usragenden Teil des Kopfes (Abb. 27), dadurch zustande gekommen, daß die beiderseitigen Gefäßanlagen nebst den zur Perikardialhöhle sich vereinigenden Seitenplatten an die Mitte der ventralen Darmwand herangerückt sind, vielleicht unter weiterer Abspaltung von Zellenmaterial aus dem visceralen Mesoderm. Dieses Stück des unpaaren Zellenstranges wird, wie schon jetzt ans seiner flachen Beschaffenheit ersichtlich ist, zum Truncus arteriosus, und zwar zu dessen längerem, vorderem Abschnitt. Es ist dies der einzige Teil der gesamten Anlage, für dessen Entstehung ein Zuschuß von Entodermzellen aus der ventralen Darmwand evtl. in Betracht kommen könnte.

Der caudal folgende Teil der Anlage wird dadurch unpaar, da $B$ der hier mit dem Dotter verbundene Darm sich ron dieser seiner Cnterlage gleich nach dem ersten Auftreten der Herzzellen in kraniocaudaler Richtung abzuschnüren beginnt. So kommen die beiderseitigen GefäBzellen ventral vom abgetrennten Darm, zwischen ihm und einem auf dem Dotter zurückbleibenden Rest desselben, dem , vorderen Darmrest", zur Vereinigung. Auf diese Weise entsteht die unpaare Anlage für einen kurzen hinteren Abschnitt des Truncus (Abb. 23) und für das gesamte Herz. Die eigentliche Herzanlage unterscheidet sich von der Truncusanlage durch die stärkere Ausclehnung ihres dorsoventralen Durchmessers und durch die größere Anzahl sowie die weniger dichte Lagerung ihrer Zellen.

Der rostrale Endabschnitt der Gesamtanlage behält seine paarige Beschaffenheit bei und liefert die Mandibulararterien. Seine nach vorne zu sehr spärlich werdenden GefäBzellen lassen sich jetzt, vielfach im Austritt aus den Seitenplatten begriffen, bis zum vorderen Ende des Darms verfolgen, wo sie mit schon vorher aufgetretenen, den Kopfsimus vorbereitenden Elementen zusammentreffen. So kann man nunmehr auch von einer durchlaufenden, wenn auch streckenweise sehr zellenarmen, ,soliden" Anlage der Mandibulararterien sprechen.

Auch der caudale Endabschnitt der Gesamtanlage ist paarig geblieben, weil in seinem Bereich der Darm sich noch nicht vom Dotter abgetrennt hat. Er besteht aus einer wieder dünneren Zellenschicht, die zu beiden Seiten der vorderen Darmnabelwand liegt, diese caudal etwas überragt, dabei spärlicher wird und sich nach hinten zu bald in ihrem Mutterboden, den visceralen Seitenplatten verliert. Diese Anlage ist noch in caudaler Ausbreitung begriffen durch Anbau neuen Zellenmaterials an ihrem hinteren Ende. Sie wird später beim Weitergreifen der Darmabschnürung unter medianer Verschmelzung noch dem Herzen einverleibt, während ihre ventrale Fortsetzung auf den Dotter die Verbindung mit letzterem aufrechterhält als Anlage des intraembryonalen Stückes der vorderen Dottervenen.

Im Gefolge der candal fortschreitenden Darmabschnürung kommen die beiderseitigen Perikardialhöhlen nun auch ventral von der eigentlichen Herzanlage, $z$ wischen dieser und dem Darmrest, zur medianen Vereinigung ( $\mathrm{Abb} .32$ ), so daB 
das Herz jetzt, vom visceralen Perikardium wie von einem Beutel umhüllt, frei in die Perikardialhöle nach abwärts vorragt. Die caudal sich vorschiebende Verschmelzung der beiderseitigen Leibeshöhlen trennt zugleich die auf dem Darmrest herabsteigenden Zellenketten der Dottervenenstämme von der Herzzellengruppe $a b$, wodurch die Abgangsstelle der Dottervenenanlagen vom Herzen sehrittweise nach hinten verlagert wird. Die beiden Dottervenenstämme verlaufen infolgedessen nun nicht mehr senkrecht zum Dotter nach abwärts, sondern in einem vom konkaven Bogen, indem sie am seitlichen Umfang des infolge der Darmabschnürung nach vome schräg abfallenden Darmrestes (Abb. 32) dem Dotter zustreben.

Diese letzteren Umgestaltungen sind zu Beginn des Stadiums ron drei Visceraltaschen bereits kenntlich. Im Verlauf dieses Stadiums, d. h. während der Fertigstellung der dritten Visceraltasche (Embryonen von $21-29$ Lrwirbein und bis zu 23 Rumpfsegmenten), wandelt sich die Anlage in ein Endothel. rohr um.

In den Mandibulararterien tritt das Lumen selbständig auf. Es erscheint zuerst in deren vorderen (dorsalen) Endstücken in Verbindung mit der Entstehung des Kopfsinus, wird hier bald ziemlich weit und breitet sioh, erheblich enger werdend, nach hinten bis zur Abgangsstelle der späteren 2. Aortenbogen aus.

Gleichzeitig geht die Bildung des Endothelrohres im Bereich des Herzens vor sich. Die solide Anlage wird zunächst infolge Längenwachstums erheblich dünner (auf den Querschnitten zellenärmer) und lockert sich, besonders in dem caudalen, zellenreicheren Abschnitt auf, so daß man hier von einem mesenchy. matösen Zwischenstadium sprechen kann, das ich für Pristiurus schon vor längerer Zeit (Rückert 1889, S. 392) beschrieben habe. Durch Zusammen. fließen der Mesenchymlücken entsteht daselbst das Lumen. Dieses tritt in der ganzen Ausdehnung des Herzens mit Ausnahme eines vorderen Bulbusabschnittes nahezu gleichzeitig auf (Abb. E und F). Am ausgedehntesten erscheint es ron Anfang an im Atrium, am engsten in dem seitlich komprimierten Bulbus, so daß man im allgemeinen sagen kann, daß es sich in caudokranialer Richtung, also umgekehrt wie in den Mandibulararterien, ausbilde. Es lassen sich noch vor dem Auftreten der Krümmungen, schon zu Beginn der Lumenbildung, Atrium, Ventrikel und Bulbus durch Kaliber und Form voneinander und vom Truncus unterscheiden, wenn auch noch lange nicht gegeneinander abgrenzen. Der Bulbus selbst ist sogar schon in der fruhen soliden Anlage als solcher zu identifizieren.

Wiederum gleichzeitig mit dem Herzen höhlen sich die intraembryonalen Dottervenenstämme, doch dringt das Lumen nicht von letzteren in das Herz vor, es erscheint vielmehr selbständig im Vorhofsgebiet dicht vor der Abgangsstelle der Dottervenen.

Im Stadium von vier Visceraltaschen (28--30 Rumpfsegmenten) ist das Endothelrohr der gesamten ventralen GefäBanlage des Kopfes durchlaufend hergestellt ( $A b b . G)$. Ein vorderer Abschnitt des Bulbus ist noch stark seitlich komprimiert (Abb. G 3), sehr eng und bei einem Teil der Embryonen sogar noch geschlossen. Die Verengung dieses rostralen Herzabschnittes erhalt sich bis in jene alten Stadien, in welchen Mesenchym zwischen dem Endothelrohr 
und dem visceralen Perikardialblatt behufs Bildung der Bulbuswülste ausgeschieden wird. Sie ist also in der ersten Anlage des Abschnittes begründet; dessen Lumenbildung von Anfang an im Rückstand bleibt. Auch die anfängliche Trennung des caudal bis zum Vorhof folgenden Endothelrohrabschnittes rom myoepikardialen Mantel durch einen mit Flüssigkeit gefüllten weiten Spaltraum ist kein Artefakt, sondern durch die erste Entwicklung des Rohres bedingt. Sie verschwindet allmählich in caudokranialer Richtung durch Anlagerung des Endothelschlauches an den Mantel. Im Stadium von vier Visceraltaschen lät wich der zuletzt entstandene Sinus venosus (Abb. G 8) vom Forhof unterscheiden.

Von der Zeit der beginnenden Lumenbildung an, also yom Stadium ron crei Visceraltaschen und 23 Urwirbeln, erfärt die Herzanlage durch die caudal fortschreitende Darmabschnürung nurmehr einen mäBigen Zuwachs durch Anbau an ibrem eaudalen Ende mittels Verschmelzung einer paarigen Gefabanlage. was schon daraus hervorgeht, daß zu dieser Zeit bereits das Atrium am caudalen Ende kenntlich ist. Die erhebliche Verlängerung des Herzens, die auch von da ab noch statthat, kommt großenteils durch Eigenwachstum desselben zustande unter gleichzeitiger Verringerung seiner Zellenmasse auf dem Querschnitt. Dieses Längenwachstum geht mit einem solchen des Kiemendarms unter Neubildung caudaler Kiemenbogen einher.

Die VisceralbogengefäBe 2-6.

Die auf die Mandibulararterien folgenden BogengefäBe treten, entsprechend der Entwicklung des Kiemendarms, in caudaler Richtung nacheinander auf. Ihre Fertigstellung zu durchlaufenden HohlgefäBen erstreckt sich daher auf einen langen Zeitraum, weit über die vorliegende Entwicklungsperiode hinaus.

Thre erste Anlage besteht aus Gefäbellenketten, die von der noch soliden tnlage des ventralen LängsgefäBes an der seitlichen Darmwand zu der ebenfalls noch soliden Aortenanlage emporsteigen ( $A b b .31$ ). Die Zellen liegen, im Gegensatz zu den späteren Hohlgefäßen, dem Entoderm unmittelbar auf, in dem engen Spaltraum zwischen diesem Blatt und dem mittleren. An günstigen Stellen laßßt sich ein Austritt dieser. Elemente aus dem Mesoderm verfolgen. Thre Ausbreitung geht in ventrodorsaler Richtung vor sich. Wie es scheint, entstehen aber die dorsalen, an die soliden Aortenanlagen angrenzenden Zellen in Verbindung mit diesen, also selbständig. An den später erscheinenden hinteren Bogengefảßen jedenfalls treten sie deutlich als ventrale Fortsïtze der hier längst hohl gewordenen Aorten auf.

Diese zwischen Darmwand und Nesoderm vom ventralen zurn dorsalen Längsgefüß ziehenden ersten Anlagen der VisceralbogengefäBe gleichen in jeder Hinsicht den erstea, noch nicht gehöhten Anlagen der Darmquergefa $B e$ des $R$ u m p fes, mit denen sie durch vorgängliche, zwischen dem letzten Visceralbogen und der Vomierenregion auftretende Quergetäßzellen auch rïumlich verbunden sind. Man ist daher. auf Grund ihres frïhembryonalen Verhaltens berechtigt, die VisceralbogengefäBe als homodynam mit den Darm. quergefäBen des Rumpfes zu betrachten.

Später, wenn die VisceralbogengefäBe hohl werden, tritt ihre Entstehung 
aus zwei Anlagestücken scharf hervor, einem kurzen dorsalen, von der Aorta zipfelartig ausgezogenen und einem ventralen, vom Truncus (Abb. $G 1$ und 2) bzw. der Mandibulararterie ebenfalls trichterförmig sich ausziehenden Abschnitt, die sich sekundär ineinander eröffnen. Die Lumenbildung in dem weitaus längeren ventralen Stück kann auch (ob stets?) diskontinuierlich in die dorsale Hälfte cles Visceralbogens hinein sich ausbreiten.

\section{Die vorderen Dottervenen.}

An der paarigen vorderen Dottervene sind zwei Hauptabschnitte zu unterscheiden, ein intraembryonaler und ein extraembryonaler.

Der intraembryonale Abschnitt, zu Anfang die einzige caudale Fortsetzung des Herzens, wurde oben zusammen mit der Entwicklung des Herzens bebandelt.

In ihrem extraembryonalen Abschnitt verlaufen die beiden Dottervenen, wenn sie ausgebildet sind (Modell Abb. 3), dem Rande der mesorlermfreien Zone entlang. Topographisch kann man an ihnen im Interesse der Beschreibung folgende Abteilungen trennen:

1. Ein die intraembryonale Vene unmittelbar fortsetzendes Stück, das vom Embryo aus in einem nach vorn konvexen Bogen lateral zieht, wwischen dem Hinterrand der mesodermfreien Zone und dem nach rückwärts angrenzenden Dottercölom, einem vom axialen Mesoderm stammenden, blasig aufgetriebenen Leibeshöhlenabschnitt, welcher das Cölom des Embryonalkörpers seitlich auf den Dotter fortsetzt. Dieser Venenabschnitt reicht peripher bis an die Grenze zwischen dem Dottercölom und der aus dem peripheren Mesoderm entstandenen Gefaßzone heran. Tch rechne ihn noch zum Stam der vorderen Dotter. vene, der somit in einen intraembryonalen (s. oben) und einen extraembryonalen Abschnitt zerfallt.

2. Die Fortsetzung des Stammes, die zwischen den Seitenrand des mesodermfreien Feldes und der vorderen GefäBzone nach vorne verläuft. Man darf diesen Abschnitt mit Rücksicht auf einen früheren Entwicklungszustand der Vene als Whren vorderen Ast bezeichnen, deun es kommt in den ersten Entwicklungsstadien des Gefäßes

3. die vergängliche Anlage eines $z$ weiten, hinteren Astes zum Vorsehein, der den Stamm an derselben Stelle verläßt wie der vordere Ast, aber von da am lateralen Umfang des Cöloms, zwischen diesem und der hinteren Gefäßzone über ein mehr oder minder langes Stïck nach hinten zieht und dabei sich in Seitenzweige verliert.

Die Entwieklungderextraembryonalen Dottervene beginnt gleichzeitig mit derjenigen des Herzens, also im Stadium der ersten Kiemenbuoht in Form von platten Gefäßzellen (Abb. $19 v d^{\prime}$ ), welche in dem Spaltraum zwischen dem vorderen Rand des erst in Eröffnung begriffenen Dottercöloms und dem darunter gelegenen Dotterentoderm liegen. Seitlich vom Embryo stellt diese früheste Anlage des Dottervenenstammes eine zusammenhängende Zellenkette dar, welche mit derjenigen des intraembryonalen Venenabschnittes verbunden ist ( $v d$ und $v d^{\prime}$ in $A b b .19$ ), weiter lateral besteht sie noch aus ganz vereinzelten Zellen. Aus dem primären Zusammenhang dieser Gefäßanlage mit 
derjenigen des Erabryo darf man nicht den Schluß eines Einwachsens der Gefäßzellen vom Dotter in den Embryo ziehen. es liegt vielmehr auch hier eine lokale Abspaltung der Gefaßzellen vor. die zudem an dieser Stelle nicht einmal vom Dotter auf den Embryo, sondern eher in umgekehrter Richtung fortschreiten dürfte. Das Auftreten dieser Zellen auf dem Dotter geschieht in Verbindung mit dem Entoderm, wie denn dieses Keimblatt neben dem mittleren für die Bildung aller DottergefäBe gegenüber der rein mesodermalen GefäBentwicklung im Eimbryonalkörper eine hervorstechende Rolle spielt.

An der Stelle des rorderen Astes der Dottervene sind zu dieser Zeit nur ganz vereinzelte GefäBzellen nachweisbar, an Stelle des hinteren Astes Gefäßzellenzüge, die über längere Strecken durchlaufen.

Im Stadium von zwei Visceraltaschen sind im Gegensatz zu dem noch durchweg soliden Herzen an der zellenreicher gewordenen Venenanlage, und zwar im Bereich threr zwei Aste, also in ihrem peripheren, an die Area vasculosa angrenzenden Abschnitt, schon stellenweise Endotheiröhrchen aufgetreten, namentlich im Gebiet des hinteren Astes. Es eilen ja auch hinsichtlich der Lumenbildung die GefäBe des Dotters denen des Embryonalkörpers voran.

Die eigentliche Umgestaltung zum Hohlgefä $B$ erfahrt die Dottervene erst während des Stadiums von drei Visceraltaschen, in welchen, allerdings hinter ihr zurückbleibend, anch das Herz und der intraembryonale Venenabschnitt ein Lumen erhalten. Man erkennt jetzt (Modell Abb. 2), daB die Vene aus einer Anzahl getrenter Stücke sich bildet, welche im Bereich ihrer an die Area vasculosa grenzenden beiden Aste nichts anderes sind, als die innersten Endothelräume des in Ausbildung begriffenen GefäBnetzes dieser Zone.

Im Stadium von vier Visceraltaschen (Modell Abb. 3) ist der Stamm der Vene durchlaufend und weit und schon mit Blut gefüllt. Der hintere Ast ist aufgelöst, der vordere, jetzt die einzige Fortsetzung des Stammes, zeigt einen stark geschwungenen Verlauf und noch einige Unterbrechungen, denn er besteht aus den inneren Randschlingen der vorderen Gefäbzone. Er ist also im Prinzip ebenso entstanden wie das äußere Ringgefäß, das sich aus den peripheren Randschlingen der Area vasculosa gebildet hat (Kap. I).

Die Fenenanlage wächst also nicht in einer bestimmten Richtung: weder vom Dotter auf den Embryo zu noch umgekehrt aus, sondern entsteht an Ort und Stelle.

Gegen Ende des Stadiums von vier Visceraltaschen haben sich die vorderen Enden der beiderseitigen Venen am vorderen Rande der mesodermfreien Zone zu einem Ringgefä. das jetzt keine Unterbrechungen mehr aufweist, vereinigt.

Zu Beginn des Stadiums von fün $V$ isceraltaschen ist durch die inzwischen erfolgte Eroffnung des rechten Venenstammes in die Aorta das in nere Ringgeia B ateriell geworden. Diese Entwicklung soll in einem späteren Abschnitt dargestellt werden.

Inzwischen ist der anfangs gefäBlose Boden des Dottercöloms von den umgebenden Dottergebieten, d. h. vom Stamm der Dottervene und von der Stelle des ehemaligen hinteren Astes und dessen Zweigen aus, vascularisiert worden.

Auch aus der Entwicklungsweise der vorderen Dottervenen geht die allgemein gilitige Tatsache hervor, daß die Entstehung der Gefaßanlagen auf dem. 
Dotter sich streng an die Ausbreitung des mittleren Keimblattes halt. Trotz der zweifellosen Beteiligung des Entoderms an dex Bildung der bluthaltigen wie der blutleeren DottergefäBe ist die Anwesenheit des Mesoderms bei diesem Entwicklungstorgang unerläBlich.

Kapitel III.

\section{Die Entwicklung der Parintestinalvene des Embryonalkörpers und der Darmquergefïle.}

\section{In Forderrumpl d. h. zwischen vorderer und hinterer Darmpiorte ${ }^{1}$ ).}

In dem Stadium von vier geschlossenen Visceraltaschen (Modell der Abb. 3), mit welchem die bisherige Beschreibung im wesentlichen abgeschlossen wurde, ist ein weites renöses LängsgefäB sowohl im vorderen als im hinteren Abschnitt des Embryonalkörpers vorhanden (Abb. oll). Das vordere ist das Herz, das hintere ist die Subintestinalvene, we'che, etwas vor der hinteren Darmpforte, beginnt und sich bis zur Afterbucht fortsetzt.

Im sehroffen Gegensatz zu diesen vom Dotter abgetrennten Endstücken des Embryo steht sein mitterer mit dem Dotter noch verbundener Abschnitt, also die Strecke zwischen den beiden Darmpforten. Diese entbehrt zur Zeit noch einer durchlaufenden Verbindungsbahn. Doch ist die Anlage einer solchen, wie das Modell der Abb. 51 zeigt, schon vorhanden, und zwar auf beiden Seiten des Embryo. Sie besteht bei den einzelnen Embryonen des Stadiums aus längeren oder kürzeren Rohrabschnitten, die durch gefäBlose, aber mit GefäBzellen versehene Strecken (punktiert in Abb.5l) getrennt sind. Diese das Herz caudal fortsetzende, den Darm seitlich begleitende venöse Längsbahn des Embryo. nalkörpers bezeichne ich als Vena parintestinalis des Embryos oder kurzweg Parintestinalvene.

Es soll nun das Auftreten dieser Venenanlage an der Hand der bisher beschriebenen Entwicklungsstadien dargestellt werden.

a) Stadium der ersten Visceraltasche.

Bei Embryonen dieser Altersstufe ist noch keine Spur einer Anlage der Parintestinalis zu finden. In dem ganzen Gebiet von den Herzzellen an nach rückwärts bis zu den Mesodermverdichtungen der zukünftigen Vena subintestinalis sind, Ton ein par vereinzelten Ausnahmen abgesehen, noch keine Gefäßzellen an der Wand des hier mit dem Dotter verbundenen Darmes aufzufinden.

b) Stadium von zwei Visceraltaschen.

$\mathrm{Zu}$ Beginn dieses Stadiums, bei einem Embryo von 16 Trwirbeln (Modell tbb. 1) und einem solchen ron 18 Urwirbeln, findet sich der Spaltraum zwischen dem risceralen Mesoderm und dem Entoderm von GefäBzellen belebt. Im grö. Beren vorderen Abschnitt der zwischen den Darmpforten gelegenen Strecke sind sie jedoch in nur sehr geringer Zahl vorhanden, spärlicher als die auf einem

1) Jfit der kurzen Bezeichnung Vordermumpf belege ich hier die, im Verlaufe der Entwicklung sich ständig verkzirzende Strecke des mit dem Dotter verbundenen Rumpfes. Mit Hinterrumpf die Strecke von der hinteren Darmpforte bis zur Kloalse (After). 
viel kleineren Raum des Querschnittes angewiesenen Aortenzellen, die zu dieser Zeit ebenfalls auftreten. Im caudalen Teil des Gebietes, in welchem die Bildung der Aortenzellen noch aussteht, trifft man die Zellen an der seitlichen Darmwand in etwas größerer Zahl an, und zwar um so mehr, je näher man der zellenreichen Anlage der Subintestinalvene des Hinterrumpfes kommt. Ein Teil dieser GefäBzellen ist im Austritt aus dem visceralen Mesoderm begriffen, ob sie aber alle diese lokale Entstehung nehmen oder ob nicht ein Teil derselben, namentlich die mehr ventral gelegenen, row Dotter eingewandert sind, mub unentschieden bleiben. Der ventrale zum Dotter herabtretende Abschnitt der seitlichen Darmwandung ist dünn ausgezogen, ein Umstand, der die Entscheidung der Frage, ob GefäBzellen von ihm sich abspalten, sehr erschwert.

\section{c) Stadium von drei Visceraltaschen.}

Der jüngste der Embryonen mit drei Visceraltaschen, deren dritte noch eine flache Bucht bildet, und mit 21 Urwirbeln (Modell der $A b b .2$ ) zeigt noch das gleiche primitive Verhalten im Gebiet der späteren Parintestinalvene, wie der zuvor beschriebene, obwohl bei ihm das Herz schon zellenreich und mesenchymatös und die Subintestinalis des Hinterrumpfes schon in Höhlung begriffen ist. Die Gefäßzellen zwischen den beiden Darmpforten sind hier auf der rechten Seite zufällig sogar noch spärlicher als bei dem jüngeren Embryo der Abb. 1. Hinten gegen die Subintestinalvene zu, wo die GefüBzellen dichter liegen als weiter vorn, ist aber rechts an zwei Stellen schon ein kurzes Endothelröhrchen gebildet.

Eine zusammenhängende, wenn auch noch kurze Anlage der Parintestinalis fand ich zum erstenmal bei einem Embryo mit 26 Trwirbeln and 20 Rumpfsegmenten. Hier zeigen die Gefäßzellen der Darmwand in der Gegend k ranial von der Vorniere noch das bisherige Verhalten. Obwohl die torten daselbst schon als paarige Hohlgefäße angelegt sind, findet man unterhalb derselben an der seitlichen Darmwand nur ganz vereinzelte Gefäßzellen.

Es folgt dann caudal die bereits kenntliche Vor nierenanlage (vn Abb. 35). Diese hat links schon ihre definitive Ausdehnung über sechs Segmente erlangt. Auf dieser Strecke treten an der Darmwand die GefäBzellen schon etwas zahlreicher auf. Ein Zellenpaar, welches seiner Lage nach als Parintestinalvene angesprochen werden darf, ist in Abb. 35 auf der linken Seite des Embryos (rechts im Bild) zu sehen. Auf der rechten Seite entsprechen ihr ein paar Zellen, die noch im Verband mit dem Mesoderm stehen. Die Zellengruppe liegt, wie aus der Abbildung ersichtlich, ungefähr in der mittleren Höhe des offenen Darmquersehnittes, jedoch auch darüber und darunter. Im Bereich der Vorniere liegt sie rechts etwas höher als links. Ganz vereinzelt, einmal rechts und einmal links auf einem Querschnitt, hat sich die GefäBzelle schon zu einem engen Endothelröhrchen gekrümmt.

Oberhalb der beschriebenen Anlage erscheinen jetzt abgeflachte Zellen, die sich von der Aorta zu den Parintestinalzellen herabriehen ( $q 9$ in Abb. 35). Es sind dies die Vorläufer der späteren Verbindungszüge beider GefäBe, der QuergefäBe. Die Herkunft dieser Zellen aus dem angrenzenden Mesoderm laßt sich leichter feststellen als die der ventral folgenden, weil sie aus einem dickeren Mesodermabschnitt ihren Ursprung nehmen. Die Schnittbilder lassen 
keinen Zweifel darüber, daß sie ans der Zylinderzellenreihe desselben sich herausschieben.

Der ventrale Abschnitt der seitlichen Darmwandung ist auf der beschriebenen Strecke, wie Abb. 35 zeigt, stark verdünnt und unter Schwund des DarmIumens mit dem der gegenüberliegenden Seite in mehr oder minder innige Verbindung getreten. Es bildet sich hier ein dünner Stiel oder richtiger eine Leiste aus, die bei der späteren Abtrennung des Embryos vom Dotter (vergl. S. jut und Kap. IV) curchreißt. Die Ausdehnung dieser Verlotung in dorsoventraler Richtung ist bei den verschiedenen Embryonen eine wechselnde, anfanglich ist sie kürzer als später. Sie kann bis zum Dotter herabreichen oder: wie das meist der Fall ist (Abb. 35), gegen den Dotter za sich wieder öffnen. Sie ist schon bei dem früher beschriebenen Embryo von 18 Urwirbeln vorhanden, wo sie im ersten Füntel der zwisehen den beiden Darmpforten befindlichen Strecke noch ein schmales, spaltî̈rmiges Lumen freiläBt, und erst in den folgenden zwei Fünteln zur vollen fusbilaung kommt. Auf den hinteren zwei Fünteln offnet sich das Lumen wieder mit nach rủckwärts zunehmender Breite (Abb. 29). Beim Embryo der Abb. 2 mit 20-21 Urwirbeln dehnt sich die Verlötung bis über das Gebiet der Vorniere nach rückwärts aus. Beim vorliegenden Embryo ( $4 b b .35)$ endet sie schon im Gebiet der Vorniere selbst. Bei einem Embryo des folgenden Stadiums hinwiederum erscheint sie erst ein Stück hinter der Darmpforte, reicht mit zufälligen Unterbrechungen bis zum hinteren Vornierenende, um an der caudalen Abschnürungsstelle des Embryo wiederum aufzutreten. Man erhäl hiernach den Eindruok, daß die Ausdehnung der Verlötung sowohl in ventraler als caudaler Richtung eine wechselnde ist und von zufalligen Druckverhälmissen, auch von der Fixierung, beeinfluBt wird. Nur dann, wenn es zu einer Durchtrennung der Leiste kommt, tritt zuvor zweifellos eine totale und unlösbare Verlötung der beiderseitigen Wände ein.

Im Bereich dieses verdünnten ventralen Abschnittes der seitlichen Darmwarid finden sich nun ebenfalls Gefäßzellen, und zwar auf der Strecke vor der Vorniere nur ganz vereinzelt, im Bereich derselben aber schon zahlreicher. Auch kurze Stücke von Endothelröhren (Abb. 35) fand ich im vorliegenden Stadium an der Basis des Stiels in der Nähe von DottergefäBanlagen.

Caudal von der Vorniere ist entsprechend dem gröBeren GefäBzellenreichtum des vorausgegangenen Stadiums die Anlage der Parintestinalvene besser entwickelt als weiter vorn. Auf der linken Seite des Embryos stellt sie schon einen kraniocaudal durchlaufenden Zug dar, welcher, in mittlerer Höhe der seitlichen Darmwand gelegen, zwar an vielen Schnitten nur aus einer oder ein paar Zellen besteht, dazwischen aber auch schon zum Rohr gelichtet ist (Abb. 36). Das Endothelröhrchen ist namentlich im hinteren Abschnitt des Gefäßes über eine längere Strecke ausgebildet. Zwischen dem 13. und 14. ${ }^{1}$ ) Rumpisomiten mündet sie, nachdem sie etwas weiter geworden, von oben in die schon stark ausgedehnte Vena subintestinalis ein, zwei Somiten hinter deren vorderen Ende. Die Müundung der linken Vene ist in Abb. 37 (rechts im Bild) dargestellt, einem Querschnitt, auf dem zufallig anch die Fortsetzung der Subintestinalis in die hintere Dottervene und dorsal die Anlage eines QuergefäBes getroffen wurden.

1) Denselben entsprechen im vorliegenden Stadium der 19. und 20. Trwirbel. 
Die rechtsgeitige Venenanlage erscheint mehrfach unterbrochen. Ihr caudaler Abschnitt bildet über eine längere Strecke ein Hohlgefäß (Abb. 37). Dieses verbindet sich schon im Bereich des 11. Rumpfsomiten mit einem engen vorderen Fortsatz der Subintestinalis. Erst am 14. Rumpfsomiten dicht hinter dem Schnitt der Abb. 37 eröfnet sie sich in die weite Subintestinalvene. Die Mündung der beiderseitigen Parintestinalvenen ist bei diesem Erabryo zufallig eine fast symmetrische.

In diesem caudal an die Vorniere sich anschließenden Gebiet laufen GefäBzellenzüge von den noch unfertigen Aorten an der seitlichen Darmwand ventral herab (Abb. 36 und 37 qg). Es sind dies die Anlagen der vordersten QuergefäBe des Darms, die weiter hinten, von der Gegend der caudalen Darmpforte an, sich zu weiten und auffallenden, die Aorta mit der Subintestinalis verbindenden GefäBräumen ausbilden. Dort wurden sie ron P. Mayer (1886) zuerst besehrieben.

Die Entwicklung dex Darmquergefaß $\mathrm{Be}^{1}$ ) rückt wie diejenige der großen LängsgefäBe des Rumpfes und Schwanzes im allgemeinen in caudaler Richtung. entsprechend dem Auftreten jüngerer Mesodermsegmente am Hinterende des Finbryo; weiter. Demnach finden wir im vorhegenden Stadium (drei Visceraltaschen) nur die vordersten der QuergefäBe angelegt, und zwar auf einer Strecke, die hinter der Forniere beginnt und ungefähr bis zur caudalen Abschnürungsstelle des Embryo vom Dotter reicht. Diese vorderen QuergefäBe sind Gebilde von nur kurzem Bestand. Einige unter ihnen bringen es vielleicht nicht einmal bis zux Ausbildung eines Lumens. Da sie aber zur ersten Entwicklung der Parintestinalvene in naher Beziehung stehen und auch sonst einiges Interesse bieten, sollen sie zusammen mit dieser Vene nun näher beschrieben werden, und zwar für die älteren Embryonen dieses Stadiums mit 24-27 Crwirbeln (darunter 18-21 Rumpisomiten).

Einen guten Uberblick über diese QuergefäBe des Darmes erhält man auf Sagittalschnittserien. Besonders, wenn die Schnittrichtung nicht genau zur Medianebene parallel verläuft, können in der einen Hälfte des Embryo, derjenigen. in welcher sie dorsomedian abweicht, die QuergefäBe in ganzer Höhe bis zu ihrer Verbindung mit der Aorta getroffen werden. Im Interesse der Ubersichtlichkeit der Darstellung wurden die Prismenzeichnungen mehrerer aufeinanderfolgender Sagittalschnitte zu einer einzigen Abbildung kombiniert, was sich mit Benützung der Urwirbel- und Aortenkonturen meist ohne Schwierigkeit durchführen lieb. Störend wirkt bei dieser Darstellung nur die Deckung seitlich nebeneinander gelegener GefäBanlagen. Hier mußten, sollten nicht Cnklarheiten entstehen. einzelne Teile, namentlich Anschnitte von GefäBanlagen, ab und zu weggelassen werden. Im ganzen stehen mir vier Sagittalschnittserien aus der vorliegenden Altersstufe zur Verfügung, von denen drei zu derartig kombinierten Abbildungen ( $A b b, 42-44$ ) verwendet wurden. Diese etwas reichliche Illustration erschien nötig, weil die Quergefaße, wie ersichtlich, ein ziemlich wechselndes Verhalten zeigen, was zum Teil auf die Fariabilität, zum Teil vielleicht auch auf

1) Fs ist hier nur von den Darmquergefaben die Rede, nicht von den Vornierenquergefäßen, weloh letatere in Kapitel IV behandelt werden. Uber das Verbältnis beider zueinander rgl. Rückert 1917 . 
das ungleichzeitige Auftreten und die frühzeitig wieder einsetzende Rückbildung dieser rergänglichen Gebilde zurückzuführen ist.

In $A b b$. 12 (Embryo mit 26 Urwirbeln hinter der 3 . Visceraltasche $=20$ Rumpfsomiten) beginnen die QuergefäBe hinter dem 13. Urwirbel mit einem feinen unter der Aorta auftretenden Zellenzug (Nr. 1). der Anlage des vordersten Quergefäßes. In stumpfem Winkel biegt dieser Strang in horizontaler Richtung um und rerläuft von da ab als Parintestinalis $(p i)$ nach hinten, wobei er stärker wird und eine Serie weiterer QuergefäBe (Nr.2-9) von oben her aufnimmt. Diese meist bogenförmigen Zellenketten bilden nach abwärts Arkaden miteinander: und die Parintestinalis in ihrer anfänglichen Gestalt stellt im Grunde nur eine Längsanastomose solcher GefäBbogen dar. Ab und zu, so z. B. in unserer Abbildung unterhalb Urwirbel 21, liegen mehrere Arkaden übereinander. Von dieser Stelle an. die dicht vor der caudalen Abschnurung des Rumpfes liegt, wird der Längszug sehr dick und zellenreich. Er enthält hier zugleich die noch solide Anlage der Vena subintestinalis, die sich auf dieser Strecke am vorliegenden Objekt ron der Zellenkette der Parintestinalis nicht abgrenzen läBt. Auch in dieses Stück münden noeh einige weitere QuergefüBe, darunter ein gegabeltes (Nr. 10) ron oben ein. Caudal setzt sich der Strang, dünner werdend, noch weiter fort bis über den letzten Urwirbel hinaus, ohne hier vorerst mit Quergefäßen in Verbindung zu stehen. Durch ihre noch fast ganz solide Beschaffenheit unterseheidet sich diese Vena subintestinalis von den schon hohlen Gefïßen der fast gleichaltrigen Querschnittserie der $A b b .37$. Sie gleicht aber darin einer zweiten ron mir nicht beschriebenen Querschnittserie unseres Stadiums, die nur um 1-2 Crmirbel jünger ist. Es scheint hiernach die Lumenbildung in der Subintestinalis trotz des groBen Zellenreichtums sehr rasch vor sich zu gehen. Der Zusammenhang der Subintestinalis mit der schon weit eröffneten Vena vitell poster. fallt in einen weiter seitlich gelegenen Schnitt und wurde daher in die Abbildung nicht mit aufgenommen. Er kommt unter den 21. Urwirbel zu liegen.

Die Aorta ( $a O$ in Abb. 42) ist vor dem Bezirk der QuergefäBe schon ein fast einheitliches Robr. Oberhalb der vorderen QuergefảBe besteht sie noch aus einzelnen Maschenräumen, die aber keine segmentale Anordnung erkennen lassen. Weiter hinten ist sie nur in Form einzelner GefüBzellenzüge angelegt. Vom 20. Crwirbel ab werden diese noch vermiBt. Eine Verbindung der QuergefäBe mit der Aortenanlage ließ sich im vorliegenden Embryo noch nicht verfolgen. Für die hinteren Quergefäße kommen sie überhaupt nicht in Betracht, da über ilhen die Aortenzellen noch fehlen. Ek darf also eine Entstehung der Quergefaßie ron der tortenanlage aus nicht als die Norm angenommen werden.

Bei dem Embryo der Abb, 43 mit 27 Urwirbeln hinter der 3 . Visceraltasche und 21 Rumptsomiten sind die QuergetäBe kräftiger entwickelt. Das vorderste (Xr. 1) ist schon fast durchweg hohl. An ihren oberen Enden sind sie sämtlich mit dem noch beinahe ganz soliden hinteren Absehnitt der Aorta verbunden. Was hier gegenüber $\mathrm{Abb} .42$ vor allem auffallt, ist der stark gebrochene Verlauf der Tena parintestinalis, die ihre Zusammensetzung aus Arkaden der Quergefäße damit deutlich erkennen läBt. Die wechselnde Höhe, welche die Parintestinalvene auf den Querschnittserien zeigt, erlxlart sich damit. Die Vene steigt hier im Gegensatz zu $A b b .42$ nach rückwärts etwas empor und senkt sich dann, nach- 
dem sie im ganzen fünf Quergefäße aufgenommen hat, ziemlich steil zu der dicken Subintestinalvenenanlage herab. Die letztere wird nach abwärts hohl und setzt sich in die hart vor der hinteren Abschnürung des Embryo senkrecht zum Dotter herabsteigende offene Vena vit. poster. $(h d)$ fort. Auch hier läßt sich die solide Vena subintestinalis caudal noch ein Stück weit bis in das Bereich des vorletzten Somiten verfolgen. Auch in diesem Abschnitt sind einige Quergefäße angelegt, die aber noch keine ganz durchlaufende Verbindung mit der Aorta herstellen.

Wieder ein anderes Bild zeigt der Embryo der Abb. 44 mit 27 Somiten (21 Rumpfsomiten). Die Pi,-Vene erseheint hier weiter nach vome getroffen als an den zwei anderen Embryonen. Sie tritt hier vielleicht schon hinter dem 9. Urwirbel, also im Bereich der Vorniere, jedenfalls aber vom 12. Urwirbel an auf als ein horizontaler Längszug, der von der Gegend des 12. Urwirbels das erste QuergefäB aufnimmt. Weiter hinten beschreibt er, nachdem er vorübergehend hobl geworden ist, einen nach anfwärts gerichteten Bogen und senkt sich dann steil, wieder unterhalb des 21. Urwirbels, in das mächtige noch solide Zellenlager der Si. Vene ein. Bis hierher nimmt die Pi.-Vene ungefähr sieben Quergefäßanlagen auf, deren vier vordere schon mit der torta in Verbindung stehen.

Die solide Si.-Venenanlage setzt sich ventrokranial durch ein vor der Eroffnung stehendes Anlagestück in die hintere Dottervene fort. Caudal erstreckt. sie sich wie bei den zwei anderen Embryonen in den vom Dotter abgetrennten Rumpfabschnitt bis zum hinteren Ende des letzten Urwirbels. Auf dieser Strecke gabelt sich die Gefäßzellenmasse in zwei übereinander gelegene parallele Stränge, deren dorsaler $(p i)$ sich noch in die ventralen Anlagestümpfe von 5 weiteren Quergefäßen auszieht. Auf dieses Verhalten werden wir bei der Beschreibung der Vene im Hinterrumpf zurückkommen.

Die Aortenanlage reicht hier nicht soweit nach hinten wie bein Embryo der $A b b .43$. Sie ist vorn hohl, aber noch in einzelne langgestreckte Maschenräume getrennt, hinten entbehrt sie noch des Lumens. Mit den Quergefäßen steht sie, ebenso wie in $A b b .42$, noch nicht in Verbindung, doch treten die vorderen derselben dicht an sie heran.

Endlich sei noch darauf hingewiesen, daß bei allen untersuchten Embryonen, auch den quergeschnittenen, Gefäßzellenzüge auch ventral von der Parintestinalis abgehen und an der Darmwand gegen den Dotter zu herablaufen (ventrale Darmquergefäße, vgl. Abb. 44), so u. a. auch ein stärkerer schräg nach vorn absteigender Zug, der in $A b b .42$ der ganzen Länge nach getroffen erscheint.

Einem aufmerksamen Betrachter der drei Sagittalschnittbilder wird es nicht entgehen, daß die Quergefäßanlagen trotz ihrer Variabilität Beziehungen zu den Somiten zeigen. Beim Embryo der Abb. 43 , bei welchem dieselben sich bis zur Aorta nach anfwärts verfolgen lassen, trifft fast auf jeden der acht Somiten $16-23$ ein Quergefäß. Diese metamere Anordnung ist nur dadurch gestört, da: 21. (auf den Schnitten nicht getroffenen) Somiten zukommende Gefäß etwas nach rückwärts auf den vorderen Umfang des 22, verschoben ist. Ferner geht das QuergefäB des 17. Somiten aus zwei Gabelästen hervor, die den benachbarten Quergefäßen entstammen. Auch in Abb. 42 treffen die zehn QuergefüBe einschließlich der zwei Gabeläste des hintersten, wenn man sje nach aufwärts aus- 
zieht. annähernd auf die Zwischenräume zwischen den Somiten 13 bis 23 bzw. auf die Somiten selbst. Da der neben der Aorta gelegene ventrale Teil der Ur. wirbel auf den Schnitten nicht mitgetroffen ist, läBt sich eine genaue Lagebestimmung der GefäBe zu ibm nicht wie in $\mathrm{Abb} .43$ durchführen. Am meisten verwischt ist die Lagebeziehung zu den Urwirbeln in Abb.44. Aber sie trit doch bei einem Teil der Quergefäße ebenfalls zutage. Jedenfalls ist, wenn man den Eindruck der drei Abbildungen zusammenfaßt, die Verteilung der Quergefäße eine solche, daB man nicht behaupten kann, sie sei eine rein zufallige, von der Metamerie unabhängige. Es müßten in diesem Falle andere, viel wechselvollere Bilder in der Gruppierung derselben zum Vorschein kommen. An einzelnen Stellen ist die segmentale Anordnung sogar strenge durchgefuhrt, so besonders in $\mathrm{Abb} .43$, wo die GefäBe bis zur Aorta hinauf neben den Urwirbeln verfolgbar sind. Aber die Metamerie, die der Anordnung offenbar zugrunde liegt, ist keine reine. Sie ist dadurch gestört, daß die QuergefaßBe unterhalb der Urwirbel erstens keine parallele, sondern eine sehr wechseinde und zur Arkadenbildung führende Verlaufsrichtung einschlagen und zweitens, sich an ihren oberen Abschnitten ab und zu sowohl untereinander vereinigen als gabeln.

Man wird nicht einwenden, daß diese Metamerie der QuergefäBe etwas Selbstverständliches sei, weil ihre oberen Enden noch aus gegliedertem Mesoderm, den ventralen Abschnitten der Urwirbel, hervorgehen. Dem wäre die einfache Überlegung entgegenzuhalten, daß dann ebenso gut von einem Teil der Urwirbel statt des einen Gefäßes deren mehrere, und zwar in sehr wechselnder Zahl abgehen könnten, und daß andere Urwirbel, und zwar wieder in sehr verschiedener Kombination übersprungen werden könnten, kurz, daB trotz des Ursprungs aus den Segmenten eine ganz unregelmäBige Verteilung zu diesen möglich wäre. Die Crsache dieser Anordnung ist eine tiefer liegende. Die queren, die Aorta mit den Längsvenen verbindenden Darmgefäße können nur vom phylogenetischen Standpunkt aus verständlich werden als Wiederholung eines primitiven GefäBsystems, deren quere den Darm umgürtenden VerbindungsgefäBe segmental waren. Die Metamerie hat sich nur weiter vorn im Bereich der Vorniere rein erhalten und hier nur dorsal, wo die Quergefäße in den Dienst der gleiohfalls segmentalen Vorniere getreten sind. Weiter hinten, wo ihnen am Darm ein freies Feld zur netzartigen Ausbreitung zur Verfügung stand, hat sich die ursprüngliche Anordmung verwischt. Aber sie hat doch auch hier unverkennbare Spuren hinterlassen (vgl. Rüekert 1917).

Schon P. Mayer (86) wirft die Frage der Metamerie der Quergefäße auf, er neigt aber dazu, sie zu verneinen. Tch selbst habe ihm darin beigestimmt ( $88 \mathrm{~b}$ ). Wir haben aber damals die hier beschriebenen unmittelbar hinter Vorniere gelegenen sehr vergänglichen QuergefaßBe nicht gekannt oder zum mindesten nicht beachtet, sondern nur jene weiter hinten gelegenen, die sich zu sehr weiten, den Darm dicht umspinnenden Gefäßräumen ausbilden, so daß sie an die Blutsinus des Darms bei Anneliden erinnern. Wenn diese hinteren Quergefaße sich gehöhlt und ausgeweitet haben, lassen sie von einer Metamerie in der Tat nichts exkennen. In diesem Zustand wurden sie von P. Mager und mir untersucht.

Ein Embryo mit 29 Urwirbeln hinter der jetzt rollständig ausgebildeten 3. Visceraltasche und 23 Pumpisomiten stellt eine Zwischenstufe dar zwischen 
den zuletzt beschriebenen und denen des folgenden Stadiums. Er zeigt in bezug auf die Entwicklung der Parintestinalvene keinen Fortschritt. Nur die QuergefäBe zwischen Vorniere und hinterer Darmpforte sind jetzt zum Teil in offene, einige sogar in weit geöffnete Endothelröhren umgewandelt.

d) Stadium von vier gesehlossenen Visceraltaschen.

Wir legen der Beschreibung das Modell der Abb. 3 zugrunde und besprechen zuerst dessen linke Seite, dio in $\mathrm{Abb}$. 51 bei stärkerer VergröBerung dargestellt ist.

Kranial von der Vorniere. Das caudale Ende des Herzens gabelt sich im vorliegenden Stadium in der Höhe des Kopfsomiten $y$ in die beiden Dotter. venen, die zur Seite der hierher rückverlagerten vorderen Darmpforte (vp) zum Dotter absteigen, um dann, enger werdend, auf diesem nach vorn abzubiegen ( $v d$ ). Der dorsale, in der Höhe des Sinus venosus $(s v)$ gelegene Teil dieses mächtigen Venenraums setzt sich jetzt, beträchtlich enger werdend, in horizontaler Richtung nach hinten bis zur Vornierengegend fort, wo er spitz auslaufend endet. Dieser bereits hohle Abschnitt der Parintestinalis stellt somit die caudale Fortsetzung des Herzschlauches in dem Embryonalkörper dar. Unter seiner kranialen Halfte zieht ein zweites kürzeres Gefäß am Darmstiel entlang, welches mit der Dottervene noch nicht verbunden ist. Es wird voraussichtlich bei fortschreitender Abschnürung des Embryos und Rückwärtsverlagerung der Herzmündung der Dottervene diesem letzteren Gefäß einverleibt werden.

Im Bereich der Vorniere ist das Rohr noch zweimal unterbrochen durch solide Anlagestücke, d. h. Gefäßzellen (punktiert). Sein Verlauf erscheint in dieser Region etwas dorsal abgebogen.

Caudal von der Vorniere. Hier fällt in Abb. 51 vor allem auf, daB die dorsalen DarmquergefäBe des vorigen Stadiums') (Abb. $42-44)$ rückgebildet sind, und zwar bis zur hinteren Darmpforte, in dem Grade, daB nur mehr vereinzelte lockergefügte Zellenzüge übriggeblieben sind. Die Pi..Venenanlage hat sich aber hier erhalten und zum durchlaufenden Rohr entwickelt, das kurz vor der Darmpforte in die Subintestinalis mündet, nachdem es vorher zweimal mit deren kranialem blindsackartigen Stumpf (vgl. S. 29) in Kommunikation getreten war. Unter ihr hat sich bei unserem Objekt aus dem Netz der ventralen DarmquergefäBe ein zweiter Längszug herausdifferenziert, der mit der Pi.-Vene anastomosiert und sich in den kranialen Stumpf der Subintestinalvene caudal fortsetzt. Dieser GefäBzug bleibt voraussichtlich als Bestandteil des venösen Darmetzes erhalten (vgl. $A b b .52$ ), wenn er nicht noch zuletzt der Pi.-Vene einverleibt wird.

A uf der rechten nicht abgebildeten Seite des Modells ist kranial von der Vorniere die Pi.. Vene nicht als durchlaufendes Endothelrohr zur Ausbildung gekommen. Es ist hier in der Horizontalebene des Herzens die Entwicklung des Gefäßes großenteils noch auf der Stufe der Gefäßzellen stehengeblieben. Dagegen ist die ventral von ihr gelegene GefäBanlage des Darmstiels hier noch stärker als links. Dieser GefäBabschnitt wird der Dotterarterie zufallen, in welche die,

$\left.{ }^{1}\right)$ Die ,dorsalen“, d. h. die zwischen Aorta und Parintestinalvene gelegenen im Gegensatz zu den ventralen zwischen der $\mathrm{Pi}_{\text {. }}$ Vene und dem Dotter bzw. der Subintestinalis gelegenen (vgl. S. 76). 
nach hinten sich verlagernde, rechte Dottervene sich bis zun nächsten Stadium umgestaltet (Kap. IV).

Am wenigsten entwickelt ist wieder die Vornierenstrecke der Pi.- Tene, die noch hinter derjenigen der linken Seite zurücksteht. Dorsal von ihr ist das Längsgefäß der Forniere (Rückert 1917) schon großenteils als Rohr angelegt.

Caudal von der Vorniere liegen die Verhälnisse wie links, nur reicht die hohle durchlaufende Parintestinalis nicht soweit nach vorn wie dort.

Funf weitere Schnittserien zeigen, obwohl sie fast gleichaltrig sind, einen ziemlich verschiedenen Entwicklungsgrad der Vene, der sich, wie bei dem beschriebenen Embryo, auch noch zwischen beiden Seiten des gleichen Tieres bemerkbar macht. Es würde daher eine Einzelbeschreibung dieser Objekte zu weit führen, weshalb ich mich auf eine Zusammenfassung der Befunde beschränke.

Noch bei keinem dieser Embryonen verläuft die Pi.-Vene als HohlgefäB ununterbrochen vom Herzen bis zur Subintestinalis. Das kraniale Anfangsotück zeigt stets ein Lumen, und zwar von relativ beträchtlichem Kaliber. In seinem weiteren Verlauf wird das Rohr aber im allgemeinen sehr eng, nur ausnahmsweise dehnt es sich aus, wohl stets infolge der Einmündung eines gleichfalls weiten Dottergefaßes. Auf seinem langen Verlauf ist es wiederholt unterbrochen, und zwar bei den einzelnen Embryonen in verschieden langer Ausdehnung, durch solide Abschnitte, die, wenn sie aus einer Anhäufung mehrerer Zellen auf dem Querschnitt bestehen, eine Weiterverfolgung der Anlage gestatten. Oft sind aber nur zerstreute Einzelzellen an deren Stelle, vorhanden, und dann kann die Verfolgung des Längszuges unmöglich werden, besonders wenn noch ein Wechsel in der Höhenlage hinzukommt. Im allgemeinen bevorzugt das Gefäß eine mittlere Hohe an der seitlichen Darmwand. Hier liegen oft die beiderseitigen Anlagen als cnge Röhrchen oder solide Stränge in nahezu der gleichen Horizontalebene einander gegenüber. Doch kommen auch Senkungen des Gefäßes am Darmstiel vor, und zwar in Verbindung mit ventralen QuergefäBen, $d$. h. solchen, die vom Dotter zu ihm anfsteigen, ebenso treten Erhebungen, speziell im Vornierengebiet, auf. Meist werden von diesen Schwankungen der Höhenlage die beiderseitigen Gefäße eines Embryos, wenn auch in ungleichem Grade, betroffen.

Zwischen der Vorniere und der Mündung der Pi.- Vene in die Subintestinalis sind die von der Aorta herabtretenden QuergefäBe jetzt bei allen Embryonen stark rückgebildet. Nur caudal, kurz vor der Mündung der Vene, fand ich einige Male ein hohles Quergefäß oberhalb der letzteren erhalten. Diese Gefäße sind also im Vorderrumpf, wo sie zuerst auftreten, so vergänglicher Natur, daß sie funktionell kaum in Betracht kommen. Es ist sehr möglich, daß ein Teil von thnen nicht einmal die Stufe offener Röhren erreicht. DaB sie trotzdem zur Anlage kommen, lïBt sich, wie erwähnt, nicht anders verstehen, als im Sinne der ontogenetischen Wiederholung eines vererbten Vorfahrenzustandes (s. Kap. V). Die Parintestinalis hingegen hat sich auf dieser Strecke erhalten, freilich in sehr verschiedenem Entwicklungszustand. Daß ich sie hier gerade auf der rechten Seite, wo sie später wieder schwindet, ofter als fertiges GefäB antraf, als links, ist wohl ein Zufall. Da, wo ihre Anlage auf dieser Strecke völlig unterbrochen gefunden wird, muB man amehmen entweder, daß sie im rorausgegangenen Stadium ( $\mathrm{Abb} .42-44$ ) überhaupt noch gefehlt hat, oder daß sie zusammen mit den QuergefäBen wieder 
zugrunde gegangen ist, was bei ihrer Zusnmmensetzung aus Arkaden dieser GefäBe sehr begreiflich wäre. In diesen Fullen würde ein Wiederaufbau der linksseitigen peritierenden Vene mit Hilfe der unter ihr erhaltenen QuergefäBe des Darmstiels oder auch vom vorderen Ende der Subintestinalis aus in Betracht zu ziehen sein.

Sohließlich mag nochmals besonders betont werden, daß die hier beschriebene Parintestinalis des Vorderrumpfes als pariges GefaB angelegt wird und daB die rechtsseitige Anlage, obwohl sie später einem völigen Schwund anheimfällt, in ihrer anfänglichen Ausbildung im allgemeinen nicht hinter der linksseitigen zurücksteht, sondern diese bei einem Teil der Embryonen auf einzelnen Verlaufsstrecken sogar übertreffen kann.

Tm der Darstellung einen AbschluB zu geben, verweise ich, der späteren Beschreibung des Kap. IV vorgreifend, auf das Modell meines jüngsten Embryos aus dem
e) Stadium von fün Visceraltasehen,

dessen 2. Tasche eröffnet ist und dessen 3 . das Mesoderm noch nicht verdrängt hat.

Hier (Abb. 52) ist auf der linken Seite die Parintestinalvene als ein vom Herzen bis zur Einmündung in die Subintestinalvene durchla ufendes Hohlgefä B fertiggestellt. Bis zur Vorniere ist es schon weit, von da ab noch eng. Caudal von seiner Mündung läßt es sich noch ein Stück weit oberhalb der Subintestinalis verfolgen. QuergefäBe zwischen ihm und der Aorta sind nicht mehr vorhanden, wohl aber zwischen ihm und dem Dottergefäßnetz. Diese letzteren Verbindungszüge haben sich kräftig ausgebildet und vielleicht zur Verrollständigung der definitiven $\mathrm{Pi}$-Vene beigetragen.

Auf der rechten Seite $(\mathrm{Ab} b .53)$ ist keine durchlaufende Pi.-Vene zur Ausbildung gekommen. Das Auftreten des Dotterarterienstammes hat hier Veründerungen hervorgerufen, die in Kap. IV dargestellt werden.

\section{Weitergreifen der GehBentwieklung auf den Hintermupf.}

Wir haben die Entwiclslung der DarmquergefißBe nur bis zur hinteren Darmpforte nach rückwärts verfolgt. Hier enden aber diese Anlagen nicht, sondern sie breiten sich von da im weiteren Verlauf der Entwicklung caudal in den vom Dotter abgetrennten Rumpfabschnitt des Embryos, also in den, Hinterrumpf" aus, und zwar über dessen ganze Länge bis zum After, wo die Subintestinalis bekanntlich an der Seitenwand des Darms, der Ektodermverlötung des letzteren ausweichend, sich dorsal erhebt. Auf dieser ganzen Strecke, und zwar schon von der Gegend der hinteren Darmptorte an - also noch vor der ektodermalen Abschnürung des Embryos - erreichen die QuergefaBBe sogar, wie schon oben erwähnt, eine vollkommenere Entfaltung als im Vorderrumpf.

Gleichzeitig mit den DarmquergefäBen rückt die Aorta und die Subinte. stinalvene caudal in den Hinterr um pf weiter. Wenn man nun die Entwicklung der genamten Vene und die der Quergefäße in dieser Region verfolgt, so ergibt sich die überraschende Tatsache, dab auch hier, an der seitlichen Darmwand, dorsal von der Si.-Vene and in Verbindung mit den QuergefäBen eine Parintestinalvene, wenn auch nur vorübergehend, zur Anlage kommt.

Es wurde oben dieses Gefaß nur bis zu seiner Finsenkung in das ventral von ihr auftauchende vordere Ende der Subintestinalis verfolgt. Dabe wurde wieder. 
holt der Tatsache gedacht, daß sie mehrere hintereinander gelegene Verbindungen mit diesem GefüB eingeht. Schon daraus geht hervor, daB sie mit ihrer Einmün. dung in dieses mächtige Gefäß nicht endet, sondern in Begleitung desselben, dorsal von ihm gelegen, sich nach hinten ausbreitet. Dieses Verhalten läßt sich nun auch äber den Hinterrumpf, und zwar bis zum After verfolgen.

Zum Verständnis des Weiteren sei folgendes vorausgeschickt. Die Parintestinalis tritt hier (Abb. 51) ebenso wie im Vorderrumpf als eine Anastomosenkette der Darmquergefiab auf. Unterhalb von ihr senken sich diese Querzuge (= ventrale DarmquergefäBe) im Vorderrumpf, wie oben gezeigt wurde, am Darmstiel herab zum Dottergefäßnetz, hier im Hinterrumpf dagegen enden sie ventral in der Subintestinalis, welche in diesem über das Blastoderm caudal hinausgewachsenen Teil des Embryo die Area vasculosa des Dotters oler wenigstens deren peripheren AbschluB, den Sinus terminalis, vertritt. So wird die Pi.-Vene daselbst durch Vermittlung der QuergefäBe auch mit der unter ihr gelegenen Si.-Vene in die innigste Verbindung gesetzt. Dieser vielfache Zusammenhang durch QuergefüBe sowohl mit der Aorta (rote in Abb. 5l) wie mit der Subintestinalis (blane in der Abbildung) ist eine der Ursachen, warum die Parintestinalis des Hinterrumpfes bisher der Beobachtung entgangen ist, denn sie kann infolge dieses Cmstandes als freies selbständiges Längsgefä nur ausnahmsweise über eine gröBere Ausdehnung zutage treten. Sie wird vielmehr meist durch nahe aufeinander folgende Quergefäße unterbrochen und, wenn diese später sich fast bis zur gegenseitigen Berührung ausweiten, streckenweise ganz von ihnen aufgenommen. Am deutlichsten sieht man sie daher gewöhnlich (Abb. 51) am jeveiligen hinteren, zuletzt entstandenen Abschnitt der Darmgefaße, weil hier zur Zeit ihres Auftretens die Quergefäße noch spärlich und eng, stellenwe:se solid sind oder noch ganz fehlen. Aber auch hier, wo der selbständigen Anlage der Vene kein Hindernis im Wege steht, kann sie ausbleiben. Ihr Entwicklungsgrad schwankt eben individuell, wie das bei so vergänglichen rudimentären Gebilden der Fall zu sein pflegt.

Das führt uns zu einem weiteren Verhalten der Vene, das ibre Verfolgung erschwert, nämlich ihren kurzen Bestand, eine Eigenschaft, die sie mit den Quergefäßen teilt: sie tritt ziemlich gleichzeitig mit diesen kraniocandal auf und schwindet auch mit ihnen in der gleichen Richtung wieder. Indes können sich Reste von ihr auch nach dem Untergang der Quergefäße noch eine Zeitlang erhalten. An solchen Stellen kann man verfolgen, daß sich die Pi. - Vene in einen dorsalen Abschnitt der erweiterten Subintestinalis fortsetzt. Dies labt den Schluß zu, daß sie bei der Rückbildung der Quergefaßie nicht völlig verlorengeht, sondern mindestens teilweise der Subintestinalis einverleibt wird unter Ausweitung der zwischen beiden gelegenen ventralen QuergefäBstücke.

Wenn nun auch die Fortsetzung der Parintestinalis in den Hinterrumpl ein vergängliches und vielfach, bei den einzelnen Embryonen in wechselndem Grade, unterbrochenes Gefäß darstellt, so beansprucht sie gerade in dieser Region des Embryos trotz ihres rudimentären Charakters ein morphologisches Interesse, weil sie daselbst neben der Subintestinalis, als Begleitzug von ihr auftritt. Es beweist dies, daß die beiden Längsvenen nicht dem gleichen System angehörenkönnen, daßdieSubintestinalisnichtetwa alsdiecaudale 
Forusetzung der Parintestinalis des Vorderrumpfes angesehen werden darf, sondern daß hier $z$ wei parallele Längsvenen des Darms vorliegen.

Es soll nun die Entwiclalung dieser beiden GefäBe ron da ab, wo sie übereinander liegend auftreten, bis zum After an den bisher beschriebenen Embryonen vertolgt werden.

a) Stadium von zwei Visceraltaschen.

Schon in diesem Stadium, in welchem die noch vorwiegend kompakte Anlage des vorderen Endes der Subintestinalis (Abb. 29) aus dem Mesoderm der Seitenplatten austritt, sieht man stellenweise oberhalb derselben eine einzelne oder ein paar Gefäßzellengruppen (pi), welche ihrer Lage nach dex späteren Paxintestinalis entsprechen. In der Abbildung exkennt man noch, dals sie aus der Seitenplatte ausgetreten sind. Die Vene entsteht also in dieser Region des Pumpfes; soweit sich ihre solide Anlage von derjenigen der Subintestinalis abgrenzen labt, gleichzeitig mit ihr und lokal aus dem Mesoderm. Das letztere gilt auch für die Quergefäße, von deren Zellen man jetzt schon einige dorsal von der Pi..Vene an manchen Schnitten in Verbindung mit dem Mesoderm vorfindet.

b) Stadium von drei Visceraltaschen.

Bei Embryonen mit drei Visceraltaschen ist in der Quersehnittserie der Abb. 37-39 die Parintestinalis schon als Hohlgefäß dorsal von dem vorderen gleichfalls hoblen Stück der Subintestinalis zu erkennen. Thr Verhalten in Abb. 37, speziell ihre Einmündung in die Subintestinalis, wurde schon oben beschrieben. Einige Schnitte weiter hinten trennt sie sich wieder von diesem Gefäß ab, wobei sie ein neues QuergefäB aufnimmt, verläuft ein kurzes Stück selbständig nach rückwärts, um schließlich mit dem oberen Ende, der hier noch teilweise soliden $\mathrm{Si}$. sich zu verbinden, was in $\mathrm{Abb} .38$ auf der linken Rumpfseite zu sehen ist, withrend rechts diese weitere Verbindung zwischen Pi. und Si. zufällig wieder auf den nächstfolgenden Schnitt fällt.

Von hier ab nach hinten erscheint die enger werdende Si. bald völlig solid und in mehr oder minder inniger Verbindung mit ihrem Nutterboden, dem ventralen Ende der Seitenplatten. Stellenweise tritt aber auch auf dieser Strecke über ihr eine zweite, vorerst kleinere GefäBanlage zutage, die nur als $\mathrm{Pi}$. gedeutet werden kann. Es ist dies Verhalten in $\mathrm{Abb} .39$ beiderseits zu sehen, einem Schnitt, der gerade die Abschnürungsstelle des Darmas and des übrigen Embryos vom Dotter trifft. Die Pi.-Vene hat sich hier in Verbindung mit dem Si. Venenmaterial aus den Seitenplatten abgespalten.

Zur Ergänzung dieser Querschnittserie mag auf den caudalen Abschnitt der ebenfalls schon oben beschriebenen Sagittalschnitte (Abb. 42-44) nochmals hingewiesen werden. Wie dort schon erwähnt, erstreckt sich die solide nach hinten sich verjüngende Zellenmasse der Subintestinalis hier bis zum hinteren Ende des gegliederten Mesoderms, also dem 26.-27. Urwirbel, und sitzen ihr dorsal die bereits gebildeten ventralen Abschnitte von bintersten QuergefäBanlagen auf, die sich ebenso wie die weiter nach vorne folgenden durch bogenförmige Anastomosen verbinden. Diese Arkadenkette entspricht weiter vorne, kranial 
Fon der Subintestinalis, der Parintestinalvenenanlage. Hinten aber, im Bereich der Subintestinalis, lät sich eine Pi.- Vene auf den Sehnitten der Abb. $42-43$ nicht mit Sicherheit als selbständiger Längsstrang abgrenzen. Anders beim Embryo der Abb. 44. Bei ihm sieht man die beiden. Zellenzüge hinter ihrer Vereinigung an der Darmpforte sich wieder voneinander trennen und mit Aus. nahme einer schmalen Verlötungsstelle selbständig weiter verlaufen bis zu ihrem caudalen Ende, d. i. über fünf Urwirbel. Bei keinem anderen Embryo dieses und des folgenden Stadiums habe ich die Parintestinalis des Hinterrumpfes äber eine gleichlange Strecke ununterbrochen als selbstandiges, d. h. von der Subintestinalis abgetrenntes Gefä rorgetunden.

c) Stadium von vier (geschlossenen) Visceraltaschen.

Das Verhalten der GefäBe des Hinterrumpfes im Stadium von vier noch uncroffneten Visceraltaschen ist am Modell der Abb. $51 \mathrm{zu}$ übersehen. Die Gegend dicht vor der hinteren Darmpforte wurde bereits oben (S. 78) beschrieben. Die dort erwähnte Rückbildung der QuergefäBe erstreckt sich, wie die weitere Verfolgung der Abbildung zeigt, bis über das Gebiet der Darmpforte nach hinten hinaus, doch ist hier der ProzeB noch nicht soweit gediehen, wie die bessere Erhaltung der Uberreste der QuergefïBe beweist. Auch die Pi.- Vene ist auf dieser Strecke nicht (mehr?) vorhanden. Wenn sie daselbst bei unserem Objekt überhaupt angelegt war, ist sie in der Si-Vene aufgegangen. Hierfür spricht die Beobachtung, daß letzteres Gefaß hier in dorsaler Richtung auffallend stäker ausgeweitet ist als weiter hinten. Wenn man die Vene in dieser Richtung weiter verfolgt, so triff man, an der Stelle, wo das erste voll erhaltene QuergefäB in sie einmündet, eine kleine Lücke in ihr, welche die $\mathrm{Pi}$. Vene vorübergehend abtrennt und noch etwas weiter hinten tritt in gleicher Höne der Spalt auf, welcher die Pi.-Vene definitiv von der Si.-Vene scheidet. Von hier ab läßt sich die Si.-Vene caudal bis zum After verfolgen, die über ihr gelegene Pi.-Vene nicht ganz soweit, aber doch etwas weiter als die Aorta. Beide Venen sind durch ein paar vollständig ausgebildete ventrale QuergefäBe (blau) verbunden. Auch zwischen der Pi.-Vene und der Aorta sind wohlentwickelte dorsale Quergefäße (rot) aufgetreten. Mit der Umbiegung in ein solches endet die Pi. Vene.

Der Fortschritt gegentiber dem Stadium mit drei Visceraltaschen (Abb. 42 bis 44) besteht also darin, daß am caudalen Ende des vorliegenden Embryos 7-8 Urwirbel angebaut worden sind, und daß in diesem neu entstandenen Rumpfgebiet sich sofort die Aorta und die beiden venösen Längszüge mit den QuergefäBen angelegt haben, während in dem weiter kranial gelegen älteren Gebiet die vergänglichen Bestandteile dieser primären GefäBbahnen, nämlich die QuergefäBe und das im Bereich der Si.-Vene gelegene Stück der Pi. Vene in Rückbildung eingetreten sind.

Auf der nicht abgebildeten rechten Seite des Embryos haben sich die Quergefäße von der hinteren Darmpforte an erhalten. Die Pi.-Vene ist hier nur durch kleinere Lücken als selbständiges Gefaß abgetrennt.

Es seien noch vier weitere Querschnittserien von nahezu gleichaltrigen Embryonen angeschlossen, um die Variabilitat der Parintestinalis des Hinterrumpfes bei den einzelnen Objekten zu demonstrieren. 
Ein Embryo von 30 Rumpfsomiten zeigt in Abb. 45 die Nündung der Si. in die hintere Dottervene $(h d)$ in Bereich des 14 . Rumpfsomiten, also an der gleichen Stelle, welche für das vorausgegangene Stadium in Abb. 37 dargestellt war. Auf die daselbst inzwischen erfolgte Abschnürung des Darms rom Dotter unter Bildung eines caudalen Darmstiels wurde schon $\$$. 28 hingewiesen. Die Quergefäbe sind im wesentlichen bis zu dieser Stelle nach hinten untergegangen. Nur einzelne Zellenketten $(g g)$ haben sich auf der rechten Seite des Embryo, links in der Abbildung, erhalten. Auch eine selbständige Parintestinalis ist oberhalb der Si. hier kawm mehr nachzuweisen, wenn nicht vielleicht das kleine Rohr (pi) oberhalb der linken Si. diese Bedeutung hat.

Schon einen Urwirbel weiter caudal, also am 15. Rumpisomiten (Abb. 46), in einer Region, in welcher der Darm sich unter Durchtrennung der Leiste des vorigen Schnittes vollständig abgeschnürt hat, tritt auf der linken Seite (rechts in der Abbildung) das vorderste der erhalten gebliebenen QuergefäBe auf. Es ist ziemlich weit geöffnet, wird aber, wie das meist bei jungen QuergefaßBen der Fall ist, an seiner Kommunikationsstelle mit der Aorta enger. Oberhalb der Si. ist die Pi. zu erkennen. Auf dem nächsten Schnitt mündet das Quergefü $B$ in die Parintestinalis und diese in die Subintestinalis. Auf der anderen Seite ist rom QuergefäB nur das dorsale Ende als Zellenkette erhalten geblieben. Die P..-Vene ist hier mit der Si. konfluiert.

Von hier an nach rückwärts folgen meist durchgängige, zum Teil sehr weite QuergefäBe. In $A b b .47$, einem Schnitt vom vorderen Umfang des 20. Rumpisomiten, ist auf der linken Seite eines der weitesten in seiner ganzen Länge getroffen. Der untere, durch eine Einschnürung abgesetzte Teil des Rohres ist die Si.-Vene, darüber; in mittlerer Höhe des Darmquerschnittes, folgt eine zweite Ausbuchtung. Diese entspricht der Pi.-Vene, wie sich ergibt, wenn man die benachbarten Querschnitte untersucht. Man sieht dann, daB sie sich nach vorn sowohl wie nach hinten $(\mathrm{Abb} .48)$ als abgetrenntes Rohr über das Bereich des QuergefäBes, obwohl dieses stark ausgedehnt ist, hinaus erstreckt. Im Bereich des 21. Rumpfsomiten senkt sich die ganz eng gewordene Pi.-Vene in Gestalt einer einzigen zum Rohr eingerollten Gefäßzelle zwischen die Zellen der visceralen Seitenplatte ein, um schon auf dem nächsten Schnitt, wieder größer werdend, diesen ihren Mutterboden zu verlassen. Das Rohr wird nun wieder selbständig (wie in Abb. 48) und nimmt vom 21. zum 22. Rumpfsomiten an der Bildung der beiden letzten, engeren QuergefäBe teil, indem sie wie in Abb. 47 eine Seitenbucht bildet, die aber viel schärfer abgesetzt ist als dort. Hinter den QuergefüBen, die hier schon mit dem 22. Rumpfsomiten enden, läßt sich die linke Pi.-Vene noch als selbständiges über der etwas weiteren Si.Vene gelegenes Rohr vom 22.-24. Rumptsomiten verfolgen, an welch letzterem Urwirbel sie sich in dieses Gefä $B$ von oben herein senkt ( $A b b .49$ ), in derselben Querschnittsebene, in welcher auch die Aortenanlage anfhört. Von hier ab zieht dann nur noch die si.-Vene als einzige Gefäßanlage weiter. Diese wird nach hinten zu eng und tritt daselbst mit den ventralen Enden der Seitenplatten, ihrem Ursprungsgebiet, wiederholt in Verbindung. Sie entsendet noch einen kurzen, dorsalen, soliden Fortsatz (Abb. 50), der als ein Anlagestück der Pi.. Vene und vielleicht zugleich eines letzten QuergefäBes anzusehen ist und endet schlieBlich am letzten $=29$. Rumpfsomiten 
im vorderen Bereich der Kloake, bis last zur Mitte von deren Seitenwand emporsteigend.

Aus dieser Beobachtung geht die von mir wiederholt festgestellte Tatsache hervor, daß die Pi.-Vene auch auf einer Strecke auftreten kann, auf welcher noch keine Quergefäße angelegt sind. Sie kann also auch ohne Verbindung mit deren Zellen selbständig ans den Seitenplatten austreten. Und endich drittens konnte festgestellt werden, daß das Zellenmaterial dex Pi. Vene in primürem Zusammenhang mit demjenigen der Si.-Vene die Seitenplatten verläßt (Abb. 39, S. 83). In unserer eben beschriebenen Serie $(\mathrm{Abb}, 49)$ weist die Verschmelzung des Tuletzt gebildeten Endstückes der Pi.-Vene mit der Si.- Vene ebenfalls auf einen solchen Entstehungsmodus hin, ebenso das Verhalten der linken Si.Vene in $\mathrm{Abb}, 50$.

Noch viel deutlicher tritt dies auf der rechten Seite des gleichen Embryos zutage, Die Quergefabe enden hier schon nach dem 20. Rumpfsomiten, also ungewönlich frühe. Die rechte $\mathrm{Pi}$.- Tene, die bis zur Kloake reicht, ist also hier äber eine Länge von neun Trwirbeln ohne jede Verbindung mit Anlagen von solchen entstanden. Zwischen dem 20. und 21. Rumptsomiten, dicht hinter $A b b .48$, senkt sie sich in die Si. Vene ein und verliert sich in ihr uber zwei Segmente. Dann schnürt sie sich von neuem von ihr ab, wird klein (Abb. 49) und sodann solid und eroffnet sich nach etwas mehr als zwei Somiten (am 25. Rumptsomit) wieder in die Si.-Vene, die dadurch wieder weiter wird. Schon am nächsten Urwirbel (26. Rumpfsomit) tritt sie in solider Anlage.als Verdickung der dorsalen Wand der Si.-Vene wieder aut. Die letztere sinkt alsbald zu der gleichen geringen GröBe wie die Pi. Vene herab and nun bilden die betlen im Beginn der Höhlung begriffenen Gefäßanlagen ein zumeist biskuitförmiges Doppelröhrchen (Abb. 50 bei stäkerer VergröBerung), mit bald stärkerer, bald geringerer Trennung seiner Halften. In dieser Form steigen sie an der seitlichen Kloakenwand empor und enden, auf dem letzten Schnitt total verschmolzen, im Bereich des 20. Rumpfsomiten wie die linke Si.- Vene. Hier entsteht also die Pi. Vene aus gemeinsamer, aber schon aus den Seitenplatten ausgetretener Anlage mit der Si.. Vene.

Von den drei übrigen Querschnittserien dieser Altersstufe stimmt eine mit der oben beschriebenen in bezug auf das wiederholte Auftreten einer oberhalb der Si. gelegenen Pi. überein. Die zwei anderen Embryonen unterscheiden sich von ihr im wesentlichen nur darin, daB ihre weiten Quergefabe engere Läcken zwischen sich lassen und daß schon aus diesem Grunde eine selbstandige Pi. Vene nicht über so lange Strecken zum Vorschein kommen kann wie dort. Bei einem dieser Fmbryonen erscheint ganz caudal, hinter der Aortenanlage, auch hinter den letzten zur dorsalen Darmwand emporsteigenden Quergefäßen auf belden Seiten über mehrere Somiten eine der Pegion angemessene ganz junge und kleine Pi. Sie liegt in mittlerer Hohe der Darmwand, die sich hier schon ventral zum After auszubuchten beginnt. Threx ziemlich weiten Entfernung von der Si.- Vene entsprechend treten zwischen ihr und der letzteren QuergefäBe auf, die aber noch solide sind.

Bei dem jüngsten Embryo des

Stadiums ron fünf $V$ isceraltaschen

und eröfneter 2. Tasche sind, wie $A b b .52$ zeigt, die Darmquergefaße in der vorderen Hälfte des Hinterrumpfes zugrunde gegangen. Trotzdem hat sich hier 
noch ein ansehnlicher Rest der Pi.-Vene in der Gegend der hinteren Darmpforte oberhalb der weiten Si.-Vene erhalten. Auf der caudal folgenden Strecke weisen nur mehr einige dorsale Ausbuchtungen der Subintestinalis darauf hin, daß hier ventrale Abschnitte der Quergefäße nebst Resten einer Pi.-Vene dem ersteren GefäB einverleibt worden sind. Erst in der hinteren, jüngeren, Hälfte des Hinterrumpfes treffen wir wohl erhaltene Quergefäße nebst der Anlage einer Pi.-Vene. Auf der rechten Seite sind die GefäBverhältnisse im Hinterrumpf die gleichen (Abb. 53).

Literatur: Uber die Entstehung der Parintestinalis im Vorderrumpf der Selachier sind nur spärliche Literaturangaben forhanden. P. May er (1886) spricht aich als erster über diesen Venenabschnit, den er mit Balfour zur Subintestinalis rechnet, etwas näher aus. Er gibt an, daß das GefaB sich durehlaufend parig anlege, worauf es rechterseits sich bis auf erhalten bleibende Reste zurückbilde. Diese Angabe habe ich bald darauf (1888) dahin korrigiert, daß nur die linke Vene als durchlaufendes Rohr zur Ausbildung gelangt, was später $\mathrm{Rab} 1$ (1892) als wahrscheinlich bestätigt hat. Rabl bezeichnet die betreffenden Venenabschnitte, ebenso wie C. K. Hoffmann (1893), als Venae omphalo-mesentericae. Er gibt an, daß dieselben von ihrer ersten an der vorderen Darmpforte gelegenen Anlage durch allmähliches eaudales Auswachsen entstehen. Die linke wächst bis zur hinteren Darmpforte aus und mündet daselbst in den Venensack (s. Kap. IV), der sich caudal in die Subintestinalvenen fortsetzt, die rechte bleibt - nach den Schemata Rabls - auf halbem Wege stehen und bildet sich dann bis auf einen proximalen Stumpf (s. Kap. IV) zurück. Diese Darstellung von der Entstehung der Venen durch caudales Auswachsen, die in Wort und Bild von Hochstetter für das Hertwigsche Handbuch übernommen wurde, entspricht, wie aus meiner obigen ausfïhrlichen Beschreibung hervorgeht, keineswegs der Wirklichkeit. Ich würde nicht verstehen, wie der sonst so sorgfältige Forscher zu ihr gekommen ist, wenn der Schlüssel dazu nicht in seiner Anschauung von der Abstammung aller GefäBendothelien aus einer gemeinsamen Endothelquelle gelegen wäre. Die ersten Endothelien sind nach ihm die zur Seite der Darmpforte auftretenden Bildungszellen für das kraniale Endstück der beiden Venae omphalo-mesentericae. Und wie von hier nach vorne die Herzanlage, so sollen nach hinten die Venenstämme auswachsen. Auf diese Theorie, die auch mit anderen Tatsachen in Widerspruch steht, werde ich im SchluBkapitel dieser Arbeit zurtickkommen.

Uber eine Parintestinalis im Hinterrumpf ist in der bisherigen Lite. ratur nichts erwähnt.

\section{Zusammenfassung.}

Als Parintestinalis bezeichne ich eine paarige an der seitlichen Darmwand gelegene, vom caudalen Ende des Herzens bis zur Kloake sich erstreckende Venenanlage. Im Vorderrampf, d. b. dem zwischen den beiden Darmpforten gelegenen, mit dem Dotter zusammenhängenden. Rumpfabschnitt, bildet sie das einzige venöse Lüngsgefäß des Darmes. Vor der hinteren Darmptorte mündet es nach abwärts in das kraniale Ende der Subintestinalvene, endet hier aber nicht, sondern verläuft im Hinterr a m pf weiter parallel mit der Subintestinalis, 
und dorsal von ihr gelegen, um in der Aftergegend, an dex Seitenwand der Kloake, durch Einmündung in cheses GefäB zu enden. Mit der Aorta verbindet sioh die Parintestinalis durch zahlreiche QuergefäBe (dorsale DarmquergefäBe) und ebenso steht aie in Zusammenhang mit ventralen Darmquergefäßen, die im Vorderrumpf zum GefäBnetz der Area vasculosa herabfuhren, wähend sie in dem dorsoventral niedrigen Hinterrumpt zu der dicht unter ihr gelegenen Subintestixalis führen, also sehr kurz sind. So stellt die Parintestinalis eine Längsanastomose des Netzes der DarmquergefäßBe dar und ist wie diese selbst eine vergängliche Anlage. Nur auf der linken Seite des Vorderrumpfes erhält sie sich als dauemde durchlanfende Verbindung zwischen den Herzen und der Subintestinalis.

\section{Entwicklung der Parintestinalis und der DarmquergefäBe im Vorderrumpf.}

Wührend im Kopt das Herz und das intraembryonale Stück der Dottervene sich frühzeitig entwickelt und ebenso früh von der hinteren Darmpforte aus die Subintestinalis, bleibt der zwischen den beiden Darmpforten gelegene Vordermumpf längere Zeit in der Herstellung einer venösen Längshahn, der Parintestinalis, in Rückstand.

Vom Stadium von zwei Visceraltaschen an trift man zerstreate Gefäbellen an der seitlichen Darmwand, vorn in sehr spärlicher, hinten in etwas größerer Zahl an. Thr Austritt aus der Splanchnopleura läBt sich an greeigneten Stellen erkennen.

Erst zur Zeit der A usbild ung der dritten Visceraltasche ließ sich caudal von der eben aufgetretenen Vorniere die Anlage der Parintestinalvene als mehr oder weniger kontinuierlicher, stellenweise schon mit Lumen versehener Gefäbzellenzug verfolgen, der sich caudal in das unter ihm gelegene Vorderende der Subintestinalvenenanlage einsenkt (Abb. 42-44). Er nimmt mit der Aorta sich verbindende, in dem gleichen Entwicklungszustand befindliche, Darmquergefäße auf. Die arkadenförmigen Anastomosen dieser ungleich langen Quergefäbe bauen diesen Abschnitt der Parintestinalvene auf, der infolgedessen einen gelonickten Verlauf zeigen kann, wenn er auch im allgemeinen in mittlerer Höhe der seitlichen Darmwand liegt. Diese Quergefäße sind nicht völlig unregelmäßig Ferteilt, sondern lassen sich an ihren dorsalen Enden (Aortenenden) auf eine segmentale Anordnung zurückführen. Auch ventral steht die Anlage der Parintestinalvene mit Quergefäßen in Zusammenhang, die schräg oder senkrecht, auch netzartig sich verbindend (Abb. 44), zum Dotter hinunterlaufen, wo sie mit den GefäBen der Area vasculosa znsammenhängen. Diese ventralen QuergefäBe sind anscheinend ganz unregelmäßig verteit gegenüber den dorsalen, direkt von der Aorta Lommenden. Auch durch sie kann die Parintestinalvene abgelent werden.

Im Bereich der Vorniere und kranial von ihr ist die Anlage des Längs. gefüßes noch im Pückstand. Tnwieweit auch in dieser Region DarnquergefäBanlagen zum Vorschein kommen, kann exst bei der Entstehung der Vornierengefäße und der Dotterarterie besprochen werden (Kap. IV).

Erst im Stadium von vier (geschlossenen) Visceraltaschen (Abb. 5l) ist die Parintestinalvene des Vorderrumpfes über lingere Strecken als offnes, 
wenn auch noch enges Endothelröhrchen ausgebildet, und zwar bei den einzelnen Embryonen und ebenso auf beiden Seiten des gleichen Embryos in ungleichem Grade. Beim Modell der Abb. 51 steht die rechte Seite, auf welcher das GefäB später wieder zugrunde geht, hinter der linken in der Entwicklung bereits zurück. Dies ist aber durchaus nicht bei allen Embryonen der Fall. Die Anlage ist auf dieser Stufe noch eine ausgesprochen paarige.

Kranial von der Vorniere. Hier ist das GefäB vorne, als Fortsetzung des Herzens, auf eine kurze Strecke stets hohl und weit. Bald darauf wird es sehr eng. Unterbrechungen durch solide Strecken sind bei einem Teil der Embryonen in diesem Abschnit noch vorhanden.

Am meisten zurückgeblieben ist gewöhnlich der mittlere, im Bereich der Forniere gelegene Abschnitt der Vene. Hier treten, mehr noch als im vorhergehenden Stück, solide Strecken auf. Wenn in deren Bereich an Stello eines zusammenhängenden Stranges noch verstreute Einzelzellen vorliegen, so wird die Verfolgung der Anlage unmöglich. Taucht nach solcher Unterbrechung das Gefäß wieder auf, so geschieht es meist im AnschluB an ein QuergefäB, besonders ein ventrales.

Caudal von der Vorniere hat sich das Bild seit dem vorigen Stadium insofern veränctert, als die dorsalen QuergefäBe der Abb. $42-44$ kranial von der Mündung der Pi.-Vene in die Subintestinalis bis auf spärliche Uberreste vieder zugr unde gegangen sind. Da man in diesem Abschnitt jetzt auch die Parintestinalvene bel einem Teil der Embryonen wieder unterbrochen findet, ist mit der Möglichkeit zu rechnen, daß sie von dem Untergang der Quergefäße streckenweise mit befallen wird. Für ihren späteren Wiederaufbau, der sicher mindestens auf der linken Seite stattfinden müßte, würden in diesem Fall die erhalten gebliebenen ventralen QuergefaßBe und das vordere Ende der Subintestinalis als Ausgangspunkte in Betracht kommen.

Erst im Stadium von fün Visceraltasehen mit eröffneter 2. Tasche stellt die Parintestinalvene af der linken Seite ein vom Herzen zur Subintestinalis durchlaufendes HohlgefäB dar (Abb. 52). Rechts dagegen (Abb. 53) ist es nicht zur Ausbildung eines solchen gekommen. Es erhält sich hier als persistierender Ubberrest der Venenanlage nur ein Kurzer kranialer, aus dem Sin. venosus nach hinten vorragender und sich leicht herabsenkender Stumpf, der später bei der Entwicklung der LebergefäBe eine wichtige Rolle spielt (Kap. IV).

\section{Entwieklung der Parintestinalvene und der DarmquergefäBe im. Hinterrumpt.}

Die parige Anlage der Subintestinalvene breitet sich von dem Ort thres ersten Auftretens, der hinteren Darmpforte, caudal in den Hinterrumpt aus und gelangt in der vorliegenden Entwicklungsperiode nach vorausgegangenem Anbau caudaler Mesodermsegmente bis an die Aftergegend heran. In lieser Richtung verlängert sie sich nicht frei, sondern unter caudal fortschreitender Abspaltung ihres Materials aus den ventralen Enden der Seitenplatten. Dabei schreitet sie der gleichsinnigen Ausbreitung der Aorten in den Hinterrumpf immer etwas voran. 
Gleichzeitig mit diesen beiden LängsgefäBen treten in der nämlichen Richtung die sie verbindenclen $Q$ uergefä Be im Hintermmpf auf, und mit oder schon etwas vor den letzteren eine dorsal von der Subintestinalis verlaufende Längsanastomose der QuergefäBe, die Parintestinalis des Hinterrumpfes, Dieses zweite, schwächere venöse Längsgefä $B$ setzt sich vom Vordermut lontinuierlich in den Hinterrumpf fort, nachdem es vorher kranial von der hinteren Darmpforte mehrere aufeinanderfolgende Verbindungen mit dem vorderen Ende der Subintestinalis eingegangen hat.

Die Parintestinalfene liegt in Hinterrumpl, ebenso wie in Vorderrumpf, meist in mittlerer Höhe der seitlichen Darmwand (Abb. 50), und zeigt, indem sie Arkaden der Quergefaße bildet, Knickungen in ihrem Verlauf, die aber nicht so bedeutend sind wie im Vorderrumpf wegen der geringeren Höhe der seitlichen Darmwand. Aus dem letzteren Grunde kann sie sehr wahe an die Subintestinal. vene heramücken, in welchem Fall die zwischen ihnen gelegenen ventralen Teile der Quergefaße entsprechend kurz sind. Letztere sind vergleichbar den ventralen, zum Dotter herabtretenden Quergefảen des Vorderrumpies.

Die hohl gewordenen Quergefiaße zeigen die Neigung, sich sinusartig auszudehnen, so daß zwischen ihnen oft nur schmale Stellen der Darmwand frei bleiben. Bei dieser Ausweitung nehmen sie Teile der Parintestinalvene in sich auf, deren Reste dann nur mehr in den engen Zwischenräumen, die sie frei lassen, zutage liegen (Abb. 51). Deshalb erscheint die Parintestinalvene als durehlaufender Zug nur an solchon Stellen, wo die Quergefüße noch eng oder überhaupt nicht aufgetreten sind, also besonders am jeweiligen hinteren, d. h. zuletzt gebildeten Abschnitt des DarmgefäBnetzes (Abb. 44 und Abb. 51). Aber auch auf Strecken, wo ihrer selbständigen Ausbreitung kein Hindernis durch QuergefäBe in den Weg gelegt wird, kann ihre Entwicklung ausbleiben, denn ihre Ausbildung variiert individuell.

Die kraniocaudale Pückbildung der QuergefußBe schreitet vom Vorder-auf den Hinterrumpf fort und mit ihr diejenige der Parintestinalvene (Abb. 52 u. 53 ), wobei jedoch Reste des letzteren GefäBes noch nach dem Schwund der Quergefäße erhalten bleiben können. Bei der Rückbildung geht die Parintestinalvene nicht oder wenigstens nicht durohweg verloren, denn es werden nachweislich Teile von ihr nebst den kurzen ventralen Abschnitten der Quergefäße von der sich aus: weitenden Subintestinalis aufgenommen.

Da die Parintestinalvene des Hinterrumpfes vorne schon wieder dem Untergang anheimfullt, während sie an threm hinteren Ende noch in Entstehung begriffen ist, wird sie auch an günstigen Objekten nie als ein von der hinteren Darmpforte bis zum After durchlaufendes Hohlgefäß gleichzeitig zutage treten, so wenig wie man jemals die Quergefiule auf dieser ganzen Strecke gleichzeitig ansgebildet findet. Sie stellt im Hinterrumpf ebenso ein vergängliches und rudimentäres Gebilde dar wie auf der rechten Seite des Vorderrumpfes und wie die Quergefäße.

Was die Ableitung des Zellenmaterials der Parintestinalis anlangt, so stammt dasselbe, wie sich an zahlreichen Anlagestücken ermitteln läBt, aus den visceralen Seitenplatten. Aus ibnen tritt es teils selbständig aus, teils in primärem Zusammenhang mit den für die Quergefäße bestimmten Zellen und namentlich 
auch in primärer Verbindung mit dem noch im Mesodem steckenden Material der Subintestinalis. Ind endlich kann die Parintestinalis, wie sich besonders an ihrem zuletzt entstehenden Hinterende zeigt, sich auch von der schon aus dem Mesoderm ausgetretenen and in erster Lumenbildung begriffenen od $x$ soliden Subintestinalis abschnüren. Diese verschiedenen Modalitäten ihrer Genese sind nur durch das jeweilige zeitliche Auftreten derselben sowie der Quergefabe bedingt, also im Grunde unwesentlicher Natur, denn das Bildungsmaterial ist in diesen verschiedenen Fillen stets das gleiche, nämlich Mesoderm der Seitenplatten, oberhalb deren ventralen, die Subintestinalis erzeugenden Zellen.

(Furtsetzung folgts)

\section{Literaturverzeiehnis $\mathbf{I}$.}

Favaro, Ricerche embr. ed anatom. intorno al twove dei Vertebrati. Parte 1. 1913. His, Cntersuchungen über die erste Anlage des Wirbeltierleibes. Leipzig 1868 . His, Anatomie menschlicher Embryonen. Leipzig 1885. - Hoehstetter, Die Entwicking des BlutgefäBsystems. Handbuch der vergleich. u. experiment. Entwickiungslehre der Wirbeltiere. Von O. Hertwig. 3, 2. 1006. - Hoffmann, C. K, Zur Entricklungsgeschichte des Herzens und der Blutgefäbe bei den Selachiern. Morph. Jahrb. 19. 1893. - Kopsch, Experimentelle Untersuchungen am Primitivstreifen des Hühnchens and an Scyllumembryonen. Verhandl. d. Anat. Gesellsch. Kiel. 1898. - Mall, Development of the human heart. The Amerie. Journ. of Anatomy 13. 1912. Mayer, P., Uber die Entwicklung des Herzens und der großen Gefäßstämme bei den Selachiern. Mitt. d. zoo. Station Neapel $\gamma$. 1886/87. - Rabl, C, Theorie des Mesoderms I. Morpholog. Jahrb. 15. 1889. - Rabl, C, Uber die Entwicklung des Venensystems der Selachier. Festschrift für Le nckart. Leipzig 1892. - Raffaele, Ricerche sullo sviluppo del sistema vascolare nei Selacei. Mitt, d. zool. Station Neapel 10. 1892. - Rückert, Demonstration von Präparaten beziiglich der Gastrulation der Selachier. Tageblatt d. 59. Vers. Deutsch. Naturf. u. Arzte. Berlin 1886. S. 271. - Rückert, Über die Anlege des mittleren Keimblattes und die erste Blutbildung bei Torpedo. Anatomischer Anzeiger $z$. 1887. $\mathrm{R}$ ückert, Über die Entstehung der endothelialen Anlagen des Herzens und der ersten GefüBstamme bei Selachierembryonen. Biol. Centralbl. 8. 1888. - Rückert, C̈ber die Entstehung der Exkretionsorgane bei Selachiern. Arch. f. Anat. u. Physiol. Anat. Abt. 1888. - Rückert, Diskussion über den Vortrag His „Über Längsverwachsung des Embryo". Verhandl. d. Anat. Ges. Humohen 1891, S. 8t. - Ruàchert, Über die Ab. stammung der bluthaltigen GefäBanlagen beim Huhn und uber die Entstehung des Randsinns beim Huhn und bei Torpedo. Sitzungsber. d. k. bayr. Akad. d. Wissenseh. 32. 1903. Rüe kert, Über die Glomeruli der Vomiere von Torpedo und deren arterielle GefäßBe. Arch $f$. milkr. Anat. 89. 1917. - Rückert, Uber die Entwicklung der Dottergefäße des Selachiereies. Arch. 1. mikx." Anat. 95. 1921. - Rüokert u. Mollier, Die erste Entstehung der GefäBe und des Blutes bei Wirbeltieren. Handb. d. vergl. u. experim. Entwicklungslehre der Wirbeltiere von 0. Hertwig. 1, Teil 1. 1906. - Tandler, Handbuch der Entwicklungsgeschichte des Menschen von Keibel und Mall. 2. 1911. - - Tandler, Anatonie des Herzens. Fundbuch der Anatomie des Menschen von Bardeleben. 1913. Vialleton, Etude sur le cceur des Lamproies usw. Arch. anat. micr. 4. 1903. - Virchow, H., toer die Entwickinng des Gefäßbezirks auf dem Selachierdottersack. Sitzungsberi. d. Ges. naturf. Freunde zu Berlin. 1895. - Vire how, H. Cbre Dottersacknalit und primaren Kreislivuf bei Scyllum. Ibidem 1897. - Virchow, H., Blutinseln und Gefaßßbezirk von Torpedo ocellata. Ibidem 1898. 


\section{Zeichenerklärung der Tafelabbildungen.}

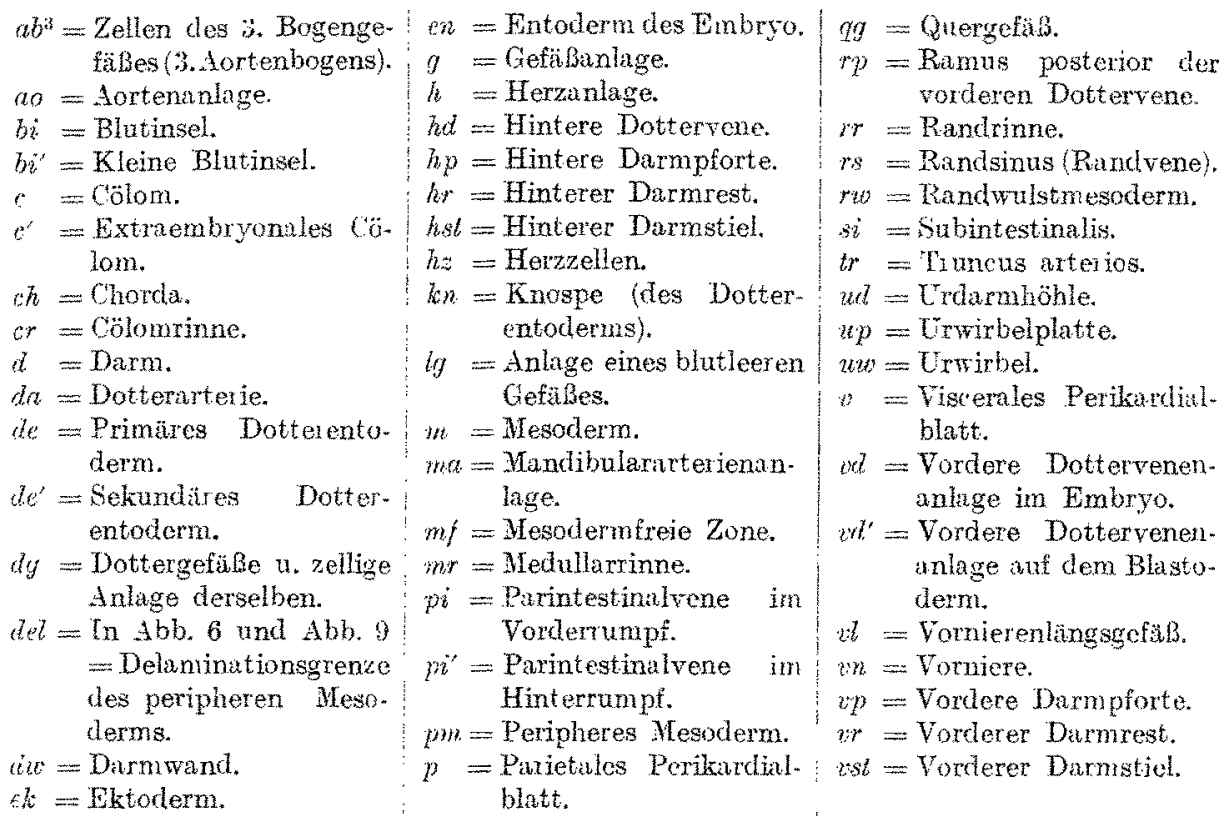

\section{Erläuterung za den Tafelabbildungen.}

Sumtliche Abbildungen stammen von Torpedo oc. Die Quersolnittserien sind von vom nach hinten angelegt, die Querschnitte also von vorn gesehen, soweit nicht das Gegenteil angegeben ist.

\section{Tafel I.}

Abb, 1. Plattenmodell eines Eimbryo mit 16 großen Urwirbeln wad 2 Visceraltaschen, die beide, namentlich stark die zweite, noch vom Mesoderm überzogen sind.

Vom Embryo wurde von der Herzgegend bis zu den Schwanzknospen das Ekto- und Mesoderm entfexnt, um die Gefäbzellen (schwarze Punkte) sichtbar zu machen.

Im Blastoderm ist die mesodermfreie Zone $(m f)$ durch eine weiBe Linie umsiumbat, ebenso das Dottercölom = extraembryouales Colom $c^{\prime}$. Blutinseln und GefäBzellen: schwarz. Offene blutleere Endothelröhren: blau. Randrinne $(r r)$ and andere wandungslose Lacunen auf dem Dotterentoderm: gelb. Am Hinterrand, wo die Randrinne noch fehlt, ist die Blastodermgrenze durch eine gelbe Limie angegeben. Das davor gelegene grane Randfeld = mesodermaler Rand. wulst der Keimscheibe. In ihm Gefäßzellengruppen (sehwarz).

Vergr. $30: 1$. Das bei 100 facher VergröBerung angetertigte Originalmodell wurde entsprechend verleinert.

Abb. 2. Plattenmodell eines Embryo mit 21 Urwirbeln, der 21. in Abgliederung begriffen. 3. Visceraltasche als schwache Bucht angelegt. Darstellung und Bezeichnung wie in Abb. 1. Starlk abgeflachte Stellen der Randrinne sind durch (gelbe) Stri. chelung gekennzeichnet.

Vergr. $30: 1$. Originalmodell $100: 1$. 


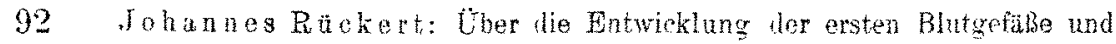

Abb. 3. Plattenmodell eines Embryo mit 28 Rumpfsomiten $(=34$ mitotischen Urwirbeln; und \pm geschlossenen Visceraltaschen.

Das zu dieser Zeit noeh rein venöe Hohlgefäßnetz der Area vacenlosa: blau, mit vorderen $(v d)$ und hinteren Dottervenen $(\hbar d)$ als AbfinBbahnen. Rand. rinne $r$ : gelb. $m f$ mesodermfreie (gefüßfrele) Zone. c' Dottercölom.

Vergr. $15: 1$. Originalmodell $100: 1$.

Abb. 4. Plattenmodell eines Embryo mit 34 Rumpfsomiten und 5 Visceraltaschen, deren zweite offen, deren dritte im Durchbruch begriffen ist.

Der Embryo nach rechts zur Seite liegend.

Veven des Embryo and Herz bis aur Wundibulararterie: blan. Jandibulararterie, Sin. cephalicus, Aorten und QuergefäBe zwischen Aorta und Parintestinalis: rot. Darmgefäßzellen punktiert.

Das Blastoderm. Dotterarterie nebst Aren vasculoga: rot. Der innere, arterielle, Gefabring rechts dureb den Embryo verdeokt. Sinus terminalis und hintere Dottervenen: blau.

Vergr. 15:1. Originalmodell $100: 1$.

\section{Tafel II.}

Vergr. von Abb. 5-11 $200: 1 ;$ Abb. $12-18$ 150:1.

Abb. 5. Querschnitt durch die Mitte des Seitenrandes einer Keimecheibe mit erstem, noch nicht vollständig abgetrennten Urwirbelpaar.

$A b b$. 6. Querschnitt durch den Rand derselben Keimscheibe, etwas weiter vorn gefüht, durch den hinteren Abschnitt des vorderen Drittels der Keimscheibe. Fine Blut. insel im Anschnitt, daher nicht an das Dotterentoderm angrenzend.

Abb. 7. Quersohnitt dureh den Vorderrand derselben Keimseheibe (Tangentialechnitt).

Abb. 8. Sagittalschnitt durch den hinteren Keimscheibenrand seitlich ron der Mittellinie (Paramedianschnitt). Erste Urwirbelpaare in Abgliederung begriffen.

Abb. 9. Sagittalsohnitt durch den vorderen Rand einer Keimscheibe mit $2-3$ in $\mathrm{Ab}$ gliederung begriffenen Urwirbelpaaren.

Abb. 10. Wie Abb. 9. Eine Blutinsel $b i$ getroffen.

Abb. 11. Querschnitt dureh den Seitenrand der Keimseheibe etwas vor deren Witte. Stadium: 3 - Urwirbelpaare.

Abb. 12. Querschnitt durch die Mitte des Seitenrandes einer Keimscheibe von 6 Urwirbel. paaren.

Abb, 13. Querschnitt durch den Rand der Keimscheibe der Abb. 12 an der Grenze von derem caudalen Drittel geführt.

kn: Knospe = Ausläufer einer vom Entoderm abgetrennten Blutinsel, der die Verbindung mit diesem Blatt noch beibehalten hat und in Form einer Knospe sich yon ihm erhebt.

Abb. 14. Querschnitt durch den Rand der Keimscheibe der Abb. 12. An der Grenze ihres caudalen Funftels geführt.

kn: Anlage eines kleinen Gefäbes als Entodermknospe.

Abb. 15. Quersohnitt durch den Hinterrand einer Keimscheibe mit der Embryonalanlage. Stadium: 8 Urwirbel.

$y^{2}-g^{3}$ : GefäBanlagen. $g^{2}$ durch einen Stiel mit dem Dotterentoderm verbunden.

Abb. 16. Querschnitt durch den Finterrand der gleichen Keimscheibe etwas weiter hinten gefuhrt.

g: GetüBanlagen in der tictsten Schicht des mesodermalen Randwulstes. To $n$ : Entodermknospe in den Randwulst sich vorschiebend.

Abb. 17-22. 6 Querschnite durch Keimscheibe und Embryo aus dem Stadium ron 14 Urwirbeln. Erste Visceraltasche angelegt, der VerschluB des Medullarrohres leitet sich im Hinterkopf ein, erste Herzzellen. Die Keimscheibe ist von hinten nach vorn geschnitten. Die Schnitte sind also ton hinten gesehen.

Abb. 17. Kranial von der Herzanlage. Zellen der Mandibulurarterien $m$ a kenntlich an den dunkler gehattenen Kernen.

Abb. 18. Durch die Herzanlagr. 


\section{Tafel III.}

Vergr. Abb. 19-23 und Abb. 25 und $26150: 1$, Abb. $24210: 1$.

Abb. 19. Durch das caudale Ende der Herzanlage, hz: Herzzellen. Die sie fortsetzenden Zellen der vorderen Dottervene $v d$ senken sich zum Dotter herab. $v d$ ': Zellen der vorderen Dottervene auf der Dotteroberfläche. $r p$ : Anlige des Ramus posterior der vorderen Dottervene.

Abb. 20. Dioht vor dem Finterrand der Keimscheibe.

$$
g^{\mathrm{i}}-g^{4} \text { GefäBanlagen. }
$$

Abb. 2L. Etwas weiter caudal als $4 b b .20$ durch den Hinterrand der Keimscheibe.

Abb. 22. Durch das die Keimscheibe caudal überagende Hinterende des Embryo. $r$ w: mesodermaler Randwulst in den Embryo aufgenommen.

tbb. 23-26. \& Querschnitte durch Embryo und Keimscheibe ans dem Stadiun von 16 Urwirbeln. Zweite Visceraltasche in erster Anlage, Medullarrohr im Hinterkopf geschlossen. Die Schnitte entatammen der Keimscheibe der Abb. 1, Taf. I.

$A \bar{b}$. 23. Dicht vor der vorderen Darmpforte, im Bereich der Anlage des Truncus arteriosus $(t r)$.

Abb. 24. $1^{1 / 2}$ Urwirbel hinter der vorderen Darmpforte. Rechte Perikardialhöble $c$ nebst Cmgebung bei stärkerer Vergrößerung 210:1. $k n$ : Entodermale Knospe zar Bildung der vorderen Dottervene. $v d$ und $v d$ : Zellen für die vordere Dottervene.

Abb. 25. Durch den linken caudal ubber den Embryo hinausgewaehsenen Lappen des Blastoderms der Abb. 1.

$r w$ : Randwulst, einige Schitte weiter vorn in die Seitenplatten des Embryo :ich fortsetzend. $g^{i}$; Gefäbanlage in der tieten Sohicht desselben.

$g$ : Anlagen blutleerer Gefäße.

$5 i^{\prime}$ : Kleinste Blutinsel am lateralen Ende des Hinterrandes.

Abb. 26. Sechs Schnitte hinter. Abb. 25 durch den hinteren Rand des linken Blastoderm. lappens der $\mathrm{Abb}$. $\mathrm{I}$.

b. $\ddot{u}^{\prime}$ : Kleinste (rudimentäre) Blutinseln des Hinterrandes der Keimseheibe.

Tafel IV.

Vergr.: Abb. 27-32 $150: 1, A b b, 33$ and $34140: 1$.

Abb. 27-30. 4 Querschnitte durch die Keimscheibe eines Embryos mit 18 Urwirben und 2 Visceraltasehen. Die Sehnitte sind von hinten gesehen wie $A b b, 17-22$.

Abb. 27. Durch den Kopf des Embryos am Hinterrand der 2. Visceraltasehe. Anlage des Trune. arter.

Abb. 28. 12/2 Koptsegmente binter Abb. 27, dicht vor der vorderen Darmpforte.

v d: Gefälzellen der vorderen Dottervene zur Seite des vorderen Darmrestes $(v r)$.

y $d^{\prime}$ : Fortsetzung dieser Zellenkette auf den Dotter.

Abb. 29. Durch den Rumpf des Embryos 4 Urwirbel vor der hinteren Abschnürungsstelle des Embryos vom Dotter.

$r w:$ Mesodermaler Randwulst als ventraler Teil der Seitenplatte in den Embryo einbezogen.

Abb. 30. Durch den Hinterrand der Keimscheibe.

Abb. 31 und 32. 2 Quersehnitte durch den Embryo der Abb. 2, Taf. I 21 Urwirbel, der 21. in Abglielerung, 3. Fisceraltasche in erster Anlage.

Abb. 31. Zwischen der 2. und 3. Visceraltasche.

a b 3: Zellen des 3. BogengefäBes (3. Aortenbogens).

Abb. 32. Durch die 3. Visceraltaschenanlage, die rechte als schwache Bucht getroffen. $v d$ : Anlagen der vorderen Dottervenen auf dem worderen Darmrest $(v r)$.

Abb. 33-39. 7 Quersehnitte durch einen Embryo mit 3 Visceraltaschen, uber der 3. das Mesoderm noch nicht vollständig verdrängt. 26 Urwirbel (26. in Abschnürung) hinter der 3. Visceraltasche, darunter 20 Rumpisomiten (20. in Abgliederung). Vergr. $140: 1$. 
94 Johann Ra Rekert: Über die Entwicklung ler ersten Blutgefäle und

Abb. 33. Durch das hintere Ende der 3. Yisceraltasehe. Schnitt ein wenig schrïg dorsoventral, deshalb Herzanlage etwas zu lang getroffen.

Abb. 34. Dureh die vordere Darmpforte, deren Vorderwand im Anschnitt etwas schriggetroffen. Zwischen 2. und 3. Crwirbel hinter der 3. Viscernltasche $(=z w$. Kopfsomit $v$ und $u$ ).

$$
\text { Tafel V. }
$$

Vergr. 110:1.

Abb. 35-39. Fortsetzung der Sohnittserie der Abb. 33 und 34 der Taf. IV.

Abb. 35. Durch den Vorderrumpf zwischen 9. und 10. Urwirbel $=3$. und 4 . Rumpfsomit. Abb. 36. Durch den Vorderrumpf, 15. Urwirbel $=9$. Rumpfsomit.

Abb. 37. Durch den Vorderrumpt, wwischen 19. wad 20. Urwirbel $=13$. nnd 14. Rumpfsomit. Mündung der Parintestinalis in die Subintestinalis.

Abb. 38. Durch den Vorderrumpt zwisehen 21. und 22. Urwirbel $=$ zwischen 15. und 10. Pumpfsomit. Auf der linken Seite Subintestinalis (si) zum Teil noch solid, eine 2. (cundale) Verbindung mit der Parintestinalis (pi) bildend.

$r r$ : Randrinne, in ihr liegt

$h d$ : Hintere Dottervene.

Abb. 39. Durch die caudale Abschnürungsstelle des Embryos vom Dotter. Hintere Darmnabelwand im Anschnitt. Zwischen 22. und 23. Urwirbel $=$ zwischen 16 . und 17. Rumpfsomit.

Abb. 40. Quersehnitt durch den seitlichen Keimscheibenrand eines Embryos von 29 und 30 Rumptsomiten und 4 gesehlossenen Visceraltaschen.

$r r$ : Randrime. $r_{s}$ : Zukänttiger Randsinus $=$ Randschlinge des DottergefulBnetzes, die noeh nicht bis in die Randrinne sich vorgeschoben hat.

Abb. 41. Quersehnitt durch den seitlichen Keinscheibenrand eines Embryos mit 5 Visceraltaschen, deren 1. bis 3. eröffnet sind.

$$
r s \text { : Randvene (Randsinus). }
$$

Abb. 42-44. 3 kombinierte Längsschnitte durch den Rumpf von Embryonen des Stadiums von 3 Visceraltaschen. Die Quergetïßanlagen sind zum Teil numeriert, ebenso sind die Urwirbel numeriert, der als Ir. $_{1} 1$ gezïhlte liegt dicht hinter der 3. Visceraltasche (Koptsomit $u$ ).

Abb. 42. Kombiniert aus 5 aufeinanderfolgenden seitlichen Längsschitten der rechten Körperhälfte eines Embryo mit 26 Urwirbein, darunter 20 Pumpisegmenten

Abb. 43. Wie Abb. 42. Von einem Embryo mit 27 Urwirbeln (21 Rumpfsegmenten).

$A b b .44$. Wie $A b b .42$ und 43 . Von einem Embryo mit 27 Urwirbein.

\section{Tafel VI.}

Abb. 45-49: Vergr. 140:1.

Abb. 45-50. 6 Querschnitte durch den Runpf eines Embryo aus dem Stadium von 4 (gesehlossenen) Visceraltasehen und 29 Rumpfsomiten.

Abb. 45. Durch die caudile Absohnürungstelle des Darms vom Dotter. 14. Rumpisomit.

Abb. 46. 5 Sehnitte hinter der Abb. 45, Darm rom Dotter abgeschnirt. 15. Rumpfsomit.

Abb. 47. Durch den Finterrumpf, oberhalb der Randkerbe des Blastoderms. 20. Rumptsomit (craniales Ende).

Abb. 48. Schnitt um fast einen Cirvirbel weiter candal, zwizchen Rumpfsomit 20 nnd 21.

Abb. 49. Durch den Hinternumpf. 24. Rumpfsomit im kranialen Anschnitt.

\section{Tafel VII.}

Vergr. von Abb. 50 200:1, Abb. 51-53 36:1.

Abb. 50. Querschnitt dureh das vordere Ende der Aftergegend des Embryos der Abb. 45 bis 49 bei stärkerer Vergroßserung. Candaler Anschnitt des 27. Rumpfisomiten. Links: Si. Vene mit dorsalem Fortsatz $=A$ bgabe der Pi.-Vene und vielleicht zugleich eines QuergefäBes.

Rechts: Teilnng des Längsgefäßes in Si.Vene und Pi.-Yone. Vergr. 200:1. 
thh. 51. Plattenmodell. Rumpt des Embryos der Abb. 3. Taf. T. Linke Seitenansicht bei stärkerer Vergrößerung.

Aorta und die DurmquergefuBe auf der Strecke zwishen der Aorta und der Parintestinalvene: rot. Alle ubrigen Gefiaße: blau. GefüBzellen in den entspre. chenden Farben punktiert.

Vergy. 36:1.

Abb. 52. Plattenmodell. Rumpf des Embryos der Abb. 1, Taf. T. Linke Seitenansicht. Aorta und Quergefäße zwischen Aorta und Parintestinalvene and linkes Endstuck der Dotterarterie $(d u)$ rot. Die ibbrigen Gefále: blau. Vergr. $30: 1$.

Abb. 53. Wie Abb. 52. Rechte Seitenansicht des gleichen Embryos. Vergr. $36: 1$. 


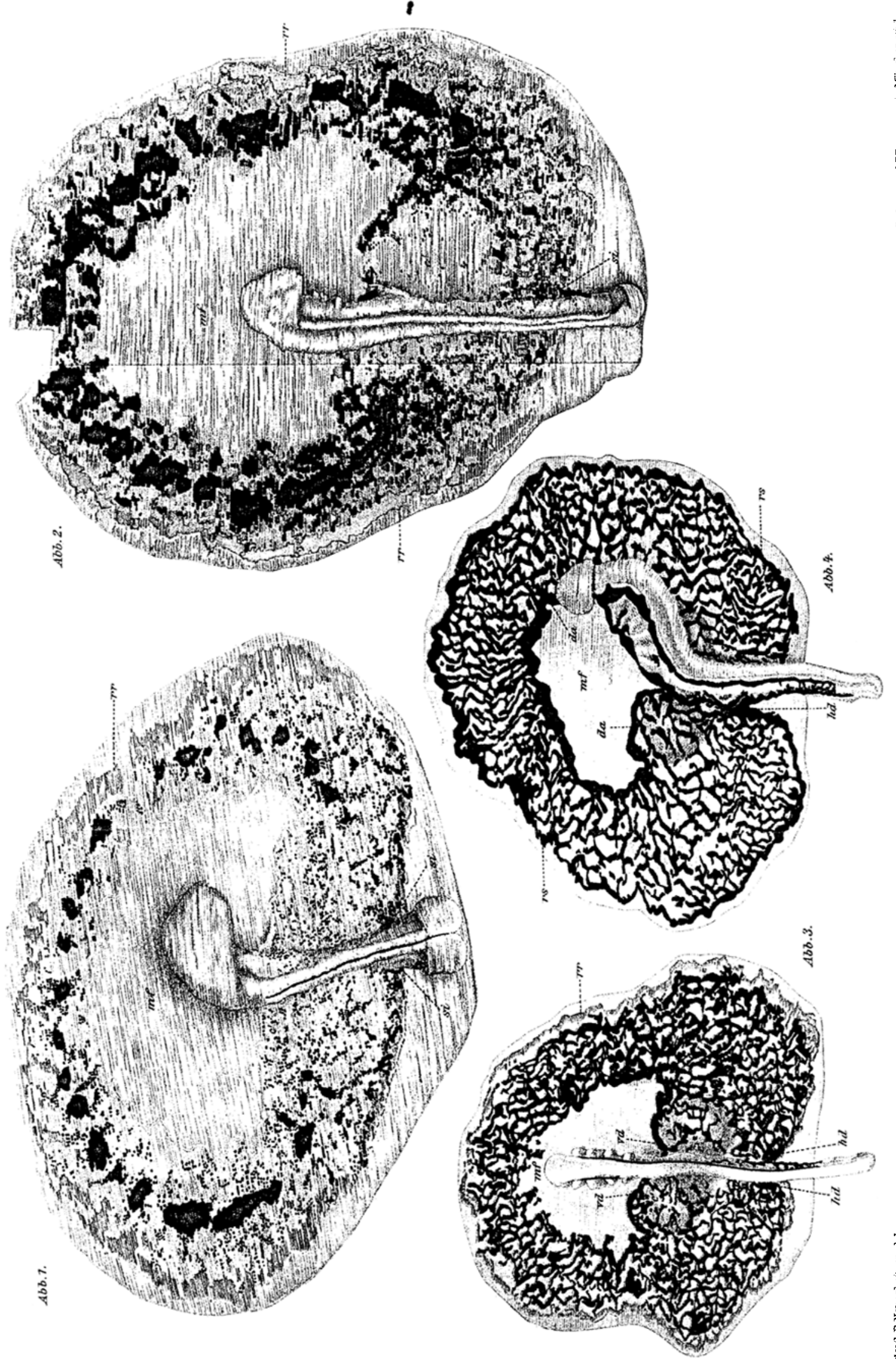



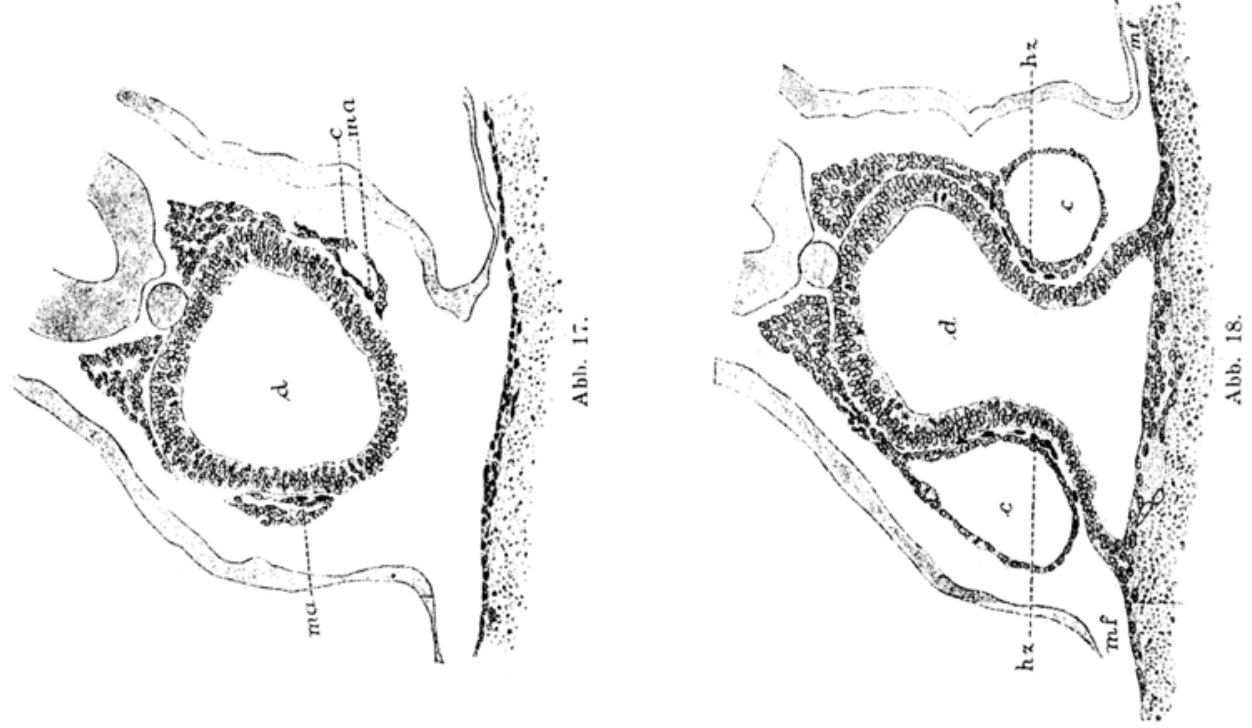

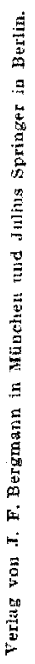

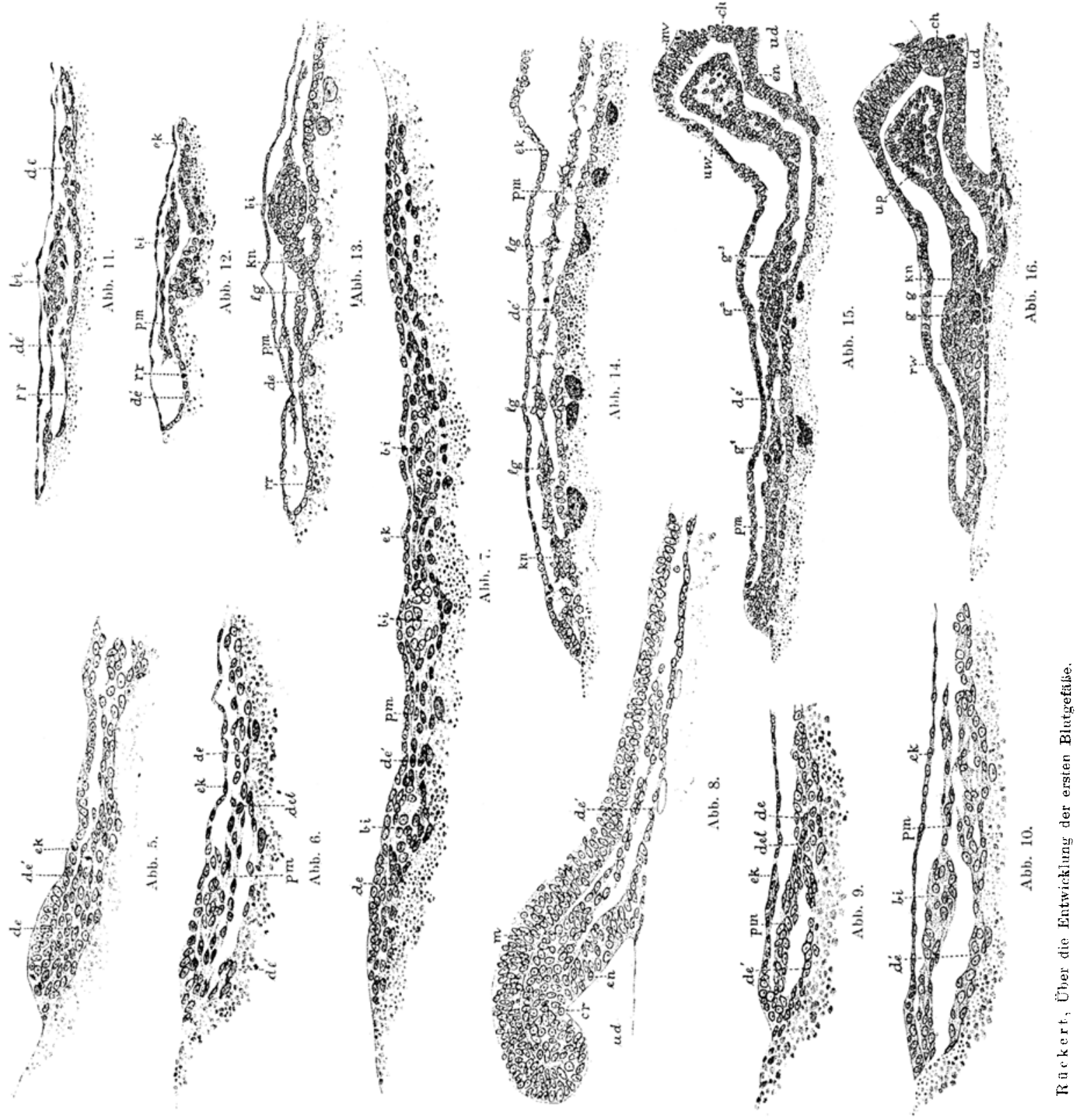



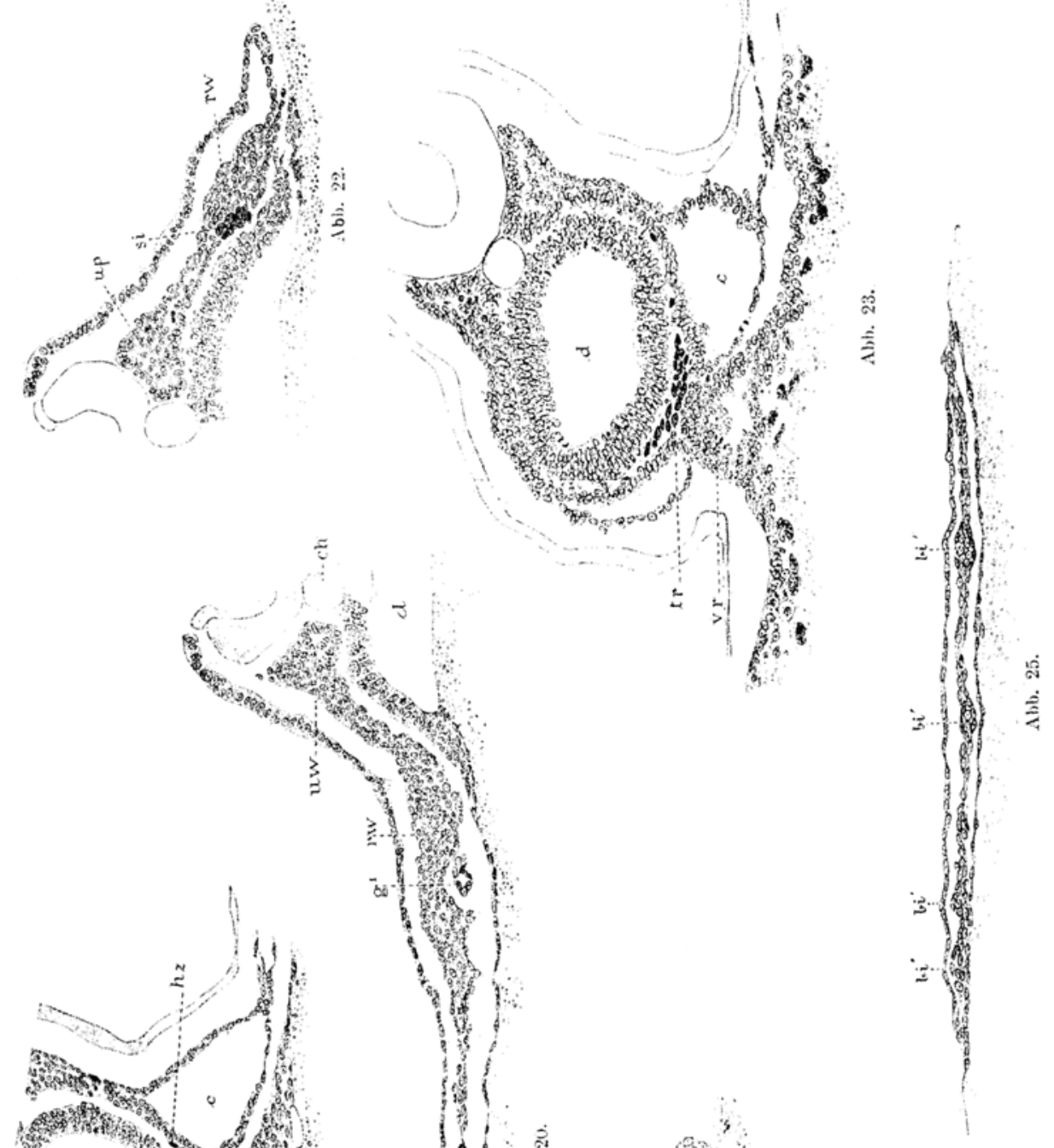

.
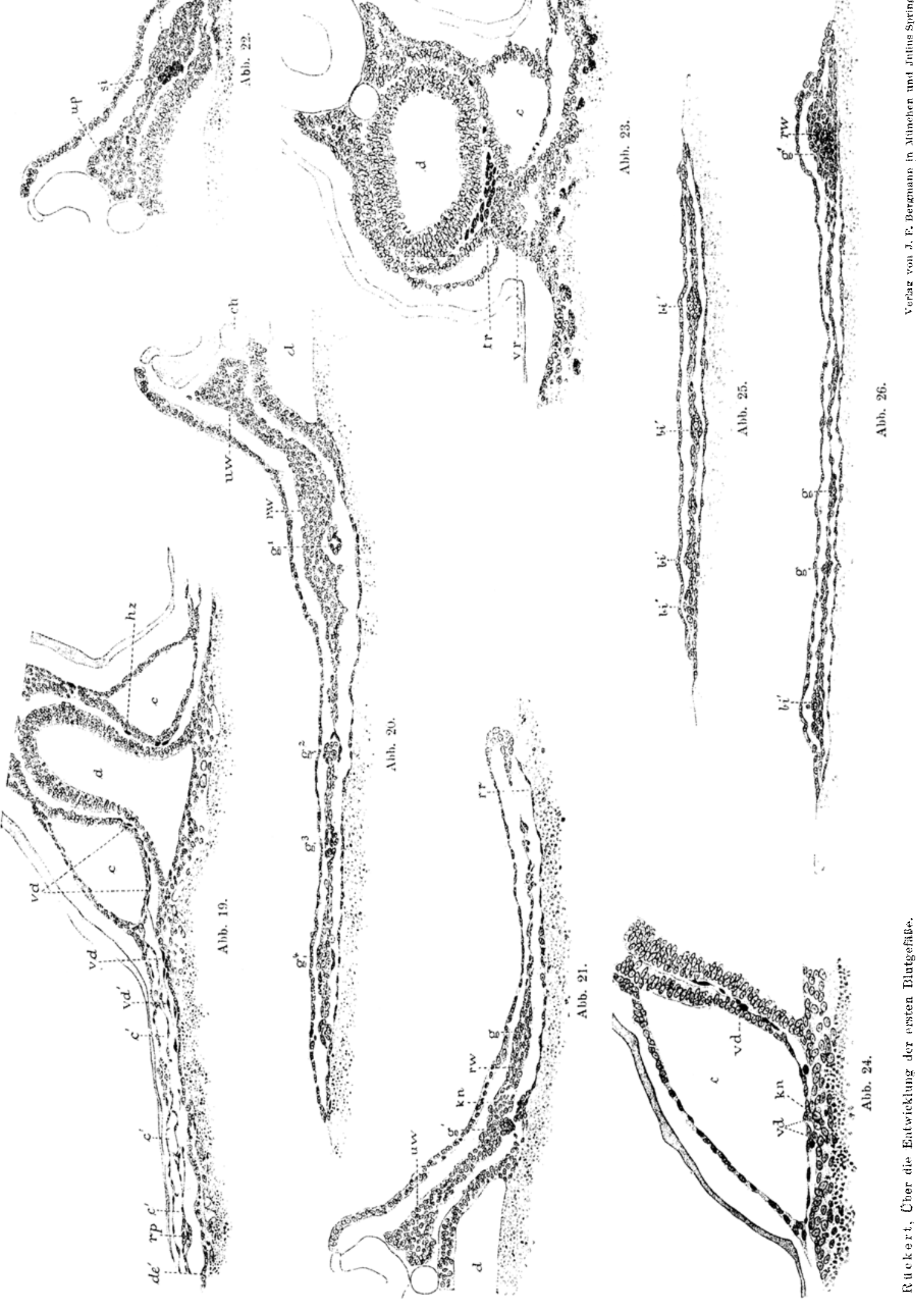


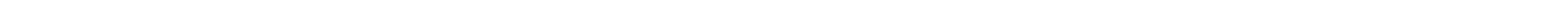


